Universidade de São Paulo

Instituto de Física

\title{
Transporte Caótico Causado por Ondas de Deriva
}

\author{
Rafael Oliveira Suigh \\ Orientador: Prof. Dr. Iberê Luiz Caldas
}

Dissertação de mestrado apresentada ao Instituto de Física para a obtenção do título de Mestre em Ciências

Prof. Dr. Iberê Luiz Caldas - IFUSP (Orientador)

Prof. Dr. Ricardo Luiz Viana - UFPR

Prof. Dr. Renato Pakter - UFRGS

São Paulo

2010 
FICHA CATALOGRÁFICA

Preparada pelo Serviço de Biblioteca e Informação do Instituto de Física da Universidade de São Paulo

Suigh, Rafael Oliveira

Transporte caótico causado por ondas de deriva.

São Paulo, 2010.

Dissertação (Mestrado) - Universidade de São Paulo. Instituto de Física - Depto. de Física Aplicada

Orientador: Prof. Dr. Iberê Luiz Caldas

Área de Concentração: Física

Unitermos: 1. Física de plasmas - transporte anômalo; 2. Ondas de deriva; 3 . Estruturas Lagrangianas coerentes; 4. Caos Hamiltoniano. 


\section{Agradecimentos}

Aos meus pais Antonio e Cristianne, por sempre me incentivarem nos estudos.

Ao meu irmão Rodrigo, por sempre me fazer relembrar física básica.

A minha namorada Natalie, pela companhia e pelo apoio nos últimos cinco anos.

Ao meu orientador Prof. Dr. Iberê, pela confiança, incentivo e pela dedicação com que sempre me ajudou.

Ao meu coordenador de estágio docente Prof. Dr. Pascholati, por me ceder a oportunidade de ministrar aulas.

A meus colegas (e ex-colegas) de grupo: Alberto, Celso, Danilo, Dennis, Elton, Everton, Gustavo, Julio e Rene, pela convivência, aprendizado e, principalmente, pelos cafés.

Aos meus colegas e amigos que sempre me deram apoio e me incentivavam com palavras amigáveis relacionadas ao prazo limite da minha defesa.

Gostaria de agradecer também a CNPQ e Capes pelo suporte financeiro. 



\section{Resumo}

Um dos problemas enfrentados pelos cientistas para o confinamento de plasma em Tokamaks, para se obter fusão termonuclear controlada, é o transporte radial de partículas pela borda do plasma. Nessa dissertação, estudamos o transporte através de um modelo que relaciona as flutuações eletrostáticas na borda do plasma às ondas de deriva. Essas ondas criam no plasma regiões de fluxo convectivo, formando ilhas que são, eventualmente, separadas por barreiras. Para apenas uma onda, o sistema é integrável e todas as trajetórias do plano de fase são curvas invariantes que, se não existirem barreiras, estão em ilhas divididas por separatrizes. Foi verificado que, quando uma segunda onda com velocidade de fase diferente da primeira é utilizada, o sistema não é mais integrável e a região anteriormente ocupada pelas separatrizes torna-se caótica. Com a quebra de separatrizes ocorre o transporte caótico de partículas. Quando uma separatriz é quebrada, surge em seu lugar uma estrutura que ainda preserva algumas características da separatriz, mas se modifica no espaço de fases ao longo do tempo. Essa estrutura é conhecida como Estrutura Lagrangiana Coerente (ELC). Nessa dissertação verificamos que as ELCs, por um lado, funcionam como barreiras de transporte, pois nenhuma trajetória consegue atravessa-la e, por outro lado, criam regiões no espaço de fases onde o transporte é alto, pois trajetórias próximas a elas tendem a ser aceleradas. Uma das principais contribuições obtidas ao se estudar ELCs no problema de duas ondas de deriva, aplicado ao confinamento de plasmas em Tokamaks, é a possibilidade de se prever a existência de ilhas, que funcionem como barreiras de transporte, no plano de fases que, por sua vez, são um importante mecanismo de aprisionamento de partículas. 



\begin{abstract}
One of the problems facing scientists in the confinement of plasma in tokamaks, to obtain controlled thermonuclear fusion, is the radial transport of particles at the plasma edge. In this dissertation, we study particle transport through a model that relates the electrostatic fluctuations at the edge of the plasma with drift waves. These waves create regions inside the plasma with convective flow, forming islands that are eventually separated by barriers. For one wave, the system is integrable and all the trajectories of phase space are invariant curves that are divided by separatrices. It was found that when a second wave with phase velocity different from the first is used, the system is no longer integrable and the region previously occupied by the separatrix becomes chaotic. With the destruction of the separatrix the transport of particles is chaotic. When a separatrix is broken, appears in its place a structure that preserves some features of the separatrix, but it is changing in phase space over time. This structure is known as Lagrangian Coherent Structure (LCS). In this dissertation we found that the LCSs, on the one hand, act as transport barriers, since no trajectory can cross it and, moreover, creates regions in phase space where particle transport is high, because trajectories close to them tend to be accelerated. One of the main contributions obtained by studying LCSs in the problem of two drift waves, applied to the confinement of plasma in tokamaks, is the ability to predict the existence of islands, which act as transport barriers, which are an important mechanism of trapping particles.
\end{abstract}





\section{Sumário}

1 Introdução 9

2 Modelo Hamiltoniano das Ondas de Deriva no Plasma 15

2.1 Equações de Movimento das Partículas do Plasma 15

2.2 Descrição Hamiltoniana das equações de Movimento 17

2.3 Modelo Hamiltoniano para $N$ ondas de Deriva 19

2.4 Sistema Integrável com uma Onda de Deriva 24

2.5 Sistema Integrável com duas Ondas de Deriva 21

2.6 Conclusões $\quad 29$

3 Caos e Transporte Radial de Partículas 31

3.1 Mapa de Poincaré $\quad 32$

3.2 Barreiras de Transporte 32

3.3 Freqüência Natural de Oscilação 34

3.4 Caracterização do Transporte 35

3.4a Relação entre o Transporte e o Parâmetro $u$

3.4b Relação entre o Transporte e o Parâmetro $A_{2}$

3.5 Conclusões $\quad 49$

$4 \quad$ Estruturas Lagrangianas Coerentes (ELC) 51

4.1 Campo de Difusão $\quad 52$

4.2 Esticamentos e Dobras no Plano de Fase 59

$\begin{array}{lll}\text { 4.3 Método Para a Calcular as ELCs } & 63\end{array}$

$\begin{array}{lll}4.4 & \text { Conclusões } & 67\end{array}$

5 Conclusão $\quad 69$

$\begin{array}{ll}\text { Referências Bibliográficas } & 73\end{array}$ 



\section{Capítulo 1}

\section{Introdução}

A busca por alternativas energéticas vem crescendo nos últimos anos. Seja devido à grande demanda mundial de energia, seja pela necessidade da utilização de fontes menos nocivas ao meioambiente, o homem precisa de novas fontes de energia. Atualmente, tem sido utilizada a energia proveniente da fissão nuclear como nova fonte de energia, porém esse tipo de fonte tem a desvantagem de gerar uma grande quantidade de lixo radioativo que, por sua vez, é nocivo ao meioambiente. Uma saída definitiva para esse problema seria a utilização da energia proveniente da fusão nuclear.

Entretanto, para se obter essa energia é necessário a construção de reatores de fusão nuclear capazes de gerar uma quantidade de energia maior do que a energia gasta para induzir a fusão nuclear. Um bom candidato para ocupar a vaga desse futuro reator é o Tokamak [1] que foi inicialmente construído na Rússia durante a década de 50 .

Tokamak é um acrônimo de toroidalnya kamera magnetnya katushka que, em russo, significa câmara de confinamento magnético toroidal. Como o próprio nome diz, esse aparelho consiste basicamente em uma câmara com formato de toróide onde é induzido um campo magnético toroidal com a finalidade de confinar o plasma [2].

O plasma é um gás ionizado que compõe aproximadamente $99 \%$ do universo visível [2]. Ele pode ser encontrado tanto em lâmpadas e televisores, quanto em estrelas. Uma característica importante e comum aos três casos citados é que neles o plasma está confinado. Nos dois primeiros o 
confinamento é dado simplesmente pelas paredes de vidro para a lâmpada e pelas microparedes de fósforo do painel do televisor. O terceiro exemplo também apresenta um confinamento simples, porém impossível de se fazer em laboratório: a intensa atração gravitacional da estrela mantém o plasma no seu interior.

No entanto, para obter energia a partir do plasma, é necessário que seus ions sofram colisões energéticas à ponto de haver a fusão nuclear. Um confinamento magnético que suporte esse tipo de energia é essencial para que o Tokamak consiga ser um reator de fusão nuclear.

Um dos problemas encontrados para o confinamento em Tokamaks é perda de partículas ocasionada pelo transporte de partículas [3] pela borda do plasma. Esse transporte é causado principalmente pelo aparecimento de ondas de deriva, que são flutuações eletrostáticas provenientes da não uniformidade do plasma. Nessa dissertação será usado um modelo hamiltoniano proposto por Horton [4] para essas ondas de deriva e para o transporte de partículas que elas causam.

O modelo de Horton descreve a trajetória do centro de guia das partículas confinadas próximas à borda do Tokamak [4]. Quando utilizamos apenas uma onda de deriva as trajetórias são integráveis [5], ou seja, conseguimos escrever uma função em que a posição é função do tempo e descrever analiticamente o movimento. Quando utilizamos duas ou mais ondas de deriva, com velocidades de fase diferentes, as equações não são mais integráveis, ou seja, não é possível achar uma função que descreva a posição em função do tempo. Esses sistemas são não-lineares e podem exibir comportamento caótico [6].

O transporte de partículas [7] do modelo utilizado aparece em decorrência das trajetórias caóticas, por isso é muito sensível à escolha das condições iniciais no plano de fase. Essa sensibilidade exibe um padrão complexo, consequência da existência de estruturas no plano de fase, dependentes do tempo, que separam regiões dinamicamente distintas. Essas estruturas têm sido associadas às Estruturas Lagrangianas Coerentes (ELCs), que aparecem em sistemas não autônomos, tem fundamental importância na dinâmica do sistema e, ultimamente, têm sido investigadas em 
problemas com fluidos geofísicos.[8]

Estudos sobre o transporte de partículas na borda de Tokamaks gerados por turbulência eletrostática tem sido temas de dissertações de mestrado $[9,10]$, teses de doutorado [11, 12] e artigos científicos $[13,14]$ do Laboratório de Física de Plasma do Instituto de Física da USP.

Essa dissertação é baseada em trabalhados realizados pelo grupo Controle de Oscilações do Instituto de Física da USP $[15,16,17]$ que visavam analisar o transporte de partículas em Tokamaks devido às ondas de deriva criadas pela turbulência eletrostática. Esses trabalhos complementam pesquisas anteriores, realizadas pelo grupo, sobre o transporte de linhas magnéticas caóticas criadas por perturbações magnéticas ressonantes [18, 19].

Esses trabalhos sobre o transporte de partículas, inclusive o dessa dissertação, têm o objetivo de investigar como se dá o transporte no modelo de duas ondas de deriva e descobrir quais fatores são mais relevantes para a compreensão desse sistema dinâmico. A principal contribuição dessa dissertação para o problema estudado foi a investigação da presença das Estruturas Lagrangianas Coerentes (ELC) nesse modelo. Para isso, foi desenvolvido o método de análise, que será explicado no decorrer da dissertação, que relaciona regiões de alto transporte de partículas com as ELCs.

Com a motivação e seu contexto, vamos passar agora a um detalhamento de cada capítulo. No capítulo 2 dessa dissertação é introduzida a hamiltoniana do modelo das ondas de deriva e, a partir dessa hamiltoniana, são descritas as trajetórias do centro de guia das partículas.

O sistema com apenas uma onda, ou com duas ondas de mesma velocidade de fase, é integrável [20]. Não há trajetórias caóticas e, portanto, não há transporte. Para o sistema com ondas de mesma velocidade de fase, existe uma mudança de referencial que torna as equações de movimento autônomas, ou seja, independentes do tempo. Nesse caso todas as trajetória estão em curvas invariantes que, no mapa de Poincaré do sistema, aparecem na forma de linhas abertas ou linhas fechadas que formam ilhas. Quando é inserida uma segunda onda, com velocidade de fase diferente, a integrabilidade do sistema é quebrada e grande parte das curvas invariantes desaparecem, contudo, as 
curvas invariantes remanescentes funcionam como barreiras de transporte.

Utilizando apenas uma onda de deriva, veremos que existe um parâmetro relacionado com a diferença entre a velocidade de deriva elétrica e a velocidade de fase da primeira onda chamado de parâmetro de confinamento $(U)[26,27]$. Dependendo do valor desse parâmetro podemos ter mais ou menos linhas invariantes abertas no plano de fase.

As linhas abertas são um conjunto de curvas invariantes, não confinadas, que separam ilhas e aparecem quando o parâmetro de confinamento $(U)$ é diferente de zero [26]. As linhas abertas que persistem, mesmo quando perturbamos as equações de movimento com uma segunda onda, geram barreiras de transporte no plano de fase. Quando $U$ é zero, nenhuma linha aberta existe e as ilhas passam a ser separadas por apenas uma trajetória. Contudo, essa trajetória pode ser quebrada facilmente por uma perturbação, o sistema, para $U=0$, é estruturalmente instável.

Nessa dissertação estudaremos principalmente o caso $U=0$ pois, quando uma perturbação é inserida, segundo as referências $[15,16,17]$, existe um transporte de partículas que é máximo quando o parâmetro de confinamento $(U)$ é nulo.

Ainda no capítulo 2, para $U=0$, foram calculados os pontos fixos hiperbólicos e elípticos do sistema autônomo e foram identificadas as variedades instáveis e estáveis dos pontos hiperbólicos. Essas variedades tem grande importância na dinâmica desse modelo: (a) por serem responsáveis pela criação de células no espaço de fase, já que agem como separatrizes; e (b) por influenciarem as trajetórias próximas a elas.

Uma variedade [20] de um sistema dinâmico é um conjunto infinito de pontos que tendem ao ponto hiperbólico quando o tempo vai a infinito se a variedade é estável, ou tendem ao ponto hiperbólico quando o tempo vai a menos infinito se a variedade é instável. Além disso, as variedades são diferenciáveis em todos os pontos e não interceptam a si mesmas transversalmente. Portanto, o único ponto em que as variedades podem se interceptar é o ponto hiperbólico.

Já no capítulo 3 começamos a estudar o sistema não autônomo. Como a hamiltoniana desse 
sistema não é mais integrável, foi utilizado o métodos Runge-Kutta de quarta ordem [21] para a integração numérica das trajetórias.

Quando o tempo é inserido na hamiltoniana, as trajetórias não podem mais ser exibidas como curvas no plano de fase pois, caso isso fosse feito, verificaríamos cruzamentos de trajetórias que ocorrem em tempos diferentes. Para evitar esse tipo de problema, utilizamos o mapa de Poincaré [5] para representar essas trajetórias, de acordo com a referência [16]. Esse mapa tem a função de reduzir o estudo das trajetórias para o estudo de um mapa de dimensão menor que, nesse caso, é a dimensão do espaço de fase do sistema autônomo.

O capítulo 3 teve como principal objetivo o estudado da relação, estudada também nas referências $[15,16]$, entre o transporte de partículas e dois parâmetros importantes no modelo: a diferença na velocidade de fase das duas ondas $(u)$ e a razão entre as amplitudes das ondas $\left(A_{2} / A_{1}\right)$. Nesse capítulo vimos (no espaço de fase analisado) que, com a introdução de uma segunda onda (com amplitude $A_{2}$ ), algumas curvas fechadas dentro das ilhas são destruídas, isto é, as trajetórias regulares que formavam uma ilha são transformadas em trajetórias caóticas.

Vimos também que a região do espaço de fases em que a perturbação é mais forte depende da escolha do parâmetro $u$. Pois cada curva fechada dentro de uma ilha tem uma freqüência natural de oscilação $(\Omega)$, que é a freqüência em que, no fluxo, uma partícula circula em torno do ponto elíptico. Quando a freqüência da diferença na velocidade de fase $(u)$ das ondas e a freqüência natural têm o mesmo valor, ocorre uma ressonância e as linhas fechadas (curvas invariantes) próximas a região atingida são destruídas.

A amplitude da segunda onda $\left(A_{2}\right)$ está relacionada com a área em torno da ilha ressonante atingida pela perturbação. Quanto maior for a amplitude da segunda onda, maior será a área atingida pela perturbação e o número de linhas fechadas destruídas. Entretanto, quando uma freqüência de perturbação tem valor muito maior do que todas as freqüências naturais de uma ilha, quase nenhuma curva invariante é destruída, apenas as mais próximas às paredes da ilha. 
Para estudar o comportamento das partículas em função da condição inicial, definimos no capítulo 4 o campo de difusão. Esse campo de difusão mede o deslocamento quadrático em $x$ por unidade de tempo de uma dada condição inicial. Nesse campo podemos identificar zonas de baixo e alto deslocamento quadrático, as zonas de baixo deslocamento quadrático estarão relacionadas com ilhas no espaço de fase e as zonas de alto deslocamento estarão relacionadas com a presença de ELCs.

Esse campo de difusão é semelhante ao campo de expoentes de Lyapunov encontrado nas referências $[23,24]$. A principal diferença entre esses dois é que o campo de expoentes de Lyapunov mede a taxa de crescimento da distância entre condições iniciais próximas, enquanto o campo de difusão mede quão longe uma condição inicial chega após um certo tempo de integração. Esses dois campos tem em comum o surgimento de máximos (do expoente de Lyapunov ou do deslocamento quadrático) nas regiões onde se encontram as ELCs.

Os dois métodos citados acima são capazes de identificar a presença de Estruturas Lagrangianas Coerentes (ELCs) no sistema estudado nessa dissertação, pois: (a) essas estruturas tem a característica de separar regiões dinamicamente distintas, o que garante a eficiência dos campos de expoente de Lyapunov, já que condições próximas a separatrizes tendem a se separar com o passar do tempo e; (b) essas estruturas induzem grande transporte na sua direção, pois essas estruturas tendem a se espalhar rapidamente ao longo do espaço de fase, o que aumenta o deslocamento médio de partículas próximas e garante a eficiência do campo de difusão.

Ainda no capítulo 4, veremos que, do mesmo modo que as variedades, as ELCs também se apresentam sob a forma instável e estável. A forma instável é responsável pela criação de barreiras que servem de fronteira para as novas ilhas e a forma estável é responsável pelo elevado transporte de partículas. Utilizando o fato de que a ELC instável está relacionada com a fronteira de ilhas, apresentaremos um método para seu cálculo.

Por fim, no capítulo 5 são apresentados um resumo das principais conclusões dessa dissertação, além de algumas propostas para estudos futuros. 


\section{Capítulo 2}

\section{Modelo Hamiltoniano das Ondas de Deriva no Plasma}

Nesse capítulo será apresentado um resumo sobre o modelo das ondas de deriva utilizado para o estudo do transporte radial de partículas do plasma confinado em Tokamaks. Além disso, serão mostrados alguns resultados para o sistema autônomo, que ilustram a importância das variedades instáveis e estáveis na estrutura do retrato de fase e sua dependência com os parâmetros dos campos de equilíbrio e das ondas de deriva que se propagam no plasma.

Na primeira parte desse capítulo será explicada de maneira breve como são as equações de movimento das partículas de um plasma, supondo que esse plasma seja composto de ions e elétrons sujeitos à um campo magnético externo. A seguir será feita uma aproximação para a borda do plasma confinado em Tokamaks, de maneira que possamos utilizar coordenadas cartesianas no lugar de toroidais.

Será introduzido, então, o modelo para ondas de deriva e serão explorados alguns aspectos importantes para uma, ou duas ondas de mesma velocidade de fase. Dentre esses aspectos estão as ilhas do plano de fase, as barreiras de transporte e as trajetórias heteroclínicas.

\subsection{Equações de Movimento das Partículas do Plasma}

As trajetórias das partículas do plasma [2] sujeito à um campo eletromagnético podem ser 
encontradas a partir da força de Lorentz com a equação

$$
m \frac{d \vec{v}}{d t}=q(\vec{E}+\vec{V} \times \vec{B})
$$

onde $m$ é a massa, $q$ a carga, $v$ é a velocidade, $\vec{E}$ é o campo elétrico e $\vec{B}$ é o campo magnético. A equação 2.1 é valida tanto para os ions quanto para os elétrons.

Quando o campo elétrico é nulo e o campo magnético é uniforme, as soluções da equação 2.1 correspondem a trajetórias concêntricas das partículas em torno das linhas do campo magnético com freqüência ciclotrônica $\omega_{c}$,

$$
\omega_{c}=\frac{|q| B}{m}
$$

O centro dessas trajetórias recebe o nome de centro de guia. Quando o campo elétrico não for nulo a trajetória do centro de guia não é mais paralela ao campo magnético. A velocidade do centro de guia será dada por

$$
\vec{V}_{E}=\frac{\vec{E} \times \vec{B}}{B^{2}}
$$

com $\vec{V}_{E}$ sendo a velocidade de deriva do centro de guia devido aos campos $\vec{E}$ e $\vec{B}$.

Note que a equação 2.3 não depende nem da carga elétrica da partícula, nem da sua massa e, portanto, tanto ions quanto elétrons têm a mesma velocidade de deriva. Em Tokamaks, essa velocidade de deriva limita o confinamento, pois o produto vetorial do campo magnético toroidal de equilíbrio com o campo elétrico poloidal das ondas gera uma velocidade de deriva na direção radial, 
jogando as partículas na direção das paredes da câmara, sendo essa, a origem do transporte estudado nessa dissertação.

É importante lembrar que a velocidade de deriva devido ao campo elétrico não é a única que age nas partículas confinadas em Tokamaks. Duas importantes derivas que não serão consideradas aqui são a deriva devido ao gradiente de pressão e a deriva devido à curvatura do campo magnético. Mas mesmo sem constar na equação 2.3 essas e outras derivas têm um papel importante no movimento das partículas, pois estas podem contribuir para o aparecimento de flutuações eletrostáticas que, com o campo magnético do plasma, causam uma deriva do tipo descrito pela equação 2.3.[1]

\subsection{Descrição Hamiltoniana das Equações de Movimento}

Naturalmente o sistema de coordenadas mais adequado para tratar o movimento do plasma no interior do Tokamak seria o sistema de coordenadas toroidais mas, como nosso modelo se restringirá apenas a região da borda de plasmas confinados em tokamaks com razão de aspecto pequena, podemos aproximar as coordenadas toroidais por coordenadas cartesianas.

Um Tokamak tem a razão de aspecto pequena se o raio do plasma $\left(r_{p}\right)$ for muito menor do que o raio do toróide que contém o plasma $\left(r_{t}\right)$. Sendo assim, podemos, a partir de uma aproximação cilíndrica de um toróide, definir a direção toroidal como sendo a direção do eixo z do cilindro, i. e. do eixo z do sistema cartesiano. Outra aproximação, valida apenas para a borda do plasma, é definir a direção radial do cilindro como sendo o eixo x do sistema cartesiano, e, conseqüentemente, a direção poloidal como o eixo y [15]. A transformação pode ser melhor entendida se observarmos a figura 2.1. 

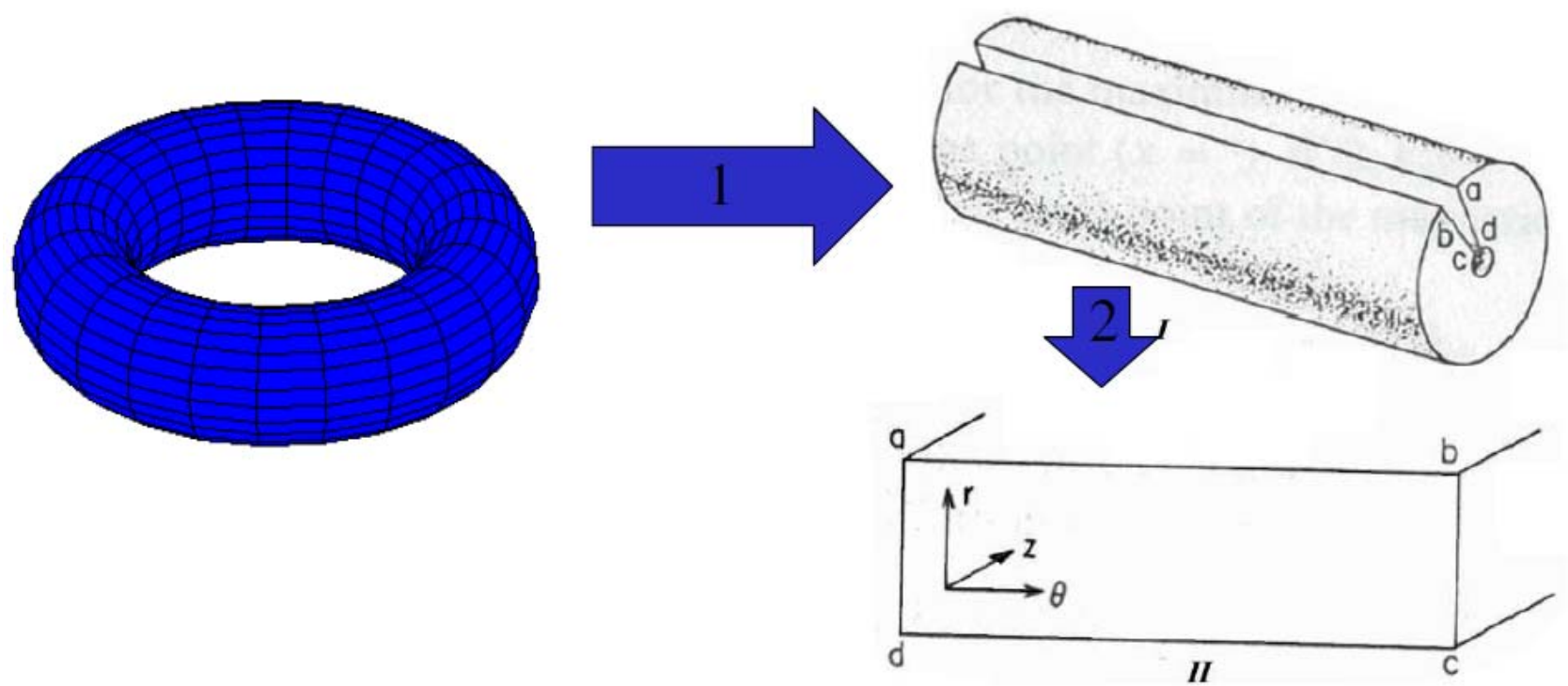

Figura 2.1: Esquema para a transformação entre coordenadas toroidais e cartesiana. Note que essa transformação só é valida para a borda de um tokamak suficientemente grande $\left(r_{p}<<r_{t}\right)$.

Sabendo que o campo elétrico pode ser escrito a partir do gradiente do potencial

$$
\vec{E}=-\vec{\nabla} \phi
$$

e que o campo magnético toroidal é uniforme

$$
\vec{B}=B_{0} e_{z},
$$

podemos escrever a equação 2.3 como

$$
\vec{v}_{E}=-\frac{1}{B_{0}} \vec{\nabla} \phi \times e_{z}=\underbrace{-\frac{1}{B_{0}} \frac{\partial \phi}{\partial y} e_{x}}_{\vec{v}_{x}}+\underbrace{\frac{1}{B_{0}} \frac{\partial \phi}{\partial x} e_{y}}_{\vec{v}_{y}} .
$$

Assim, podemos identificar a hamiltoniana como:

$$
H=\frac{\phi}{B_{0}}
$$


Então teremos $x$ como sendo o momento generalizado e $y$ como sendo a coordenada generalizada. Portanto, a equação 2.6 pode ser escrita como:

$$
\left\{\begin{array}{l}
\frac{d x}{d t}=-\frac{\partial H}{\partial y} \\
\frac{d y}{d t}=\frac{\partial H}{\partial x}
\end{array}\right.
$$

O sistema da equação 2.8 possui apenas um par canônico de coordenadas $(x, y)$, pois possui apenas um grau de liberdade e, portanto, o sistema será integrável quando houver uma constante de movimento.

\subsection{Modelo Hamiltoniano para $N$ Ondas de Deriva}

As instabilidades de densidade no plasma, geradas pelo movimento das cargas, criam campos elétricos que se propagam no plasma através de ondas de deriva. Nessa dissertação usaremos um modelo de ondas de deriva proposto por Horton [4], em que as ondas se propagam na direção poloidal (y) com uma modulação na direção radial (x).

Nesse modelo, é considerado um plasma não uniforme, magnetizado (equação 2.5) e sujeito a um campo elétrico radial constante

$$
\vec{E}=E_{0} e_{x}
$$

As partículas desse plasma estão sujeitas ao potencial elétrico dado pela soma do potencial de

equilíbrio $\left(\phi^{\prime}{ }_{0}\left(x^{\prime}\right)\right)$ com o potencial das $\mathrm{N}$ ondas de deriva $\left(\sum_{i=1}^{N} \phi_{i}{ }_{i}\left(x^{\prime}, y^{\prime}, t^{\prime}\right)\right)$. 
O potencial é dado por

$$
\phi^{\prime}\left(x^{\prime}, y^{\prime}, t^{\prime}\right)=\phi_{0}^{\prime}\left(x^{\prime}\right)+\sum_{i=1}^{N} \frac{A_{i}^{\prime} \sin \left(k^{\prime}{ }_{x i} x^{\prime}\right) \cos \left(k^{\prime}{ }_{y i} y^{\prime}-\omega^{\prime}{ }_{i} t^{\prime}\right)}{\phi_{i}^{\prime}}
$$

onde $A^{\prime}{ }_{i}$ é a amplitude de cada onda, $k^{\prime}{ }_{x i}$ e $k^{\prime}{ }_{y i}$ são os números de onda na direção $x$ e $y$ e $\omega^{\prime}{ }_{i}$ é a freqüência angular da i-ésima onda.

Portanto, segundo a equação 2.7 a hamiltoniana é dada por

$$
H^{\prime}\left(x^{\prime}, y^{\prime}, t^{\prime}\right)=H_{0}^{\prime}\left(x^{\prime}\right)+\sum_{i=1}^{N} A_{i}^{\prime} \sin \left(k_{x i}^{\prime} x^{\prime}\right) \cos \left(k^{\prime}{ }_{y i} y^{\prime}-\omega^{\prime} t^{\prime}\right)
$$

A hamiltoniana do equilíbrio é

$$
H^{\prime}{ }_{0}\left(x^{\prime}\right)=a^{\prime}{ }_{0} x^{\prime}
$$

onde, o parâmetro

$$
a^{\prime}{ }_{0}=-\frac{E_{0}}{B_{0}}
$$

depende apenas dos campos elétrico e magnético de equilíbrio.

Escolhemos variáveis adimensionais segundo as relações:

$$
\begin{gathered}
x=\frac{x^{\prime}}{r_{0}}, y=\frac{y^{\prime}}{r_{0}}, t=\frac{t^{\prime}}{t_{0}}, \omega=\omega^{\prime} t_{0}, k=\frac{\omega}{u}=k^{\prime}{ }_{i} r_{0} \\
H=\frac{H^{\prime}}{v_{0} r_{0}}, A=\frac{A^{\prime}}{v_{0} r_{0}}, a_{0}=\frac{a^{\prime}}{v_{0}}, u=\frac{u^{\prime}}{v_{0}},
\end{gathered}
$$

com $r_{0}$ sendo o raio do plasma, $v_{0}=E_{0} / B_{0}$ o módulo da velocidade de deriva do campo elétrico 
radial de equilíbrio e $t_{0}=r_{0} / v_{0}$ o tempo característico. Utilizando as transformações da equação 2.14 obtemos a hamiltoniana adimensional

$$
H(x, y, t)=a_{0} x+\sum_{i=1}^{N} A_{i} \sin \left(k_{x i} x\right) \cos \left(k_{y i} y-\omega_{i} t\right) .
$$

Para N=1, a hamiltoniana da equação 2.15 é integrável e, portanto, existe uma solução analítica para o sistema da equação 2.8 e as trajetórias serão regulares. Já para $\mathrm{N}>1$, o sistema é integrável se todas as $\mathrm{N}$ ondas tiverem a mesma velocidade de fase $u_{i}=\omega_{i} / k_{y i}=\omega_{1} / k_{y 1}$. E finalmente, caso existam $\mathrm{N}>1$ ondas, com pelo menos uma onda com velocidade de fase diferente das demais, o sistema não é mais integrável e algumas trajetórias serão caóticas.

Nessa dissertação estudaremos a hamiltoniana da equação 2.15 com uma e duas ondas de deriva. O sistema com apenas uma onda de deriva será chamado de não perturbado e, conseqüentemente, o sistema com duas ondas será chamado de perturbado.

\subsection{Sistema Integrável com uma Onda de Deriva}

Para N=1 a hamiltoniana da equação 2.12 fica:

$$
H(x, y, t)=a_{0} x+A_{1} \sin \left(k_{x 1} x\right) \cos \left(k_{y 1} y-\omega_{1} t\right)
$$

Essa hamiltoniana é integrável, embora dependa explicitamente do tempo e não seja uma constante de movimento. Mas existe uma transformação canônica [25] que elimina o tempo da hamiltoniana da equação 2.16. Essa transformação é dada pelas equações: 


$$
\left\{\begin{array}{c}
y^{\prime}=y-u_{1} t=\frac{\partial F\left(x^{\prime}, y, t\right)}{\partial x^{\prime}} \\
x=x^{\prime}=\frac{\partial F\left(x^{\prime}, y, t\right)}{\partial y}
\end{array}\right.
$$

Nesse caso, a transformação canônica é simplesmente uma mudança de referencial. Assim, passamos do referencial do laboratório $(O)$ para o referencial da onda de deriva que se propaga na direção poloidal $\left(O^{\prime}\right)$. Para satisfazer a equação 2.17 escolhemos a função geratriz $F\left(x^{\prime}, y, t\right)$ tal que:

$$
F\left(x^{\prime}, y, t\right)=x^{\prime}\left(y-u_{1} t\right)
$$

E como consequência da mudança de referencial a nova hamiltoniana será:

$$
H^{\prime}\left(x^{\prime}, y^{\prime}\right)=H\left(x^{\prime}, y^{\prime}\right)+\frac{\partial F}{\partial t}=\left(a_{0}-u_{1}\right) x^{\prime}+A_{1} \sin \left(k_{x 1} x^{\prime}\right) \cos \left(k_{y 1} y^{\prime}\right)
$$

O termo $u_{1} x^{\prime}$ representa o potencial elétrico que surge devido à mudança de referencial.

Para simplificar a notação, omitiremos as linhas da equação 2.19. Assim, tendo em mente que a partir desse ponto o referencial utilizado será sempre o da primeira onda de deriva, a hamiltoniana para uma onda de deriva é

$$
H(x, y)=\left(a_{0}-u_{1}\right) x+A_{1} \sin \left(k_{x 1} x\right) \cos \left(k_{y 1} y\right)
$$

Assim, com apenas uma onda de deriva a nova hamiltoniana não depende do tempo e, portanto, esse sistema autônomo é integrável e as trajetórias são regulares. Pode-se obter as trajetórias isolando a variável y na equação 2.20 para $\mathrm{H}=$ cte. Mas, com o intuito de introduzir a metodologia usada para duas ondas de deriva, substituiremos essa hamiltoniana na equação 2.8, obtendo assim: 


$$
\left\{\begin{array}{l}
\frac{d x}{d t}=A_{1} k y_{1} \sin \left(k_{x 1} x\right) \sin \left(k_{y 1} y\right) \\
\frac{d y}{d t}=\left(a_{0}-u_{1}\right)+A_{1} k x_{1} \cos \left(k_{x 1} x\right) \cos \left(k_{y 1} y\right)
\end{array}\right.
$$

Definindo as coordenadas:

$$
X=k_{x 1} x, Y=k_{y 1} y \text { e } T=A_{1} k_{x 1} k_{y 1} t
$$

o sistema da equação 2.21 passa a ser

$$
\left\{\begin{array}{l}
\frac{d X}{d T}=G_{X}(X, Y)=\sin (X) \sin (Y) \\
\frac{d Y}{d T}=G_{Y}(X, Y)=U+\cos (X) \cos (Y)
\end{array}\right.
$$

onde $U$ é o parâmetro de confinamento definido como [26]

$$
U=\frac{a_{0}-u_{1}}{A_{1} k_{x 1}}
$$

Na figura 2.2, está ilustrada a importância do parâmetro de confinamento $U$ na trajetória das partículas. Como a hamiltoniana da equação 2.20 é uma constante de movimento, as trajetórias dessa figura serão curvas de nível com $H(x, y)=c t e$. Os valores de $H$ estão representados na escala linear de cores.

Para $U=0$, na figura 2.2a, as trajetórias são todas fechadas e as partículas confinadas nessas trajetórias giram em torno de pontos elípticos $\left(P_{E}\right)$. Essas trajetórias confinadas estão em ilhas e as linhas entre as ilhas são as separatrizes. O retângulo definido pelas separatrizes será chamada de célula. Note que, para $U=0$, não existe nenhuma trajetória entre células, portanto as partículas ficam confinadas em células e não existe transporte de partículas em nenhuma direção. 
a)

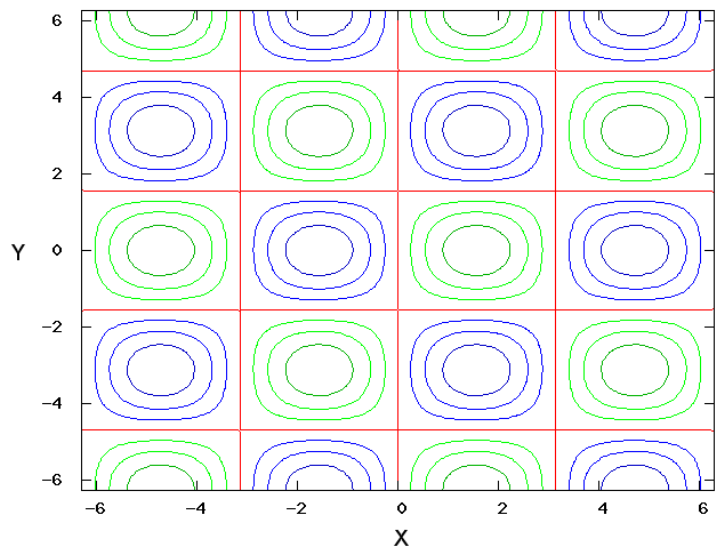

c)

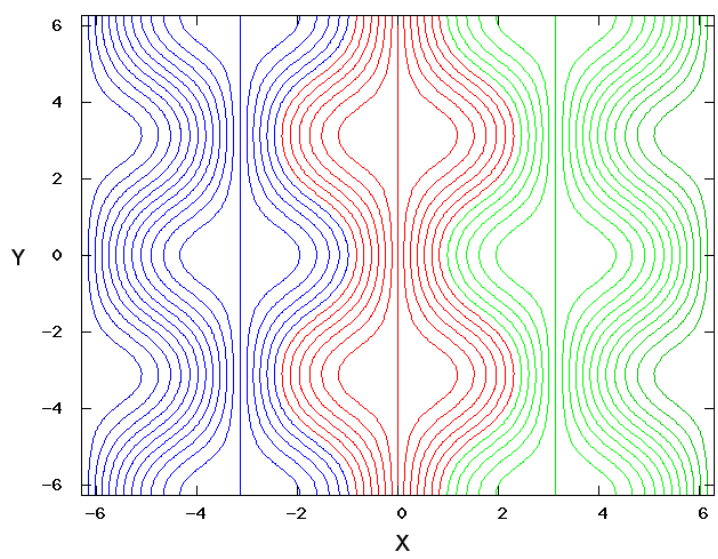

b)

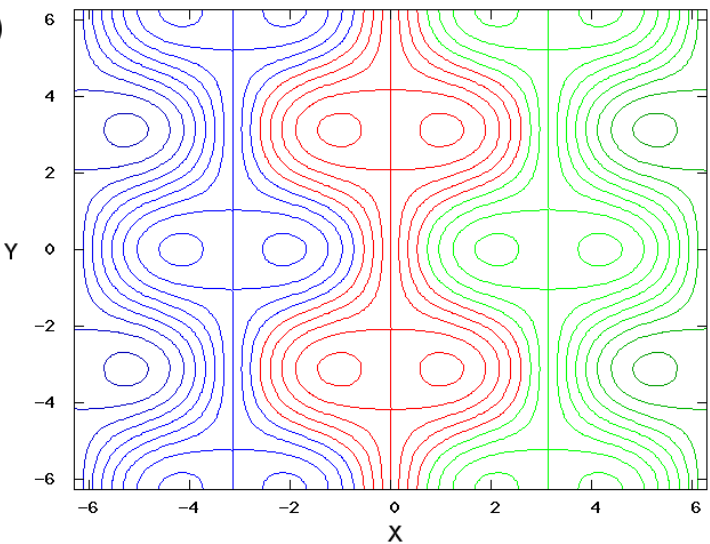

d)

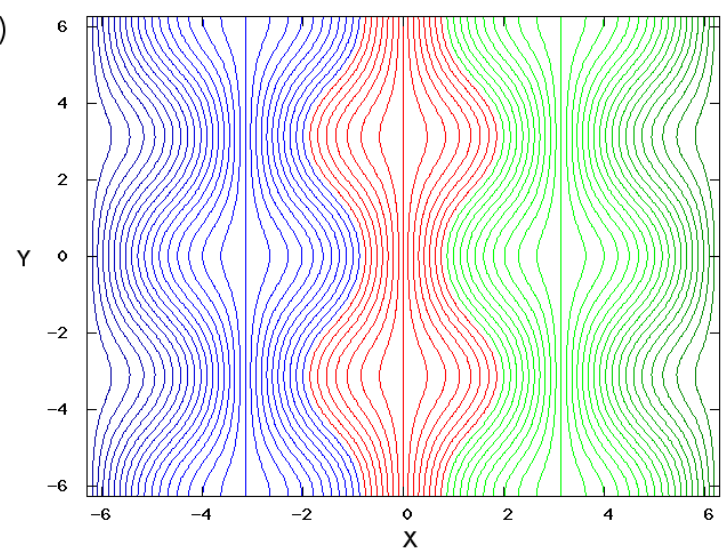

Figura 2.2: Plano de fases do sistema não perturbado para a) $U=0$; b) $U=0,5$; c) $U=1,0$;) $U=1,5$. As curvas em verde tem $H>0$, as curvas em azul $H<0$ e as em vermelho $H \sim 0$.

O encontro das separatrizes ocorre no ponto hiperbólico de sela $\left(P_{H}\right)$. Podemos ver que uma separatriz tem origem em um ponto hiperbólico e termina em outro, logo essa separatriz é a variedade instável de um ponto hiperbólico e a estável do outro. O comportamento dessas variedades é de grande importância nesse sistema, pois as trajetórias próximas a elas tendem a seguir de perto a trajetória das variedades.

Aumentando o valor do parâmetro de confinamento para $U=0,5$ obtemos a figura $2.2 \mathrm{~b}$. Nessa figura podemos notar que, além das ilhas, existem também trajetórias abertas (não confinadas) que funcionam como barreiras de transporte na direção x. Tais barreiras impedem que as partículas migrem da esquerda para direita ou vice-versa. 
A partir do valor crítico $U=1$, as ilhas já não existem mais e todas as trajetórias são abertas. Nas figuras $2.2 \mathrm{c}$ e $2.2 \mathrm{~d}$, com $U=1$ e $U=1,5$.

Quando inserirmos uma perturbação no sistema, as barreiras criadas pelo parâmetro de confinamento $U$ se tornam um importante mecanismo de contenção de transporte radial de partículas [17]. Pois quando $U$ é diferente de zero, vimos na figura 2.2 que existem um conjunto de trajetórias abertas entre as ilhas, quanto maior o módulo de $U$, mais trajetórias existem. Para que exista um transporte de partículas em alguma direção, uma perturbação deve quebrar todas as curvas invariantes que funcionem como barreiras de transporte naquela direção. Como para $U$ igual a zero existem poucas barreiras e são quebrada facilmente por uma perturbação, esse será o caso em que o transporte é maior.

Como estamos interessados em estudar esse transporte de partículas nos concentraremos no caso em que $U=0$. Os pontos fixos da equação 2.23 para esse caso são:

$$
P_{H}=\left(m \pi,\left(n+\frac{1}{2}\right) \pi\right) \text { e } P_{E}=\left(\left(n+\frac{1}{2}\right) \pi, m \pi\right)
$$

O primeiro conjunto de pontos recebe o índice $H$ porque os autovalores da matriz Jacobiana, $J_{G}\left(x_{j}\right)=\left[\partial G_{j} / \partial x_{j}\right]$, são reais, $\lambda_{X}=-(-1)^{(n+m)}$ e $\lambda_{Y}=(-1)^{(n+m)}$, e de soma nula, portanto o índice $H$ refere-se ao conjunto de pontos hiperbólicos de sela. Já o segundo conjunto de pontos recebe o índice $E$, pois os autovalores da matriz jacobiana são números imaginários puros, ou seja, são pontos elípticos.

O sistema da equação 2.23 é integrável e as soluções são trajetórias descritas por curvas com $H(X, Y)=$ cte. Nenhuma trajetória do plano de fase pode cruzar com outra ou consigo mesma, exceto no ponto hiperbólico. Uma trajetória que passa por um ponto hiperbólico deve necessariamente ir a um ponto hiperbólico quando evoluímos o sistema para o tempo tendendo a infinito. Essa trajetória é chamada de homoclínica caso retorne ao mesmo ponto, e de heteroclínica (como no caso que estamos 
considerando) caso vá para outro ponto. As trajetórias heteroclínicas dos pontos hiperbólicos dão origem as variedades instáveis e estáveis desses pontos e são trajetórias tais que $H(X, Y)=0$, mostradas em vermelho na figura 2.2 para $U=0$ (retas verticais e horizontais).

\subsection{Sistema integrável com duas Ondas de Deriva}

Adotando o referencial da primeira onda e escolhendo-a com velocidade de fase igual a velocidade de deriva do campo elétrico $(U=0)$, a hamiltoniana da equação 2.15 para duas ondas de deriva $(N=2)$ resulta na equação

$$
H(x, y, t)=A_{1} \sin \left(k_{x 1} x\right) \cos \left(k_{y 1} y\right)+A_{2} \sin \left(k_{x 2} x\right) \cos \left(k_{y 2}(y-u t)\right),
$$

onde $u=\left|\frac{\omega_{2}}{k_{y 2}}-\frac{\omega_{1}}{k_{y 1}}\right|$ é a diferença de velocidade de fase das ondas 1 e 2 .

As equações de movimento são dadas por:

$$
\left\{\begin{array}{l}
\frac{d x}{d t}=G_{x}(x, y, t)=\frac{A_{1} k y_{1} \sin \left(k_{x 1} x\right) \sin \left(k_{y 1} y\right)}{G_{x 1}}+\frac{A_{2} k y_{2} \sin \left(k_{x 2} x\right) \sin \left(k_{y 2}(y-u t)\right)}{G_{x 2}} \\
\frac{d y}{d t}=G_{y}(x, y, t)=\underbrace{A_{1} k x_{1} \cos \left(k_{x 1} x\right) \cos \left(k_{y 1} y\right)}_{G_{y 1}}+\underbrace{A_{2} k x_{2} \cos \left(k_{x 2} x\right) \cos \left(k_{y 2}(y-u t)\right)}_{G_{y 2}}
\end{array}\right.
$$

O caso mais simples ocorre quando $u=0$, ou seja, as duas ondas tem mesma velocidade de fase. Nesse caso, o sistema da equação 2.26 ainda é integrável e existem duas configurações possíveis para o plano de fase. (a) Com $k_{x 1} / k_{x 2}$ racional, a soma das ondas é periódica em $x$ e existe uma linha separatriz vertical comum entre as ilhas. (b) Quando $k_{x l} / k_{x 2}$ é irracional, a soma das ondas não é mais periódica e essa linha vertical não existe mais. No lugar dela aparece uma nova separatriz que envolve um número maior de ilhas, permitindo a existência de algumas trajetórias entre células. Um exemplo disso pode ser visto na figura 2.3 . 


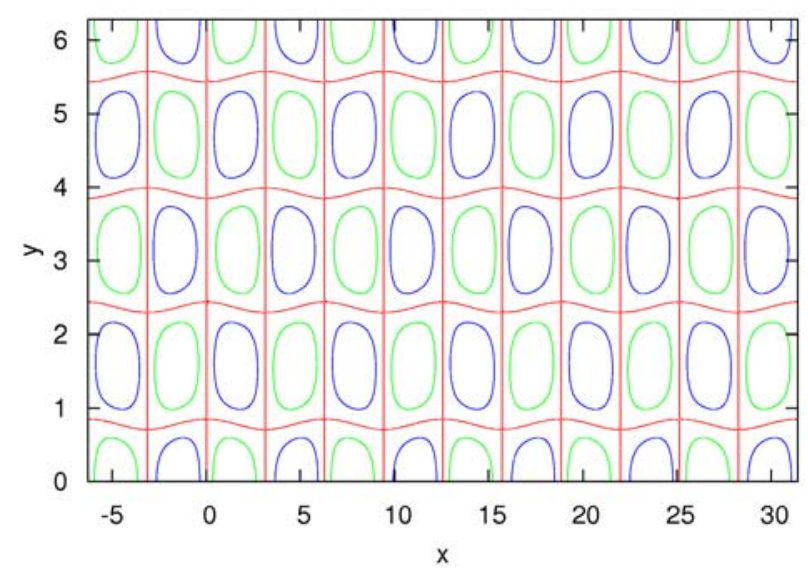

(a)

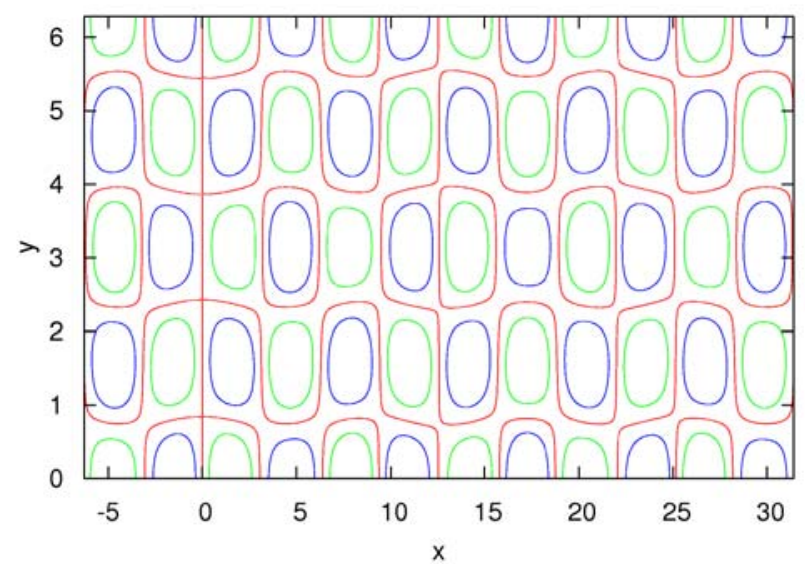

(b)

Figura 2.3: Plano de fase da equação 2.26 para $\mathrm{u}=0, A_{2} / A_{1}=0,1$ e $k_{y 2} / k_{y l}=0,5$. a) $k_{x 2} / k_{x l}=2$, b) $k_{x 2} / k_{x l}=\sqrt{3}$. As curvas em verde tem $H>0$, as curvas em azul $H<0$ e as em vermelho $H \sim 0$.

No caso (a), a razão entre os números de onda das duas ondas é racional e não existem trajetórias entre células, portanto, para o caso mostrado na figura 2.3 , cada trajetória está confinada em apenas uma ilha e é separada das demais por uma separatriz (em vermelho). Já no caso (b), a razão entre os números de onda é irracional, é possível haver trajetórias entre ilhas e, portanto, uma condição inicial escolhida próxima da separatriz pode viajar de uma ilha para outra. Assim, como estamos interessados em estudar o fenômeno de transporte radial (na direção x), utilizaremos nessa dissertação uma razão irracional entre os números de onda na direção x.

Veremos no próximo capítulo que as linhas verticais em vermelho da figura 2.3a criam uma barreira de transporte persistente a perturbação.

Para entender melhor a diferença entre o caso (a) e o caso (b), vamos construir os gráficos de $G_{x}=0$ e $G_{y}=0$, onde $G_{x, y}$ estão definidos na equação 2.26 . Na figura 2.4 , os conjuntos de pontos em que a velocidade na direção x é nula $\left(G_{x}=0\right)$ são representados pelas linhas cheias em vermelho e os pontos com velocidade na direção y nula $\left(G_{y}=0\right)$ são representados pelas linhas pontilhadas em azul. 


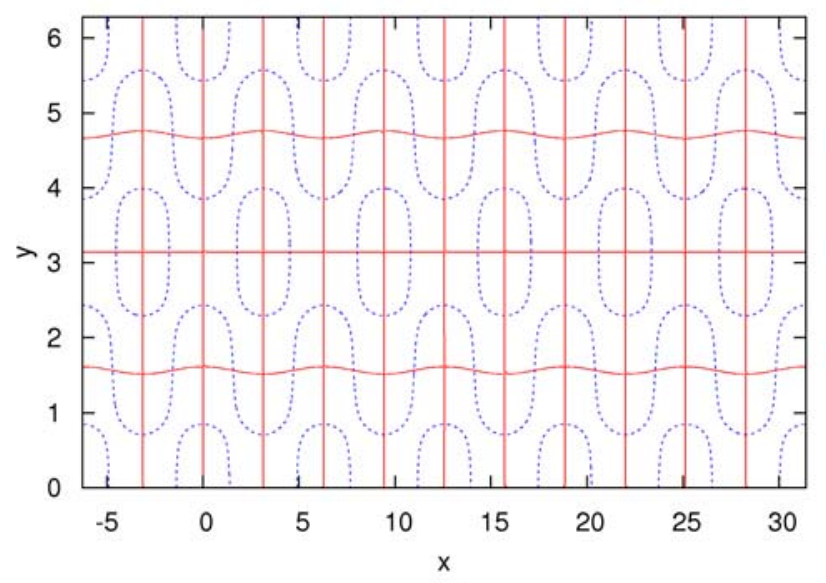

(a)

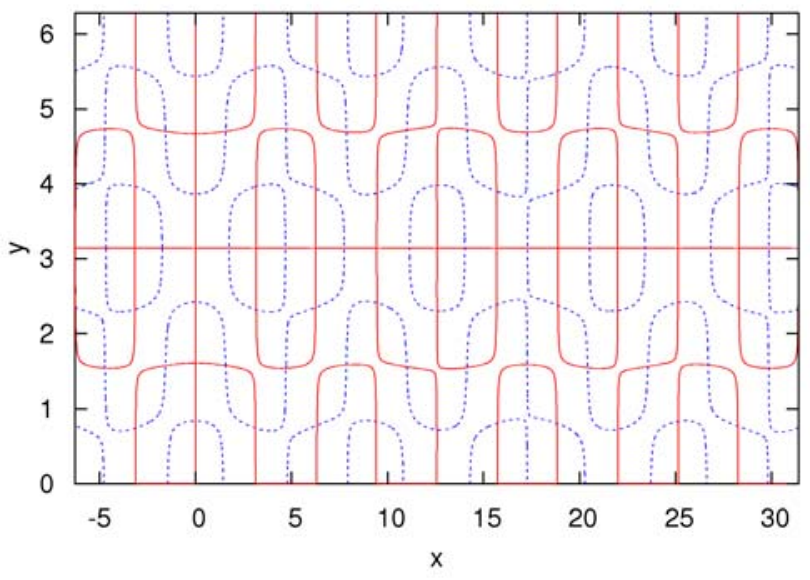

(b)

Figura 2.4: Conjunto de pontos em que $G_{x}=0$ (linhas cheias em vermelho) e $G_{y}=0$ (linhas pontilhadas em azul) utilizando a equação 2.26 para $u=0, A_{2} / A_{1}=0,1$ e $k_{y 2} / k_{y l}=0,5$. a) $k_{x 2} / k_{x l}=2$, b) $k_{x 2} / k_{x l}=\sqrt{3}$.

A figura 2.4 foi obtida calculando-se as curvas de nível de $G_{x}=0$ e de $G_{y}=0$ tanto para o caso (a) quanto para o caso (b). Analisando a figura 2.4a, vemos que quando a razão entre os números de onda é racional (caso (a)) existem linhas verticais $\left(G_{x}=0\right.$, em vermelho) onde a velocidade na direção x é nula. Essas linhas verticais são exatamente as separatrizes da figura 2.3a. Como essa é uma curva contínua não existe nenhuma trajetória transversal com velocidade não nula que a intercepte, por isso, nenhuma partícula a esquerda de uma linha vermelha $\left(G_{x}=0\right)$ pode alcançar o lado direito e vice-versa.

Já na figura $2.4 \mathrm{~b}$ vemos que as linhas vermelhas com $G_{x}=0$ não criam uma barreira em todo o plano de fase, existem "buracos" que permitem um fluxo de trajetórias na direção x. Pode-se perceber que as trajetórias em vermelho da figura 2.3(b) escapam das ilhas exatamente pelos buracos em $G_{x}=0$ para o caso (b). É importante notar que os pontos de encontro entre as linhas $G_{x}=0$ e $G_{y}=0$ são os pontos fixos do sistema da equação 2.26 .

Assim, para estudar o transporte de partículas na direção x (radial do Tokamak), devemos utilizar o modelo hamiltoniano de ondas de deriva com uma razão irracional entre os números de onda na direção $\mathrm{x}$, pois nesse caso, não existirão linhas verticais como barreira, permitindo a existência de trajetórias entre células. 


\subsection{Conclusões}

Nesse capítulo estudamos o caso em que o modelo para ondas de deriva é autônomo, ou seja, possuí equações de movimento independentes do tempo. Portanto, o sistema é integrável e todas as trajetórias são curvas invariantes.

Vimos que existem dois tipos de curvas invariantes nesse modelo: as linhas fechadas que formam ilhas e as linhas abertas. Nas ilhas, as trajetórias fechadas são confinadas e giram em torno de um ponto fixo elíptico. Já as linhas abertas são formadas por trajetórias que se estendem por todo plano de fase. Quando o parâmetros de confinamento é zero, essas linhas abertas desaparecem.

Quando estudamos apenas uma onda com o parâmetro de confinamento igual a zero, vimos que as ilhas são separadas por trajetórias heteroclínicas, ou seja, por trajetórias que ligam pontos fixos hiperbólicos distintos. Assim, devido à existência dessas trajetórias heteroclínicas uma pequena perturbação nas equações de movimento pode mudar completamente a estrutura do plano de fases, ou seja, o sistema é estruturalmente instável.

Além disso, vimos que, quando a razão entre os números de onda na direção x é racional, surge uma linha vertical em que, para qualquer valor de y, a velocidade na direção x é nula, além do mais, veremos no próximo capítulo que, para qualquer tempo essa linha se mantém fixa, portanto ela funcionará como uma barreira de transporte. 


\section{Capítulo 3}

\section{Caos e Transporte Radial de Partículas}

No capítulo anterior, para $U=0$, vimos os casos em que apenas uma onda ou duas ondas de mesma velocidade de fase eram inseridas no sistema. Os dois casos eram integráveis e as trajetórias eram confinadas em ilhas, assim, o transporte de partículas era nulo. Nesse capítulo veremos que, quando uma segunda onda com velocidade de fase diferente da primeira é incluída no sistema, as separatrizes das ilhas são quebradas e na região próxima a essa separatriz aparecem trajetórias caóticas que geram transporte de partículas. [30]

Para caracterizar o transporte de partículas, o modelo do capítulo 2 será explorado numericamente para o parâmetro de confinamento $U$ igual a zero. A partir disso, serão gerados gráficos do mapa de Poincaré do plano de fases e com eles serão calculados os coeficientes de difusão.

Começaremos esse capítulo introduzindo o mapa de Poincaré para o sistema estudado. A partir disso, serão mostrados uma série de gráficos relacionando as trajetórias do mapa de Poincaré com os parâmetros do modelo. Verificando, assim, que o transporte é máximo quando inserimos uma segunda onda que destrói curvas invariantes próximas às separatrizes.

Por fim, é explorado a relação entre o transporte de partículas e a amplitude da segunda onda, chegando a conclusão de que, existe um valor de amplitude a partir do qual o coeficiente de difusão fica constante em consequência a destruição completa das ilhas. 


\subsection{Mapa de Poincaré}

A partir desse capítulo utilizaremos a equação 2.25 do capítulo anterior com a diferença de velocidade de fase entre as ondas $(u)$ diferente de 0 , portanto as trajetórias do plano de fase não se darão mais em superfícies onde $H$ é constante. Como introduzimos uma nova variável ao sistema, o tempo, nossa hamiltoniana agora possui um grau e meio de liberdade [5], logo, quando exibimos as trajetórias no plano $x y$ encontramos cruzamentos de trajetórias. Para escapar desse inconveniente não apresentaremos as trajetórias em planos de fases, mas sim em mapas de Poincaré dessas trajetórias.

Podemos reduzir o estudo de um fluxo para o estudo do mapa através do cálculo das intersecções do mesmo com uma superfície. A superfície onde são calculadas as intersecções é chamada de seção de Poincaré e o mapa obtido através da seção de Poincaré será o nosso mapa de Poincaré. Como a hamiltoniana da equação 2.25 é periódica, tomaremos nossa seção de Poincaré em tempos múltiplos do período $(2 \pi / u)$, e o conjunto de pontos que possuem tempo múltiplo desse período formarão nosso mapa.

\subsection{Barreiras de Transporte}

Como visto no capítulo anterior, existem algumas escolhas de parâmetros para os quais, no espaço de fase, há barreiras de transporte na direção $x$. Utilizando os mesmos parâmetros da figura 2.3 (com $U=0)$, mas agora com uma velocidade de fase relativa igual a $1(u=1)$, podemos observar na figura 3.1 que, quando a razão entre os números de onda é racional, existem barreiras e, quando essa razão é irracional, há trajetórias não confinadas no espaço de fase. [22]

As posições $x(t)$ e $y(t)$ de cada partícula podem ser calculadas integrando numericamente as equações vistas no capítulo 2: 


$$
\left\{\begin{array}{l}
\frac{d x}{d t}=A_{1} k y_{1} \sin \left(k_{x 1} x\right) \sin \left(k_{y 1} y\right)+A_{2} k y_{2} \sin \left(k_{x 2} x\right) \sin \left(k_{y 2}(y-u t)\right) \\
\frac{d y}{d t}=A_{1} k x_{1} \cos \left(k_{x 1} x\right) \cos \left(k_{y 1} y\right)+A_{2} k x_{2} \cos \left(k_{x 2} x\right) \cos \left(k_{y 2}(y-u t)\right)
\end{array}\right.
$$

obtida através das equações de Hamilton para hamiltoniana de duas ondas de deriva:

$$
H(x, y, t)=A_{1} \sin \left(k_{x 1} x\right) \cos \left(k_{y 1} y\right)+A_{2} \sin \left(k_{x 2} x\right) \cos \left(k_{y 2}(y-u t)\right) .
$$

Para obter a figura 3.1 foram integrados numericamente dois conjuntos de 75 condições iniciais igualmente separadas. Os dois conjuntos estão marcados em verde na figura. O primeiro conjunto foi colocado $\operatorname{com} x$ entre zero e $\pi$ e o segundo foi colocado entre $2 \pi$ e $3 \pi$.

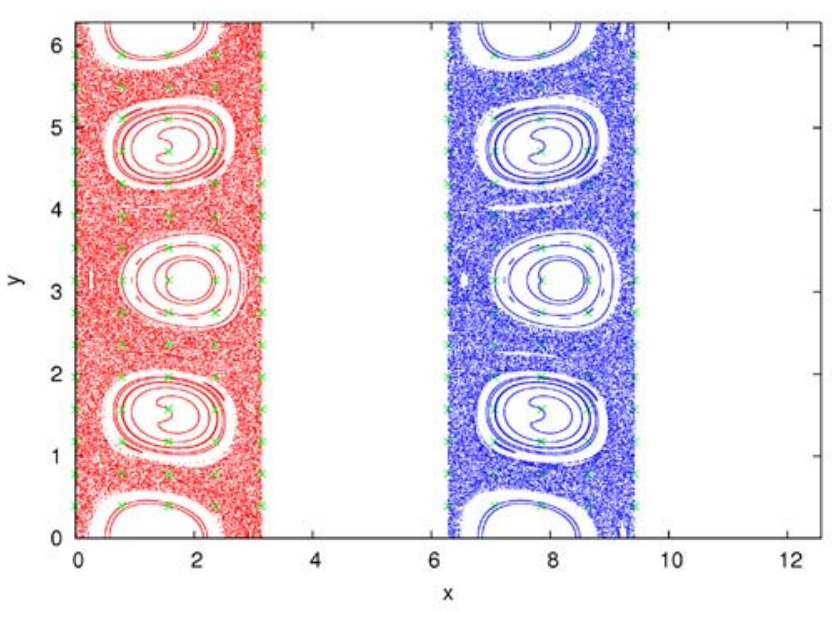

(a)

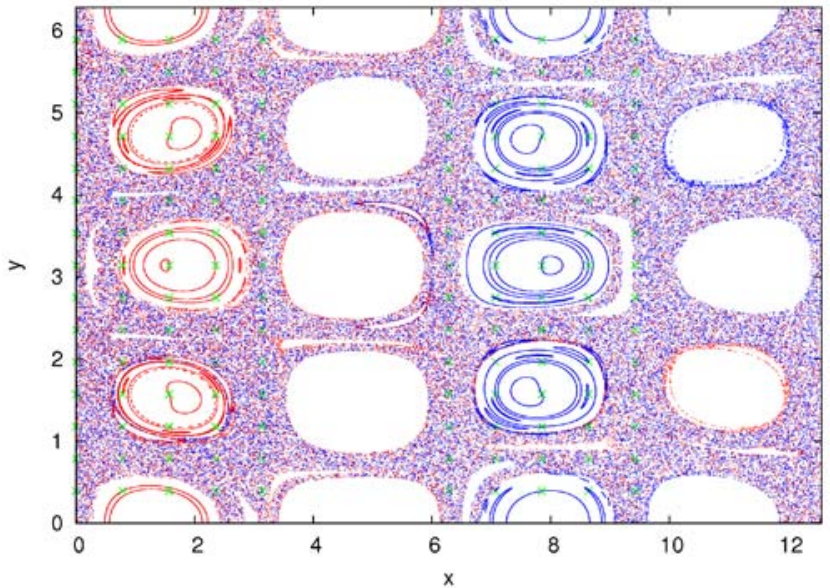

(b)

Figura 3.1: Mapa de Poincaré para duas ondas com $u=1, A_{2} / A_{1}=0,1$ e $k_{y 2} / k_{y 1}=0,5$. Em (a) está mostrado o plano de fase para razão $k_{x 2} / k_{x l}=2$ e em (b) está mostrado o plano de fases para a razão $k_{x 2} / k_{x l}=\sqrt{3}$.

Chamaremos o caso (a) de espacialmente periódico, pois existe uma distância em x após a qual a estrutura do plano de fase se repete. No caso (a), o transporte em x é nulo e as trajetórias com condição inicial à esquerda de $\pi$ ficam confinadas entre 0 e $\pi$. Já no caso (b), o transporte é diferente de zero e as trajetórias com condição inicial externa às ilhas podem andar por todo o espaço 
de fases. A este caso daremos o nome de espacialmente quase-periódico, pois não existe uma distância em x em que a estrutura do plano de fase se repita exatamente, mas apenas com algumas semelhanças.

\subsection{Freqüência Natural de Oscilação}

Cada condição inicial dentro de uma ilha tem uma freqüência de oscilação $\Omega$. Essa freqüência é alta quando a partícula está próxima ao centro da ilha e é baixa quando está próxima à separatriz. Para o cálculo dessa freqüência foram integrados numericamente um conjunto de condições iniciais com $\mathrm{x}$ indo de 0 (próximo a separatriz) até $\pi / 2$ (próximo ao centro da ilha) para $y=0$. Os parâmetros utilizados nessa simulação foram os mesmos da figura 2.2a: $k_{x l}=1, k_{y l}=2$ e $A_{l}=1$.

A figura 3.2 mostra a relação entre a freqüência natural e a condição inicial quando utilizamos apenas uma onda. Note que quando a condição inicial está muito próxima da origem a freqüência tende a zero. Esse fato é esperado, pois, pela origem, passa a trajetória que sai de um ponto fixo hiperbólico e que demora um tempo infinito para retornar ao mesmo ponto hiperbólico (caso seja homoclínica) ou outro (caso seja heteroclínica). Portanto, as trajetórias próximas que tendem a imitar as trajetórias hiperbólicas, demoram um tempo muito longo para completar uma volta.
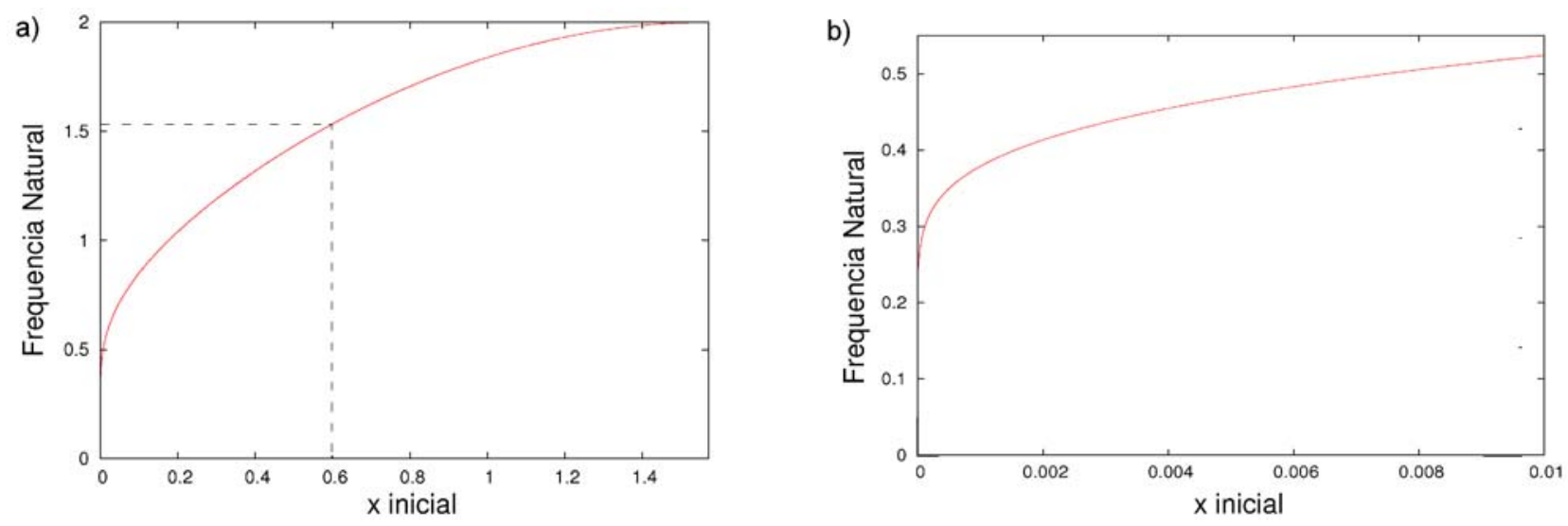

Figura 3.2: (a) Relação entre a freqüência natural de oscilação e a condição inicial e (b) ampliação em torno da origem. 
É importante conhecer essa freqüência de oscilação natural, pois as trajetórias mais atingidas pela perturbação serão as que possuem freqüência natural próxima ao valor da freqüência de perturbação inserida no sistema. Assim, a perturbação vai atuar mais intensamente no local em que for ressonante. Logo, se inserirmos uma segunda onda com freqüência igual a 1,5, as ilhas compostas por trajetórias com posição inicial próximas de 0,6 serão destruídas, pois, de acordo com a figura 3.2, existe uma correspondência entre freqüência natural de 1,5 com a posição inicial 0,6.

No modelo estudado, a freqüência responsável pela ressonância vista acima é a freqüência de perturbação $v$. Essa freqüência é definida através da relação $v=u / k_{y 2}$. Onde $k_{y 2}$ é o número de onda na direção $y$ da segunda onda e $u$ é a diferença na velocidade de fase das duas ondas.

\subsection{Caracterização do Transporte}

Uma limitação ao confinamento magnético de plasma no Tokamak é a perda de partículas pela borda. Essa perda gera um transporte em $x$ que será caracterizado a partir da razão entre variância em $x, \sigma^{2}$, e o tempo. O $\sigma$ é o desvio padrão de $x$ em relação a uma posição inicial.

A variância de um conjunto de $N$ trajetórias com condição inicial $x_{i}(0)$ é calculada em um instante $t$ pela equação:

$$
\sigma^{2}(t)=\frac{1}{N} \sum_{i=0}^{N}\left(x_{i}(t)-x_{i}(0)\right)^{2}
$$

A partir da equação 3.3 podemos calcular o coeficiente de difusão $D_{x}$ :

$$
D_{x}=\lim _{t \rightarrow \infty} \frac{\sigma^{2}(t)}{2 t}
$$

Caso $\sigma^{2}(t) \propto t$ quando $t \rightarrow \infty$, o transporte é difusivo, mas de maneira geral a variância não será diretamente proporcional ao tempo, mas a uma potência do tempo. 


$$
\sigma^{2}(t) \propto t^{y}
$$

onde $\gamma$ é o coeficiente de transporte. Assim, teremos transporte difusivo quando o coeficiente de transporte for igual a 1 e teremos transporte anômalo quando o coeficiente for diferente de 1 .

Existem dois tipos de transporte anômalo. Quando $\gamma<1$, o transporte é subdifusivo e ocorre quando existe algum mecanismo que retém as trajetórias. Quando $\gamma>1$, o transporte é superdifusivo e ocorre quando existe algum mecanismo que acelera as trajetórias.

Calcularemos, também, a função $D_{x}(\mathrm{t})$, como:

$$
D_{x}(t)=\frac{\sigma^{2}(t)}{2 t}
$$

que denominaremos coeficiente de difusão temporal [27].

As posições $x(t)$ são calculadas a partir da integração numérica da equação 3.1.

\section{4a Relação entre o Transporte e o Parâmetro $u$}

Para as simulações numéricas foram utilizados os parâmetros da tabela 3.1. Nessa tabela estão apresentados os números de onda na direção $x$ e $y$ e as amplitudes tanto para a primeira quanto para segunda onda. Como dito no capítulo anterior, a primeira onda é escolhida como a onda que tem velocidade de propagação $u_{l}$ igual a velocidade de deriva do campo elétrico $\left(a_{0}\right)$. Fixando $a_{0}=1$ teremos $u_{1}=\omega_{1} / k_{y 1}=a_{0}=1$, e assim, quando escolhemos um valor para o número de onda para a primeira onda, encontramos automaticamente um valor para sua freqüência. Para os valores da tabela 3.1, $\operatorname{com} k_{y l}=2$, teremos $\omega_{1}=2$. 
Tabela 3.1: Número de onda e amplitude de onda utilizados nas simulações numéricas.

\begin{tabular}{|c|c|c|}
\hline Parâmetros & Primeira onda & Segunda onda \\
\hline$k_{x i}$ & 1 & $\sqrt{3}$ \\
\hline$k_{y i}$ & 2 & 1 \\
\hline$A_{i}$ & 1 & 0,1 \\
\hline
\end{tabular}

As simulações consistem na integração numérica da equação 3.1 utilizando o método de RungeKutta de ordem 4 por um tempo de integração igual a 4000. Em cada simulação foram integradas 360 trajetórias com condições iniciais entre 0 e $4 \pi$, na direção x, com passo de $\pi / 10$ e entre 0 e $2 \pi$, na direção $y$, com passo de $\pi / 4$. Utilizando as relações 2.14 , esse tempo de simulação equivale a um confinamento no Tokamak [28] TBR-1 com $E_{0} \approx 3000 \mathrm{~V} / \mathrm{m}, B_{0} \approx 0,4 T$ e $r_{0} \approx 0,08 \mathrm{~m}$ de cerca de $40 \mathrm{~ms}$. O Tokamak gerava descargas de até $10 \mathrm{~ms}$.

Nas figuras a seguir estão os resultados de algumas simulações para diferentes valores do parâmetro $u$. No lado esquerdo de cada figura é mostrado o mapa de Poincaré de período $2 \pi / u$ e no lado direito é mostrado o coeficiente de difusão temporal $\left(D_{x}(\mathrm{t})\right)$ durante a simulação que é obtido calculando-se para cada instante a equação 3.6. Para todas as simulações o limite desse coeficiente temporal, para o tempos grandes, é aproximadamente constante, o que indica que o transporte é difusivo.

A primeira simulação (figura 3.3) é obtida $\operatorname{com} u=0$. Para esse parâmetro o sistema de equações 3.1 é integrável e por isso as trajetórias são regulares. Vale ressaltar que a simulação numérica mostrada na figura 3.3 é consistente com o resultado analítico da figura $2.3 \mathrm{~b}$ e que, em ambas, esperase que a difusão de partículas em $x$ seja nula. 

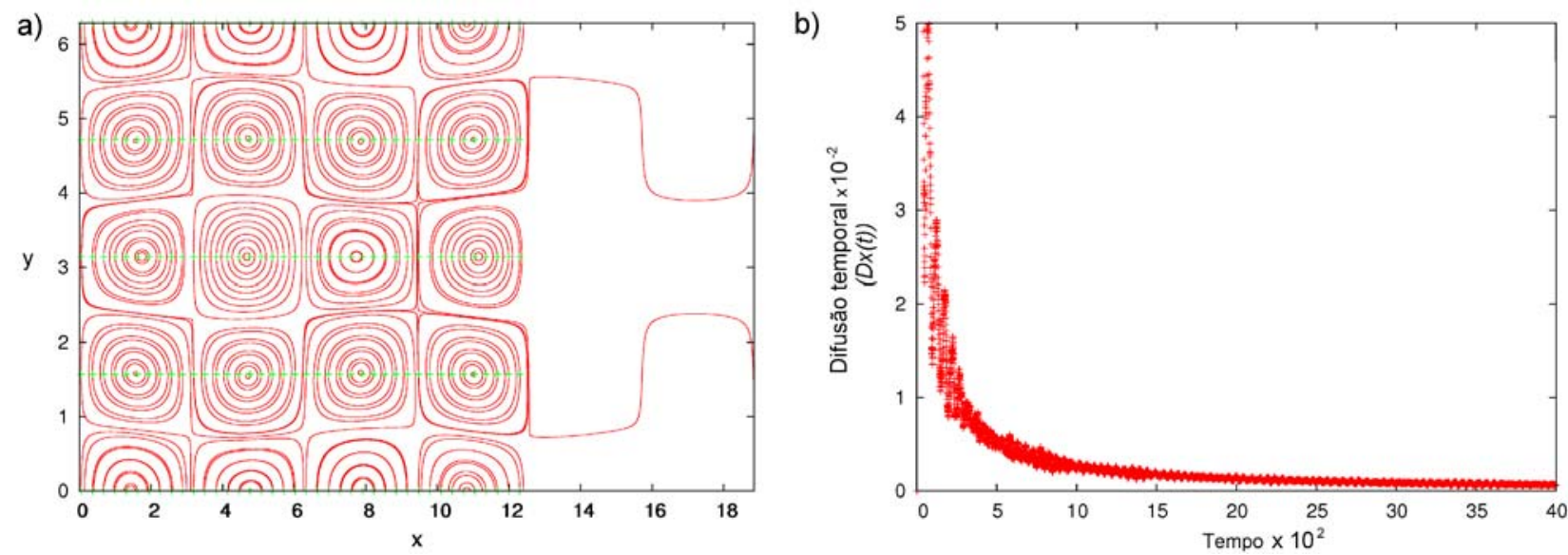

Figura 3.3: Simulação numérica utilizando os parâmetros $k_{x 1}=1, k_{y 1}=2, A_{1}=1, k_{x 2}=\sqrt{3}, k_{y 2}=1, A_{2}=0,1$ (tabela 3.1) e $u=0$.

Em (a) está mostrado o mapa de Poincaré com cruzes em verde representando as condições iniciais. Em (b) está mostrada a difusão temporal $\left(D_{x}(\mathrm{t})\right)$ em função do tempo de integração.

Como é possível notar na figura 3.3, para o parâmetro $u=0$, as trajetórias mostradas são regulares, ou seja, não são caóticas, e o cálculo numérico do coeficiente difusão tem um valor muito pequeno, próximo a zero para tempos grandes.

Se voltarmos à figura 2.3 do capítulo anterior veremos que, quando a razão entre os $k_{x i}$ das duas ondas é irracional, não existem barreiras de transporte na direção $x$, dessa maneira, existirão trajetórias que não são confinadas e que conseguem levar partículas de uma ilha para outra. Por isso, mesmo com $u=0$, pode-se observar uma difusão não nula, entretanto, muito menor do que a que ocorre com trajetórias caóticas.

É importante ressaltar um detalhe técnico. Para não prejudicar a qualidade da figura 3.3a, algumas trajetórias com condição inicial próximas à separatriz não foram mostradas, mas foram utilizadas para o cálculo da difusão temporal da figura 3.4b.

A figura 3.4 é obtida com o parâmetro $u=0,5$. Nesse caso, a Hamiltoniana não é mais integrável, mas como a segunda onda tem amplitude pequena, apenas as trajetórias próximas à separatriz são caóticas. De acordo com o que foi escrito na seção 3.3, as primeiras trajetórias de dentro de uma ilha a serem quebradas são as que possuem freqüência próxima a freqüência de perturbação. Esse fato é 
confirmado pois, de acordo com a figura 3.2, a freqüência de 0,5 corresponde a uma trajetória muito próxima á separatriz e como podemos ver na figura 3.4 as trajetórias que passam próximas á separatriz tornam-se trajetórias caóticas.
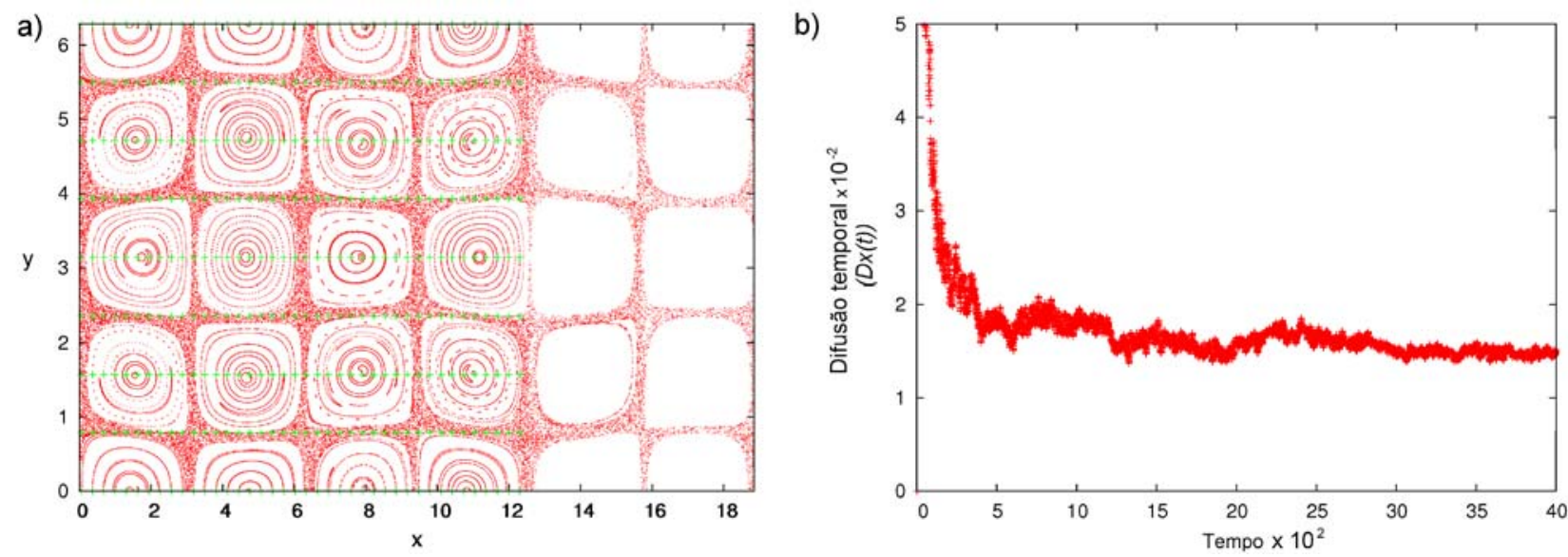

Figura 3.4: Simulação numérica utilizando os parâmetros da figura anterior com $u=0.5$. Em (a) está mostrado o mapa de Poincaré com cruzes em verde representando as condições iniciais. Em (b) está mostrada a difusão temporal $\left(D_{x}(\mathrm{t})\right)$ em função do tempo.

Em principio, esta explicação sobre a relação entre as trajetórias quebradas e a freqüência de perturbação só é valida para trajetórias próximas à origem, porém, devido a quase-periodicidade do plano de fases, podemos estendê-la com a ressalva de que nem todas as ilhas possuem trajetórias com freqüência exatamente igual, mas apenas aproximadamente igual.

Aumentando um pouco a freqüência de perturbação, utilizando $u=1,0$, obtemos a figura 3.5. Nessa figura nota-se que a área ocupada pelas trajetórias caóticas aumenta. Esse fenômeno ocorre porque uma perturbação com freqüência maior consegue destruir trajetórias nas partes mais internas de uma ilha, conforme podemos ver na figura 3.2 onde a freqüência de 1,0 é capaz de destruir trajetórias com condição inicial próximas a $(0,2 ; 0)$. Mas, mesmo com número maior de trajetórias perturbadas, vemos na figura $3.2 \mathrm{~b}$ que a difusão de partículas é menor. 

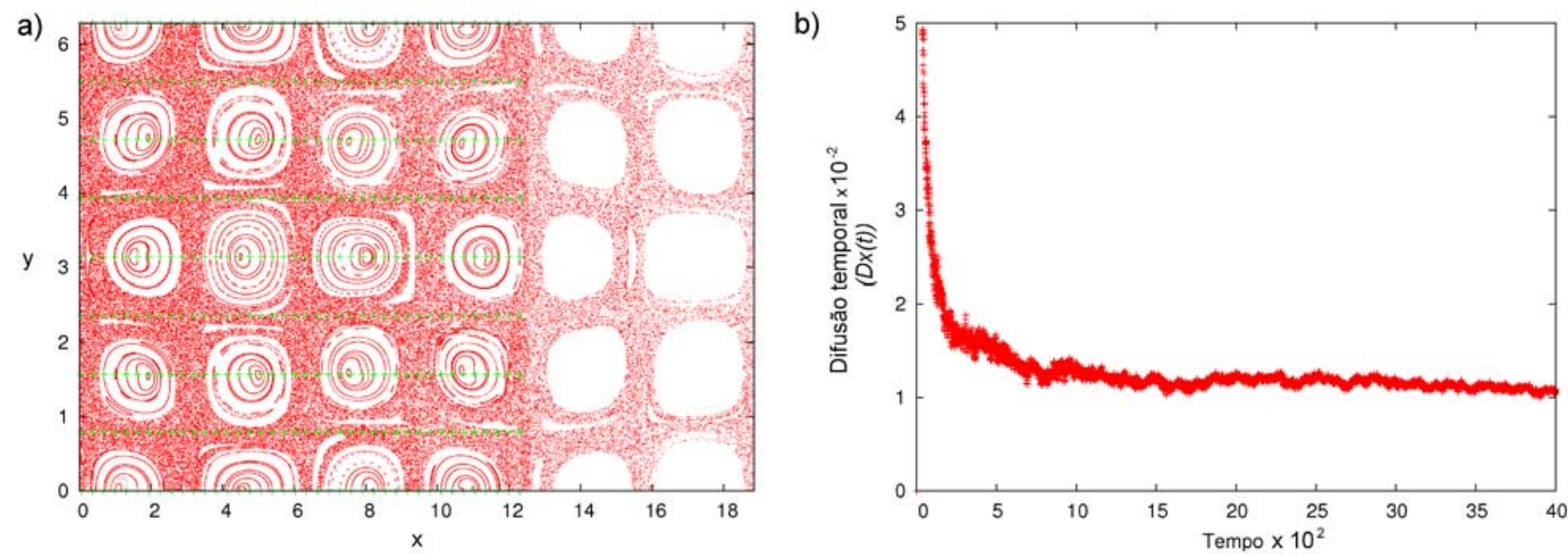

Figura 3.5: Simulação numérica utilizando os parâmetros da figura anterior com $u=1,0$. Em (a) está mostrado o mapa de Poincaré com cruzes em verde representando as condições iniciais. Em (b) está mostrada a difusão temporal $\left(D_{x}(\mathrm{t})\right)$ em função do tempo.

A difusão é menor porque a freqüência de perturbação que destrói as trajetórias das regiões mais internas das ilhas (próximas ao ponto elíptico) não consegue destruir com tanta eficiência as mais externas (próximas a separatriz). E são justamente as trajetórias próximas à separatriz que geram um transporte maior.

Para entendermos melhor, podemos imaginar um balanço oscilando com freqüência $\omega_{0}$, no qual é aplicado uma força externa de freqüência $\omega$. Podemos separar o movimento em três configurações distintas: (a) Quando $\omega \ll \omega_{0}$ a amplitude de oscilação do balanço permanece praticamente inalterada; (b) Quando $\omega \approx \omega_{0}$ a amplitude de oscilação aumenta a medida em que $\omega$ se aproxima de $\omega_{0}$; (c) Quando $\omega \gg \omega_{0}$ a amplitude de oscilação vai rapidamente a zero a medida em que $\omega$ se distancia de $\omega_{0}$.

Aplicando essas idéias ao nosso problema de transporte, podemos concluir que, quando temos uma freqüência de perturbação pequena, conseguimos destruir trajetórias de freqüência natural de oscilação pequena, mantendo as trajetórias com freqüência natural maior praticamente inalteradas. A medida que vamos aumentando o valor da freqüência de perturbação, as trajetórias de freqüência 
natural mais alta começam a ser quebradas, mas as trajetórias de freqüência natural baixa começam a se reconstruir. Desta forma, como as trajetórias próximas à separatriz tem freqüência baixa, encontraremos um valor de difusão maior usando uma freqüência de perturbação baixa, aumentando essa freqüência de perturbação começamos a não quebrar mais trajetórias próximas as borda das ilhas, diminuindo a difusão de partículas.
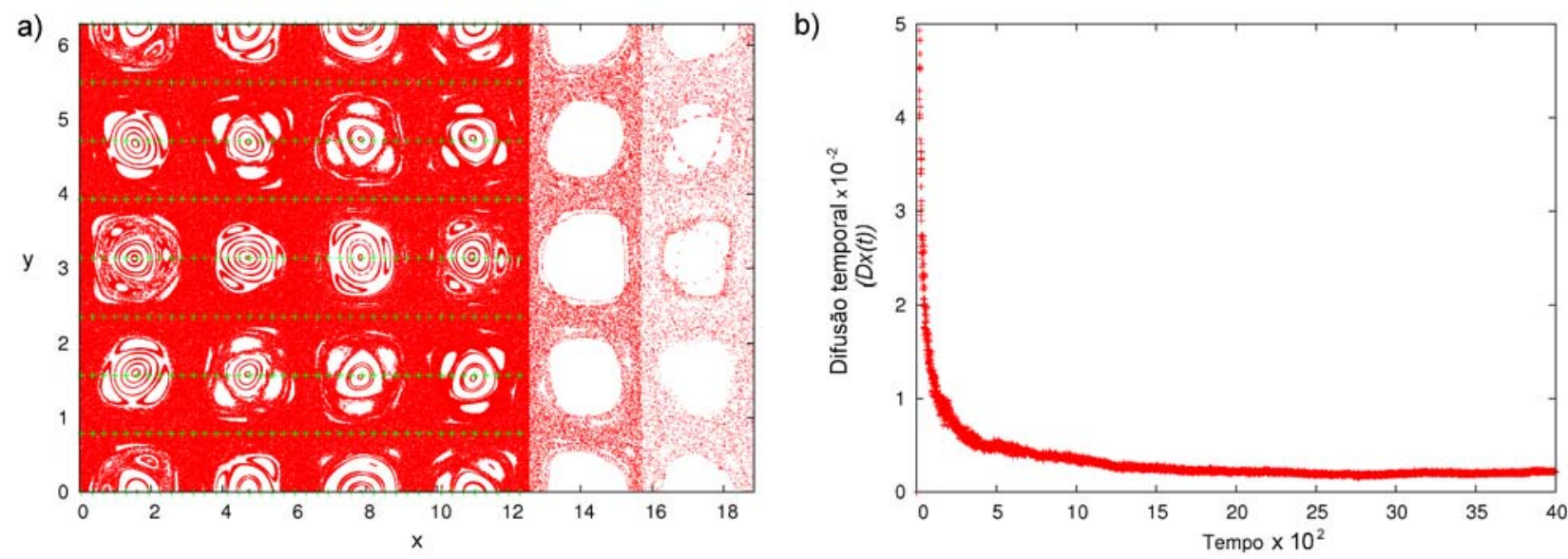

Figura 3.6: Simulação numérica utilizando os parâmetros da figura anteior com $u=5,0$. Em (a) está mostrado o mapa de Poincaré com cruzes em verde representando as condições iniciais. Em (b) está mostrada a difusão temporal $\left(D_{x}(\mathrm{t})\right)$ em função do tempo.

Agora, aumentando um pouco mais a freqüência de perturbação, utilizando $u=5,0$, obtemos a figura 3.6. Quando o valor do parâmetro parâmetro $u$ está entre 1,5 e 8,5, geramos uma freqüência intermediária, intermediária no sentido de que não é uma freqüência baixa o suficiente para quebrar uma trajetória específica dentro de uma ilha, mas também não é alta o suficiente para ser ignorada por todas as trajetórias.

Uma explicação para o transporte de partículas baixo para freqüências intermediárias pode ser obtido observando que essas freqüências geram ilhas secundárias em torno das ilhas principais. Cada ilha secundária, por sua vez, também tem suas ilhas secundárias e essa cadeia de ilhas aumenta consideravelmente o tempo médio em que as partículas ficam dentro de uma ilha, por consequência, diminuindo a difusão. Esse fenômeno é conhecido na literatura como grudamento [29] (em inglês, 
stickiness).

Na figura 3.7 é mostrado o mapa de Poincaré do plano de fases e a difusão temporal para $u=10$. Nessa figura, observam-se trajetórias muito próximas às trajetórias obtidas para o sistema com apenas uma onda (figura 2.2a) e com difusão muito baixa. Então, é confirmada nossa estimativa inicial (cuja base esta na idéia do balanço sujeito a uma força externa) de que altas freqüências de perturbação não são capazes de destruir trajetórias e, conseqüentemente, não são capazes de gerar transporte de partículas.
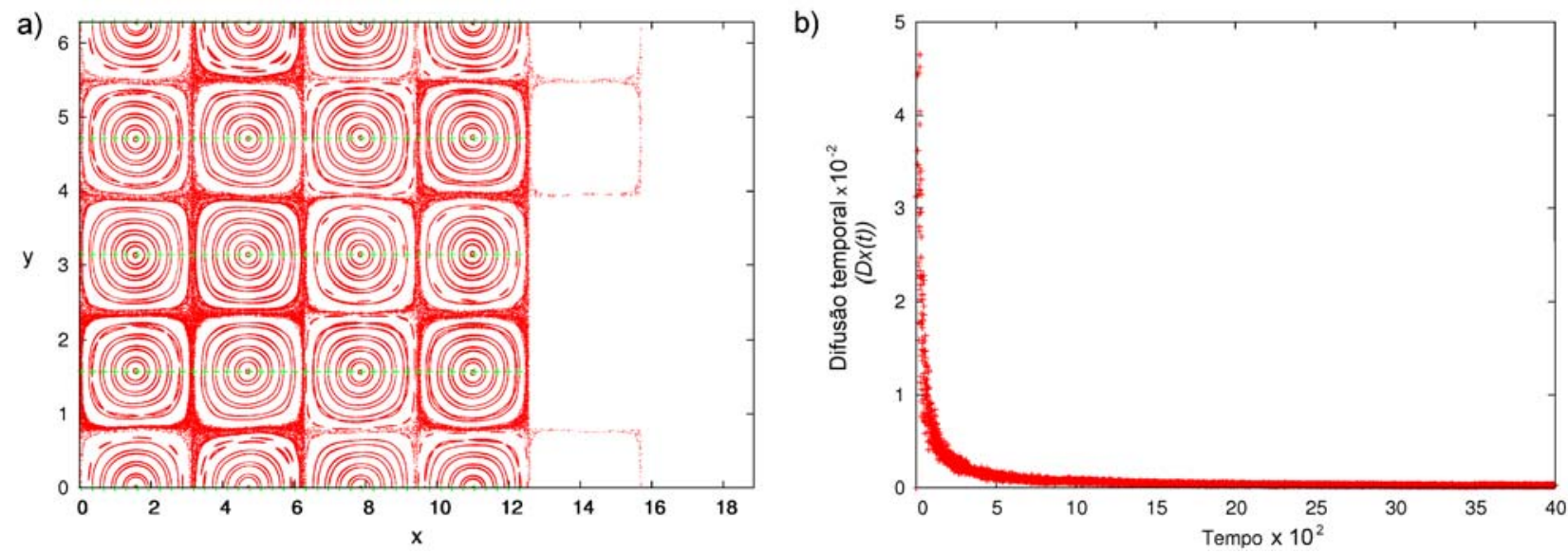

Figura 3.7: Simulação numérica utilizando os parâmetros da figura anterior com $u=10$. Em (a) está mostrado o mapa de Poincaré com cruzes em verde representando as condições iniciais. Em (b) está mostrada a difusão temporal $\left(D_{x}(\mathrm{t})\right)$ em função do tempo.

Cada simulação numérica possui um gráfico de difusão temporal $\left(D_{x}(\mathrm{t})\right)$ e para cada gráfico obtido foi calculado o coeficiente de difusão $\left(D_{x}\right)$. Quando o transporte é difusivo, esse coeficiente é obtido a partir do limite, com o tempo tendendo a infinito, do coeficiente de difusão temporal. O coeficiente de difusão $\left(D_{x}\right)$ será calculado numericamente como a média da difusão temporal $\left(D_{x}(t)\right)$ durante o intervalo de $t=2000$ até $t=4000$. A relação entre o coeficiente de difusão e o parâmetro $u$ está mostrado na figura 3.8. 
No gráfico da figura 3.8 observa-se que freqüências de perturbação baixas criam um transporte alto, e freqüências altas criam um transporte baixo. Pode-se também notar nesse gráfico que o máximo valor obtido para o coeficiente de difusão ocorre para $u=0,5$.

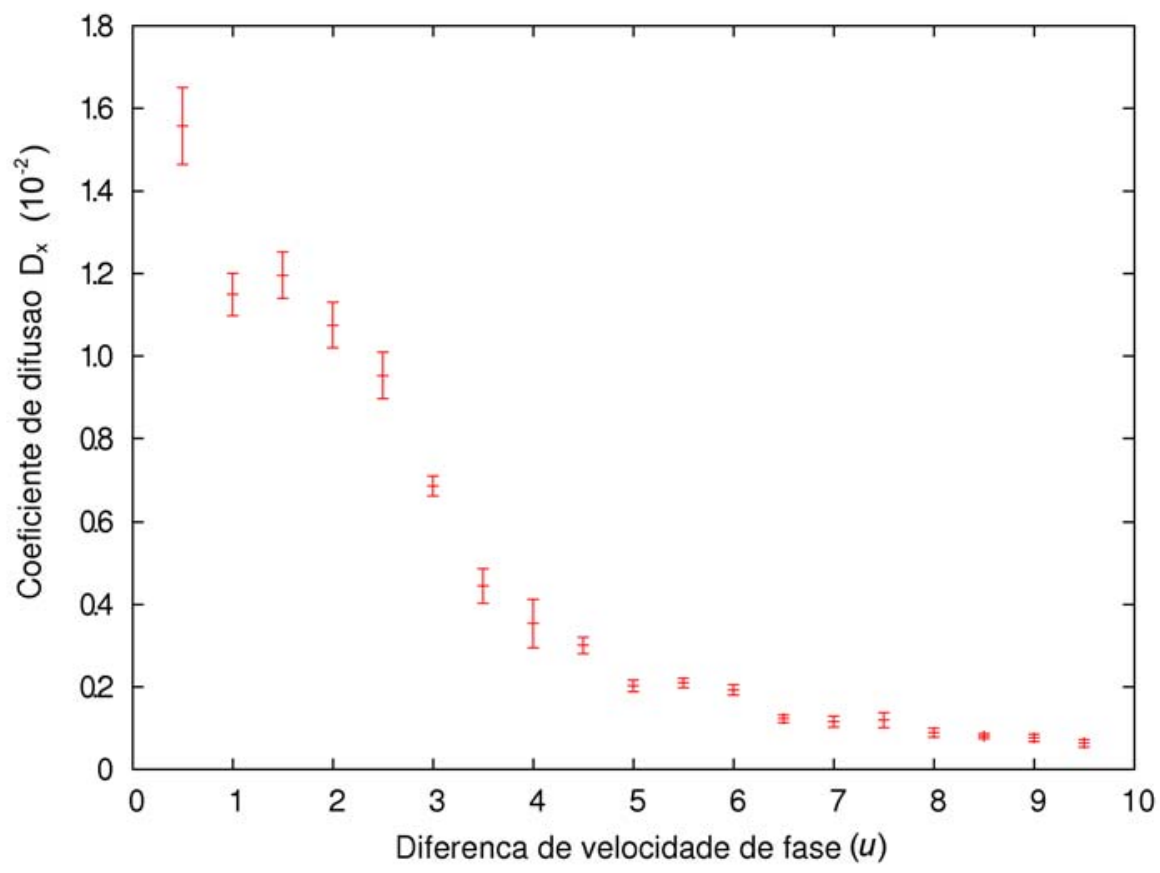

Figura 3.8: Gráfico do coeficiente de difusão $\left(D_{x}\right)$ em função da diferença de velocidade de fase das ondas $(u)$ para a amplitude da segunda onda $A_{2}=0,1$. As barras verticais representam o desvio padrão no intervalo utilizado para o cálculo dos valores médios.

Assim, de acordo com o que foi mostrado anteriormente nas simulações numéricas, o coeficiente de transporte $\left(D_{x}\right)$ é alto quando a perturbação destrói alguma trajetória dentro de uma ilha; quando a freqüência da perturbação é baixa, as trajetórias destruídas estão na região mais externa de uma ilha e o transporte é alto; quando a freqüência de perturbação é intermediária, as trajetórias destruídas estão na região mais interna de uma ilha e o transporte é baixo; e quando a freqüência de perturbação é alta, praticamente nenhuma trajetória é destruída e o transporte é quase nulo. 


\section{4b Relação entre o Transporte e o Parâmetro $A_{2}$}

Para estabelecer a relação entre a amplitude da segunda onda e o transporte de partículas, manteremos fixos os números de onda e a diferença na velocidade de fases de acordo com a tabela 3.2. A diferença de fases escolhida foi $u=0,5$, pois é a diferença de velocidades que causa o maior transporte de partículas.

Tabela 3.2: Número de onda e freqüência angular das ondas utilizadas nas simulações.

\begin{tabular}{|c|c|c|}
\hline Parâmetros & Primeira onda & Segunda onda \\
\hline$k_{x i}$ & 1 & $\sqrt{3}$ \\
\hline$k_{y i}$ & 2 & 1 \\
\hline$\omega_{i}$ & 2,0 & 1,5 \\
\hline
\end{tabular}

A primeira simulação, mostrada na figura 3.9, é obtida para a amplitude da segunda onda igual a zero, ou seja, nessa figura está mostrado o plano de fase para o caso integrável.
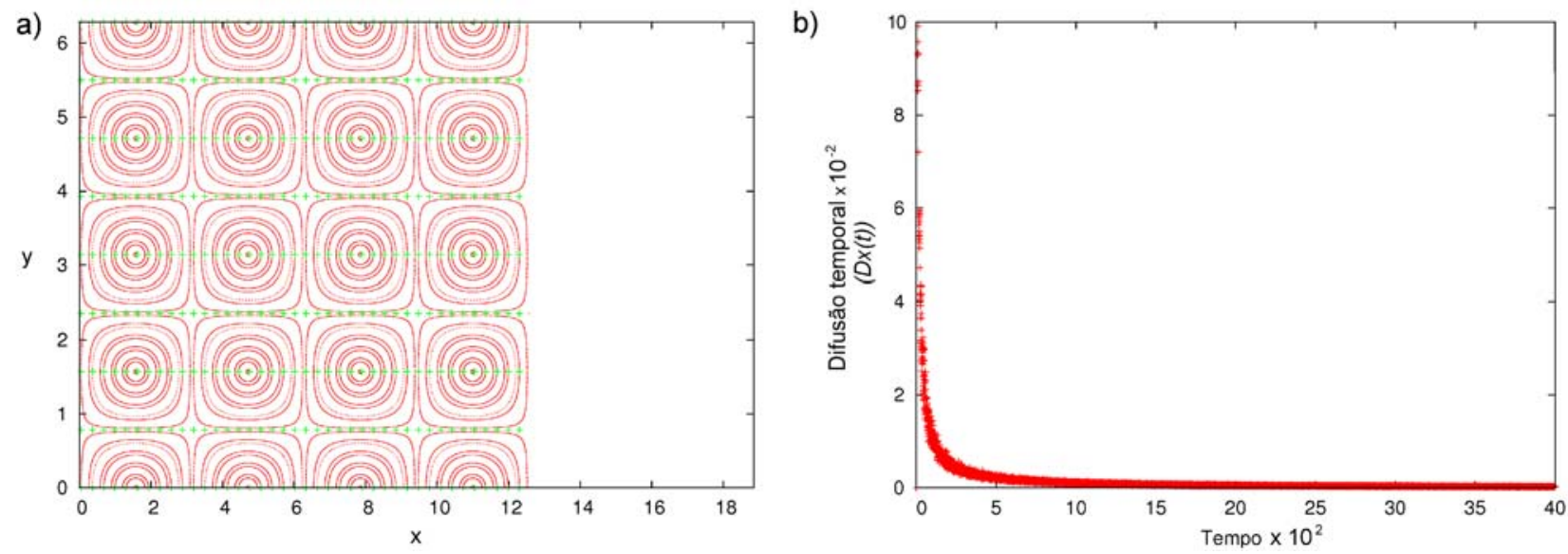

Figura 3.9: Simulação numérica utilizando os parâmetros $k_{x l}=1, k_{y l}=2, A_{1}=1,00, k_{x 2}=\sqrt{3}, k_{y 2}=1, u=0,5$ (tabela 3.2) e $A_{2}=0,00$. Em (a) está mostrado o mapa de Poincaré com cruzes em verde representando as condições iniciais. Em (b) está mostrada a difusão temporal $\left(D_{x}(\mathrm{t})\right)$ em função do tempo de integração. 
Comparando as figuras 3.9 e 3.7 vemos que, de fato, uma freqüência de perturbação alta modifica muito pouco a trajetória das partículas e a estrutura das ilhas. Tendo isso em vista, é possível diminuir o transporte radial de partículas introduzindo no sistema uma onda dominante que gere ilhas com freqüência natural muito baixa. É possível conseguir ilhas de freqüência baixa a partir de uma onda com amplitude $\left(\mathrm{A}_{1}\right)$ pequena, ou seja, quando o potencial elétrico de equilíbrio $\left(\phi_{0}\right)$ é muito maior do que o potencial das ondas de deriva $\left(\phi_{i}\right)$.

Ainda no caso em que a segunda onda tem amplitude nula, podemos observar, na figura 3.9b, que a difusão temporal cai rapidamente para zero e, portanto, o coeficiente de difusão será zero. Isso ocorre porque, com apenas uma onda de deriva, não existem trajetórias entre ilhas, logo, todas as trajetórias ficarão limitadas em suas ilhas de origem.
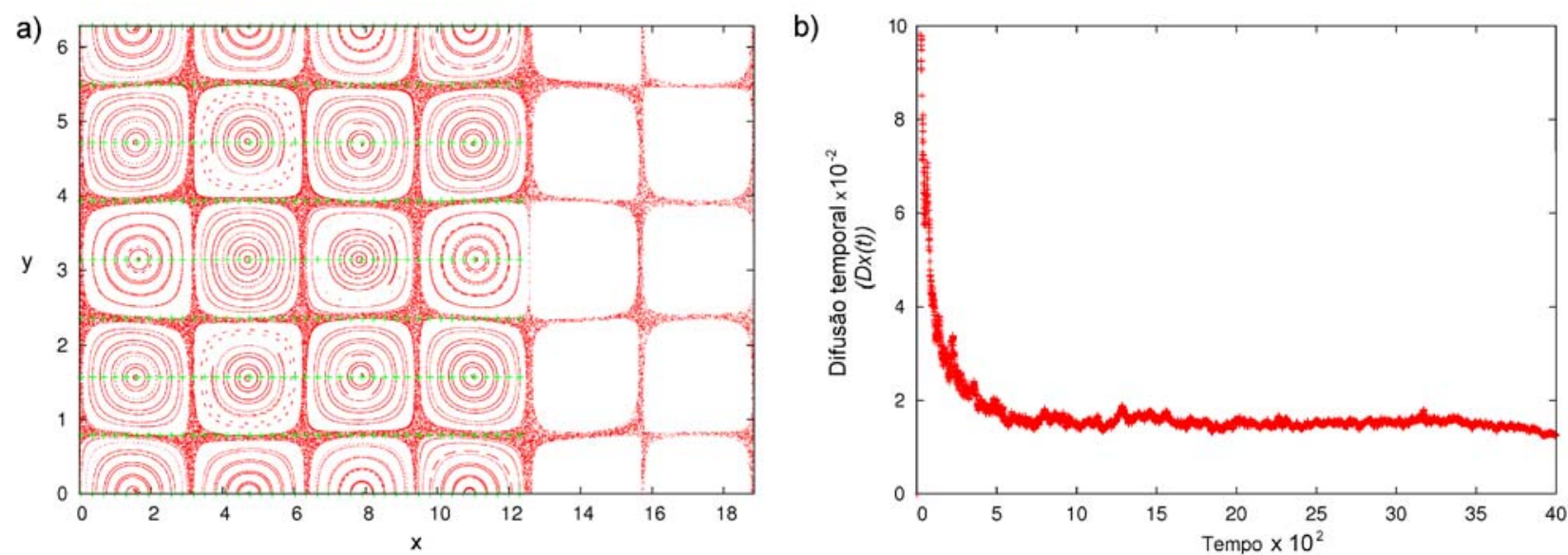

Figura 3.10: Simulação numérica utilizando os parâmetros da figura anterior com $A_{2}=0,05$. Em (a) está mostrado o mapa de Poincaré com cruzes em verde representando as condições iniciais. Em (b) está mostrada a difusão temporal $\left(D_{x}(\mathrm{t})\right)$ em função do tempo.

Se aumentarmos a amplitude da segunda onda para $A_{2}=0,05$, vemos, na figura 3.10 , que uma região caótica aparece entre as ilhas. Na parte (b) dessa figura, podemos observar que a segunda onda, mesmo com amplitude baixa, gera um transporte radial de partículas. 
Com o parâmetro $A_{2}=0,20$, é possível observar na figura 3.11 que a área coberta pelas trajetórias caóticas aumenta e que as ilhas são ligeiramente deformadas. Entretanto, não é verificado um aumento significativo no coeficiente de difusão: tanto na figura 3.10, quanto na figura 3.11 o coeficiente de difusão é algo em torno de 0,02 .

Se olharmos com cuidado o centro das ilhas da figura 3.11, podemos notar que algumas ilhas foram deformadas e que outras ilhas se duplicaram, mas no interior de cada célula continuam existindo trajetórias periódicas ou quase periódicas. Por isso na figura $3.11 \mathrm{~b}$ observamos um coeficiente de difusão baixo.
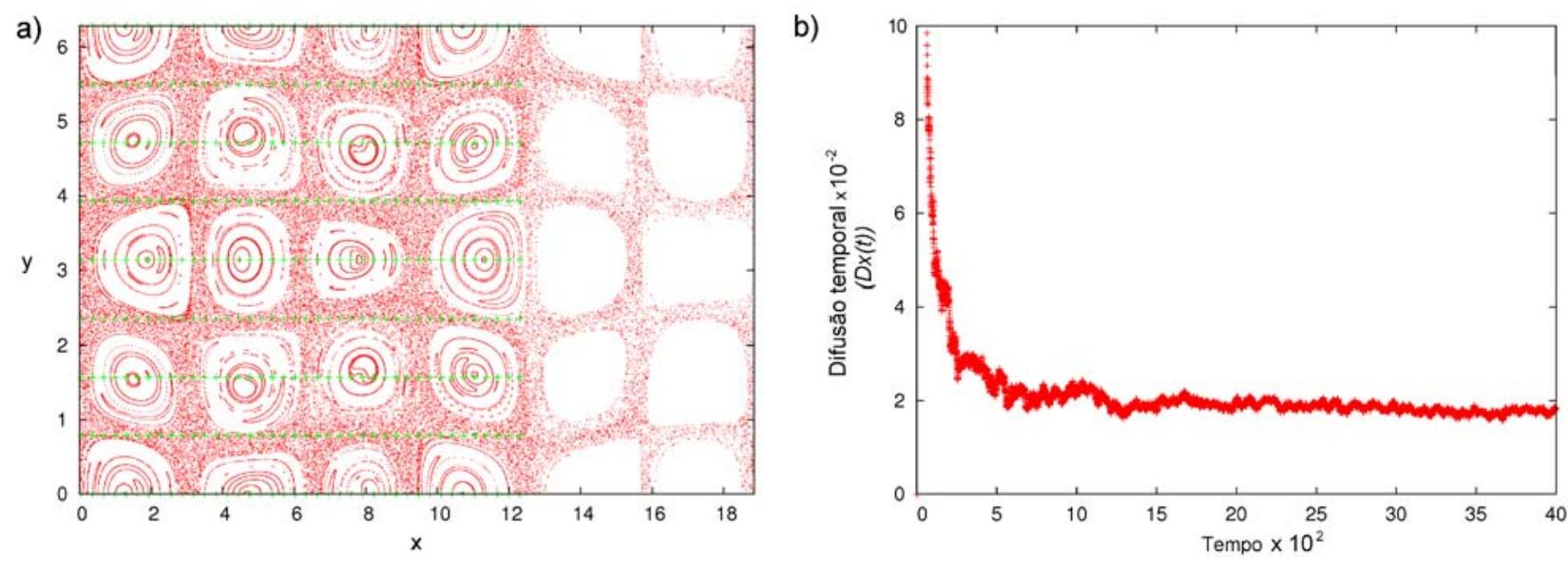

Figura 3.11: Simulação numérica utilizando os parâmetros da figura anterior com $A_{2}=0,20$. Em (a) está mostrado o mapa de Poincaré com cruzes em verde representando as condições iniciais. Em (b) está mostrada a difusão temporal $\left(D_{x}(\mathrm{t})\right)$ em função do tempo.

Quando fornecemos mais energia à segunda onda aumentando sua amplitude para $A_{2}=0,35$, podemos verificar na figura 3.12 que a área ocupada pelas trajetórias caóticas aumenta drasticamente e, por consequência, a área ocupada pelas ilhas diminui. Como as trajetórias próximas à separatriz das ilhas foram quebradas, o transporte para as trajetórias caóticas será alto, e por isso, aumentando a área caótica, aumentaremos a difusão de partículas, como pode ser visto na figura 3.12b. 
Na figura 3.12 ainda pode-se notar a existência de algumas ilhas no plano de fases, portanto, existem condições iniciais em que o sistema não é caótico. Já na figura 3.13 , para $A_{2}=0,55$, grande parte das trajetórias é caótica e qualquer condição inicial, fora das pequenas ilhas remanescentes, gera uma trajetória que preenche praticamente todo o plano de fase.
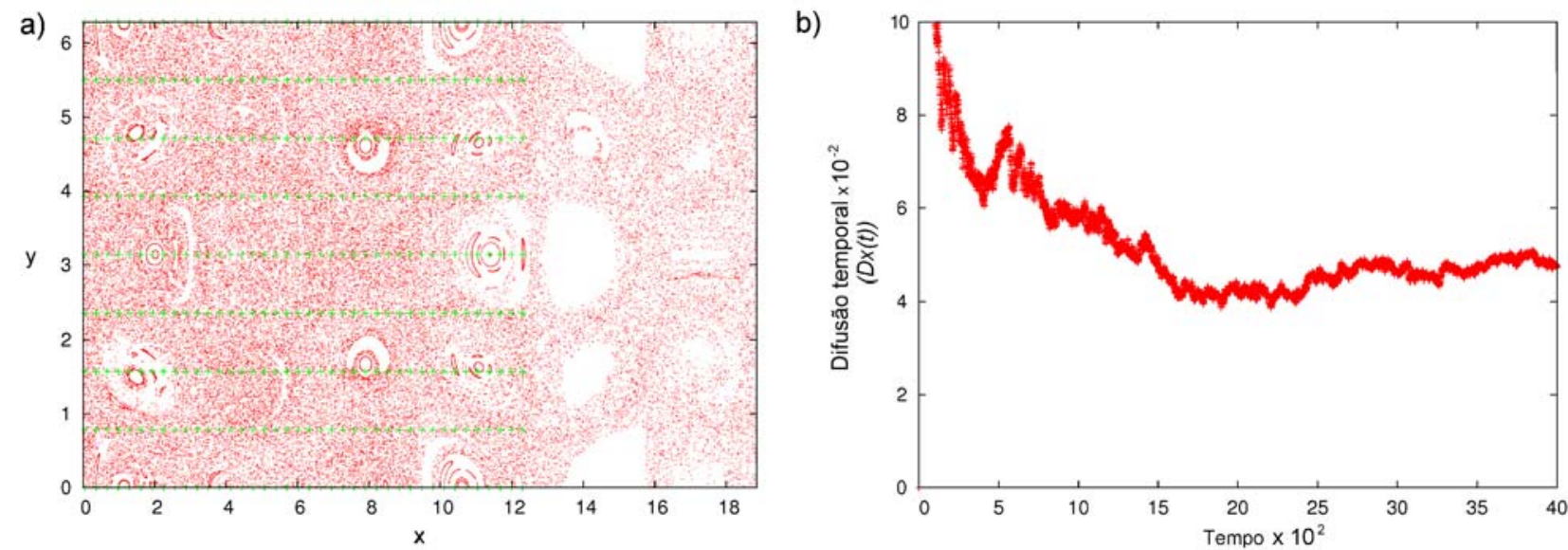

Figura 3.12: Simulação numérica utilizando os parâmetros da figura anterior com $A_{2}=0,35$. Em (a) está mostrado o mapa de Poincaré com cruzes em verde representando as condições iniciais. Em (b) está mostrada a difusão temporal $\left(D_{x}(\mathrm{t})\right)$ em função do tempo.
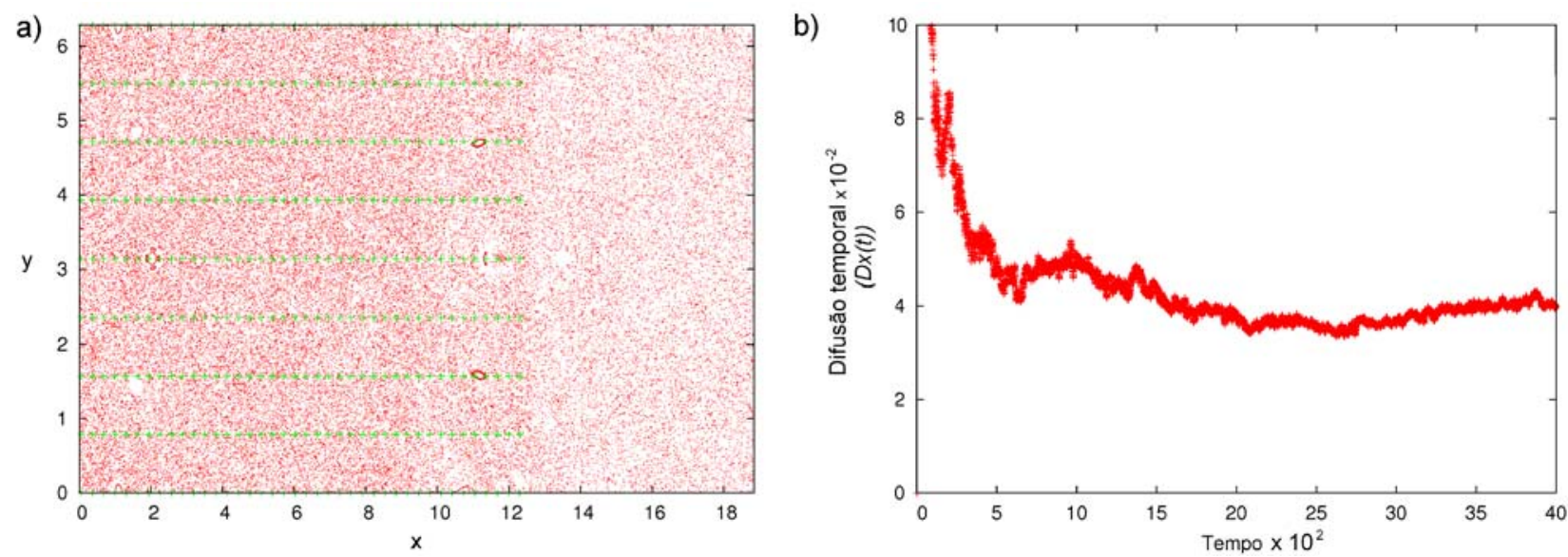

Figura 3.13: Simulação numérica utilizando os parâmetros da figura anterior com $A_{2}=0,55$. Em (a) está mostrado o mapa de Poincaré com cruzes em verde representando as condições iniciais. Em (b) está mostrada a difusão temporal $\left(D_{x}(\mathrm{t})\right)$ em função do tempo. 
Por fim, utilizando $A_{2}=0,90$, não é possível mais identificar nenhuma ilha, como pode ser verificado na figura 3.14. Mas é interessante reparar que, mesmo com as trajetórias caóticas tendo dominado o plano de fases, a difusão das partículas vista na figura 3.14 b tende a um número muito próximo ao obtido $\operatorname{com} A_{2}=0,55$, na figura $3.13 \mathrm{~b}$.
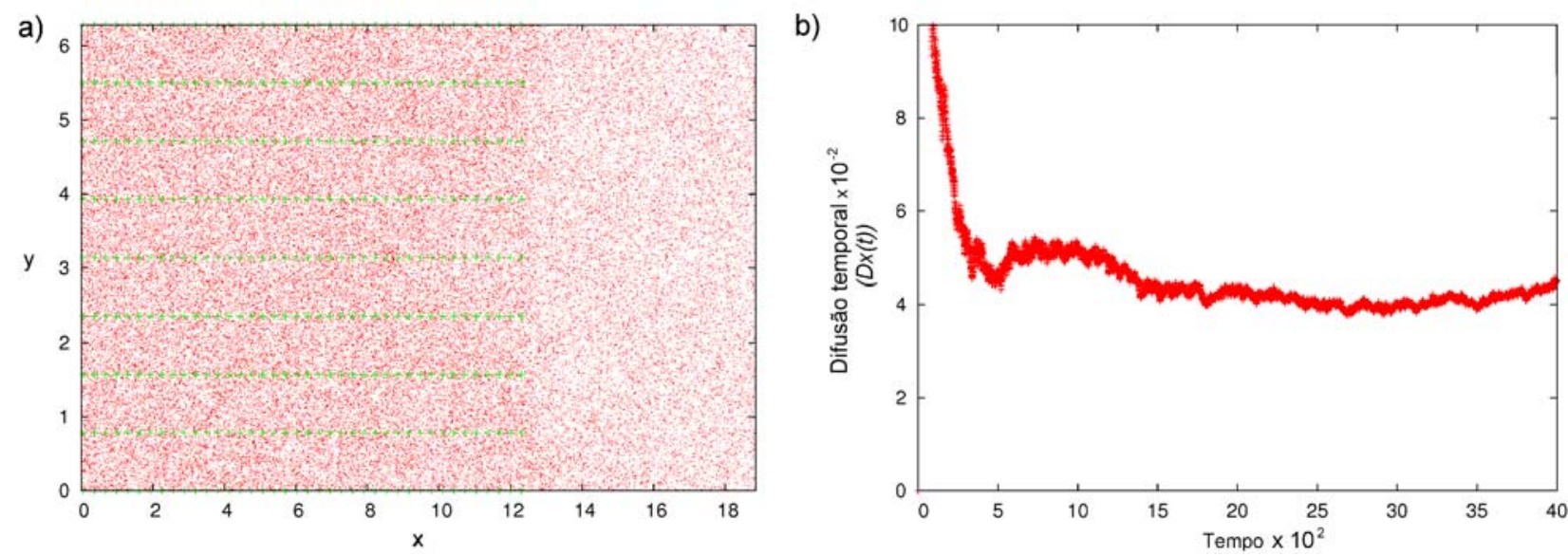

Figura 3.14: Simulação numérica utilizando os parâmetros da figura anterior com $A_{2}=0,90$. Em (a) está mostrado o mapa de Poincaré com cruzes em verde representando as condições iniciais. Em (b) está mostrada a difusão temporal $\left(D_{x}(\mathrm{t})\right)$ em função do tempo.

Foram calculados, novamente, o coeficiente de difusão $\left(D_{x}\right)$ para diferentes valores de amplitude da segunda onda $\left(\mathrm{A}_{2}\right)$. Esse coeficiente é obtido através da média do coeficiente de difusão temporal no intervalo de tempo de 2000 a 4000 e está representado no gráfico da figura 3.14.

Na figura 3.15 é possível identificar dois patamares. O primeiro patamar ocorre entre 0 e 0,2 e o segundo ocorre entre 0,4 e 1,0. No primeiro patamar existem ilhas grandes que são destruídas no segundo patamar. A zona intermediária apresenta uma rápida ascensão do coeficiente de difusão. Essa ascensão é devida a destruição gradativa das ilhas em função do aumento da amplitude da segunda onda: Quanto maior a amplitude, mais trajetórias são destruídas e, conseqüentemente, menor será a ilha. 


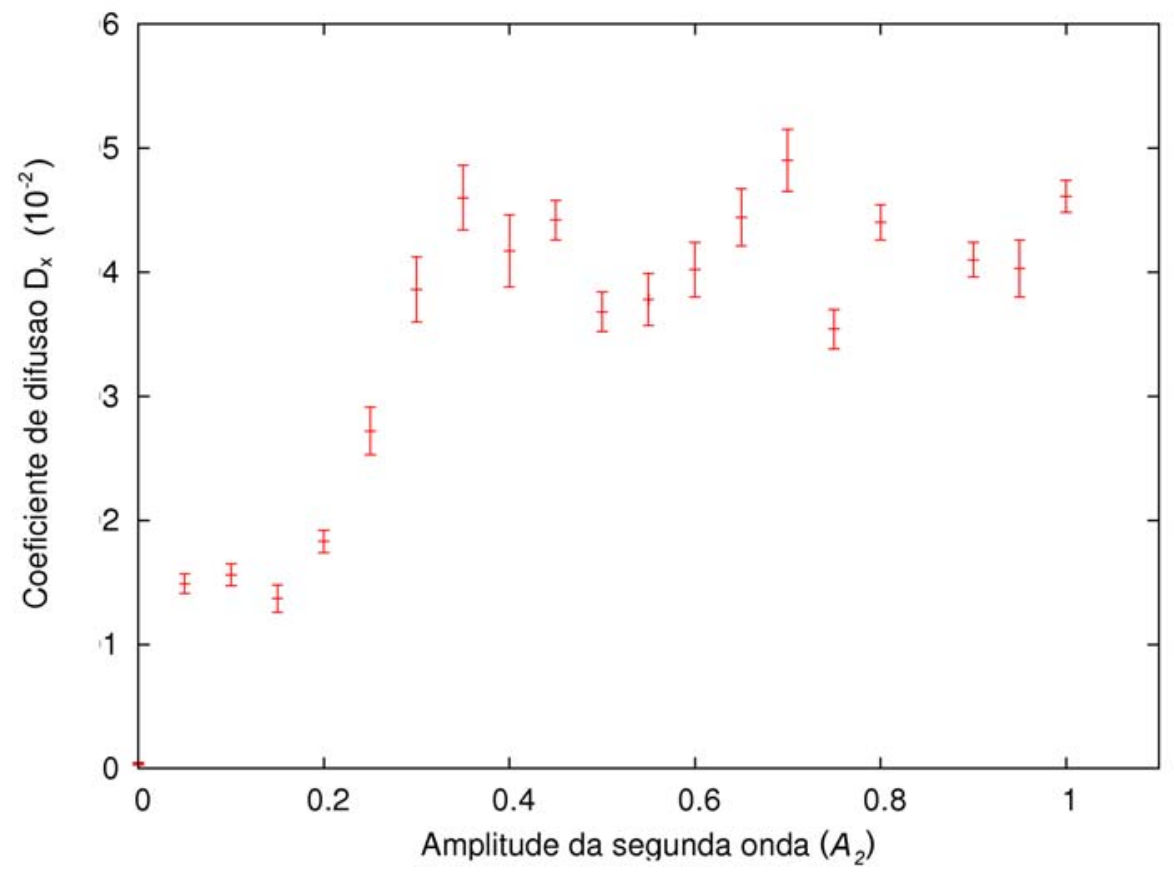

Figura 3.15: Gráfico do Coeficiente de difusão $\left(D_{x}\right)$ em função da amplitude da segunda onda $\left(\mathrm{A}_{2}\right)$ para a diferença de velocidade de fase $u=0,5$. As barras verticais representam o desvio padrão no intervalo utilizado para o cálculo dos valores médios.

À exemplo do que ocorre no primeiro patamar, temos as figuras 3.10 e 3.11 , com $A_{2}=0,05 \mathrm{e}$ $A_{2}=0,20$. Para esses parâmetros existem ilhas bem definidas dentro das células e grande parte do plano de fases é periódico ou quase-periódico. Um exemplo do que acontece na zona intermediária está mostrado na figura 3.12, nela podemos observar o aparecimento de algumas trajetórias caóticas no interior das ilhas que, no segundo patamar, se fundem com as trajetórias caóticas externas as ilhas. Com essa fusão de trajetórias caóticas, o caos passa a dominar praticamente todo o plano de fases, como é mostrado na figura 3.13 .

\subsection{Conclusões}

A diferença na velocidade de fases está diretamente ligada a freqüência da perturbação e pode ser relacionada com o transporte de partículas segundo o gráfico da figura 3.8. Nessa figura vimos 
que, quando a freqüência de perturbação é muito alta, a difusão é baixa. Vimos também que, a difusão apresenta valores maiores quando a freqüência de perturbação está entre 0 e 2 , ou seja, a difusão é maior para perturbações que tenham freqüências próximas a freqüência natural das ilhas.

Já a amplitude da segunda onda $\left(A_{2}\right)$ esta relacionada com o transporte de partículas de acordo com o gráfico da figura 3.15. Nele, vimos que o transporte pode ser dividido em dois patamares. O primeiro possui ilhas grandes que ocupam uma parte considerável do plano de fases e ocorre quando a segunda onda tem amplitude baixa. O segundo não contém ilhas, pois as mesmas são destruídas devido a alta amplitude da segunda onda e, devido a isso, nele obtemos um transporte maior de partículas. 


\section{Capítulo 4}

\section{Estruturas Lagrangianas Coerentes}

No capítulo 2, quando estudamos o sistema autônomo, vimos que as variedades instáveis e estáveis dos pontos hiperbólicos tem grande importância na dinâmica do sistema. Elas são responsáveis pelo aparecimento de barreiras que criam células no espaço de fase e também influenciam trajetórias próximas à elas. No entanto, quando inserimos o tempo nas equações, não é mais possível calcular um ponto fixo, pois o ponto de equilíbrio passa a depender do tempo, e, por consequência, também não podemos definir as variedades. Entretanto, nesse capítulo, veremos que existe uma estrutura dependente do tempo, conhecida como Estrutura Lagrangiana Coerente (ELC, ou, em inglês, Lagrangian Coherent Structure - LCS), que é de grande importância na dinâmica do sistema e toma o lugar das variedades do sistema autônomo. [31]

Com a finalidade de calcular as ELCs desse sistema, foi desenvolvido um método de análise utilizando os gráfico do campo de difusão. Nesse campo de difusão são apresentados os valores de deslocamento quadrático por tempo para um conjunto de $1 \times 10^{6}$ condições iniciais. As cristas de deslocamento quadrático desse campo de difusão serão nossas ELCs.

Ainda utilizando o campo de difusão, veremos que quanto maior a amplitude da segunda onda, maior será a área em que se localizam as ELCs e quanto maior o tempo de integração, maior é a quantidade de detalhes e ramificações que podemos observar nessas ELCs.

Assim como as variedades, veremos que as ELCs também se apresentam de maneira estável e instável. Sua forma estável está relacionada com as regiões do campo de difusão com deslocamento 
quadrático em $x$ elevado e sua forma instável com as fronteiras das ilhas.

Por fim, baseados nos efeitos das ELCs sobre as fronteiras das ilhas, será apresentado um método alternativo para sua obtenção. Esse método consiste em integrar uma grande quantidade de condições inicialmente colocadas sobre uma curva que, no sistema autônomo, seja uma separatriz. Para encontrar a ELC instável, integrarmos as equações de movimento para o futuro e para encontrar a ELC estável, integramos as equações para o passado.

\subsection{Campo de Difusão}

No capítulo anterior foram calculados os coeficientes de difusão $\left(D_{x}\right)$ para um conjunto de condições iniciais arbitrariamente escolhidas de maneira a preencher a parte do plano de fases

estudado. É esperado que a escolha de condições iniciais próximas à separatriz leve a uma difusão maior do que a que seria obtida com as condições iniciais próximas aos centros das células.

A dependência da difusão com as condições iniciais é uma questão complexa, que será investigada nesse capítulo a partir do estudo do deslocamento quadrático $\left((\Delta x)^{2}\right)$, na direção $x$, calculado em relação a uma condição inicial $x(0)$, para cada uma das trajetórias

$$
[\Delta x(t)]^{2}=[x(t)-x(0)]^{2}
$$

Definiremos o deslocamento quadrático por unidade de tempo $<(\Delta x)^{2}>_{L}$ como a razão entre o deslocamento quadrático e o tempo, quando esse for igual a $L \tau+t_{0}$. Assim, teremos:

$$
<(\Delta x)^{2}>_{L}=\frac{\left[\Delta x\left(L \tau+t_{0}\right)\right]^{2}}{L \tau+t_{0}}
$$

onde $\tau$ é o período da perturbação e $L$ é o número de intervalos considerados na integração. 
Calcularemos nessa seção o deslocamento quadrático por unidade de tempo para $1 \times 10^{6}$ condições iniciais espalhadas pelo plano de fase entre $x=[0 ; 4 \pi]$ e $y=[0 ; 2 \pi]$, por um tempo de $L$ períodos da perturbação $(\tau=2 \pi / u)$ e verificaremos a influência da escolha dessas condições iniciais no deslocamento quadrático. Para isso serão confeccionados gráficos do plano de fases com uma escala em cor representando o deslocamento quadrático das partículas obtido para cada condição inicial durante os $L$ períodos de integração numérica. Devido a relação entre o deslocamento quadrático de uma partícula e a difusão de um conjunto de partículas, esses campos serão chamados de campos de difusão.

De maneira geral, sistemas dinâmicos não autônomos não apresentam separatrizes independentes do tempo, pois as equações de movimento desses sistemas dependem do tempo e, portanto, as separatrizes também. Entretanto, para um tempo fixo, é possível observar no plano de fases, regiões com diferentes tipos de comportamento separados por linhas divisórias que lembram as separatrizes. As estruturas que formam essas linhas divisórias são chamadas de Estruturas Lagrangianas Coerentes (ELCs)[8, 31].

Assim, tal como as variedades dos sistemas autônomos, as ELCs tendem a esticar um volume de condições iniciais ao longo de sua extensão e a encolher esse volume na direção perpendicular a sua extensão. Como consequência dessa característica, as ELCs funcionam como barreiras de transporte na direção perpendicular e induzem um alto transporte de partículas ao longo de sua extensão, sendo assim, de grande importância na difusão de partículas e na criação de ilhas.

Por induzirem um alto transporte ao longo de sua extensão, as ELCs estáveis criam regiões de máximos deslocamento quadrático nos campos de difusão que indicam sua localização. Assim, podemos utilizar esse fato para identificar a existência de ELCs de maneira análoga aos métodos encontrados na literatura que utilizam os picos nos campos de expoente de Lyapunov a tempo finito (ELTF, em inglês, finite-time Lyapunov exponents - FTLE)[23, 32]. 
A principal diferença entre os campos de difusão dessa dissertação e os campos de ELTF encontrados na literatura é que: os campos de difusão estão relacionados com quão distante uma partícula pode chegar a partir de uma condição inicial; e os campos ELTF estão relacionados com quanto uma partícula se distancia de outra próxima.

Todos os campos de difusão serão obtidos integrando-se numericamente a eq 3.1 com um conjunto de $1 \times 10^{6}$ condições iniciais por um tempo de integração de $L$ períodos de perturbação. $O$ campo da figura 4.1 é obtido com os parâmetros: $k_{x l}=1, k_{y l}=2, A_{1}=1, k_{x 2}=\sqrt{3}, k_{y 2}=1, u=1, A_{2}=0,10$, $t_{0}=0$ e $L=2$. Nessa figura, é possível notar que, a medida que nos afastamos do centro da célula, nos deparamos com uma estrutura complexa de mistura entre condições iniciais com diferentes valores de deslocamento quadrático.

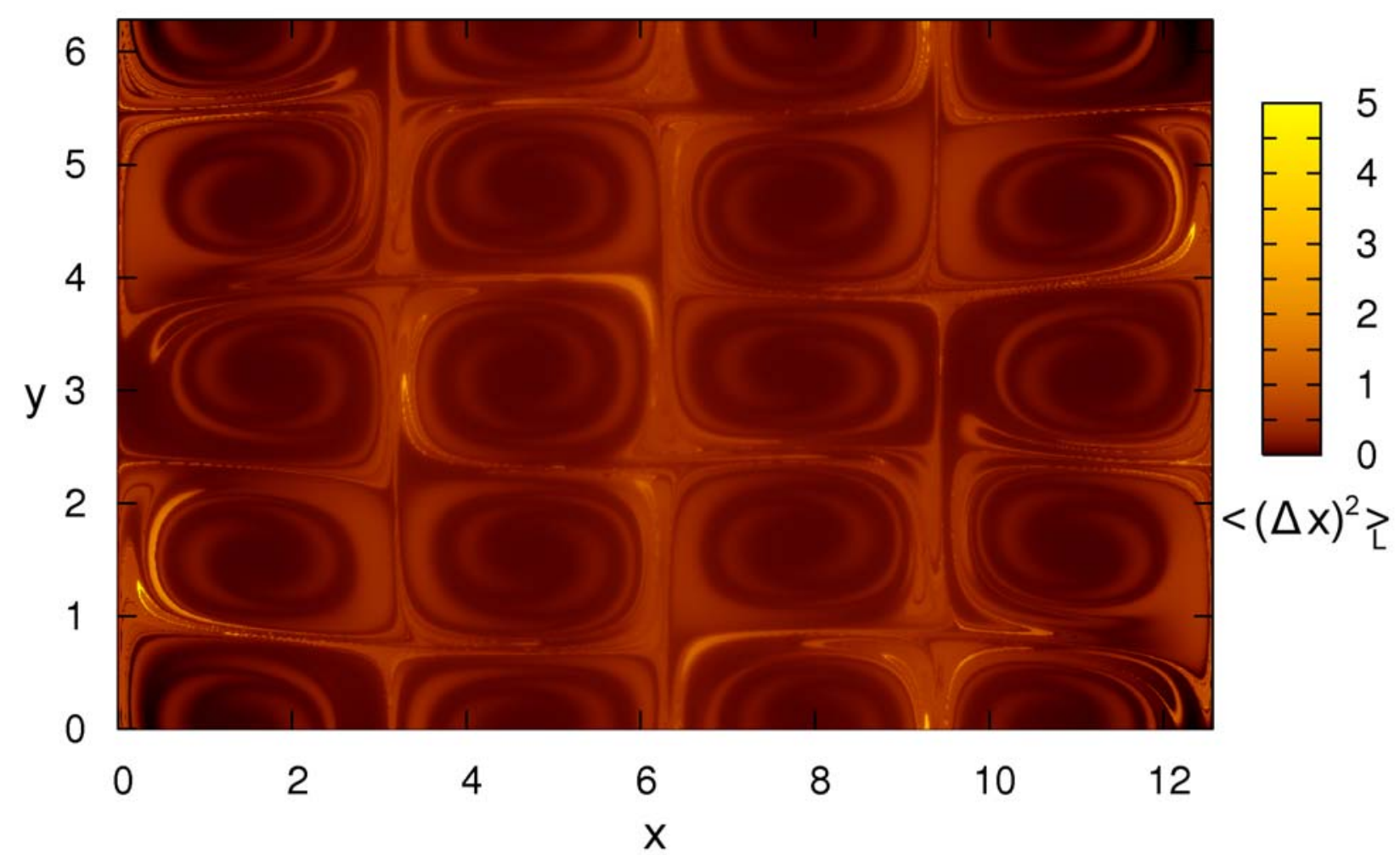

Figura 4.1: Campo de difusão para os parâmetros $k_{x l}=1, k_{y l}=2, A_{1}=1, k_{x 2}=\sqrt{3}, k_{y 2}=1, u=1, A_{2}=0,10$ e $t_{0}=0$ com $L=2$. A escala em cores representam os valores de deslocamento quadrático $\left(<(\Delta x)^{2}>_{L}\right)$ obtidos para um conjunto de $1 \times 10^{6}$ condições iniciais uniformemente distribuídas. 
No campo de difusão da figura 4.1 pode-se notar a predominância de condições iniciais com baixo deslocamento quadrático (cores escuras da escala). Contudo, existe uma cadeia de estruturas finas entre as ilhas, formando uma teia que se espalha pelo plano de fases com deslocamento quadrático alto (cores mais claras) que indicam a existência de ELCs, responsáveis pela quebra das separatrizes. [33]

Se aumentarmos a amplitude da segunda onda para $A_{2}=0,30$, mantendo os outros parâmetros iguais ao da figura anterior, obtemos a figura 4.2. Nessa figura, notamos que a área mais escura diminui em consequência do aumento da área ocupada pelas ELCs. É interessante perceber que a complexidade do campo de difusão da figura 4.2 é muito maior do que o da figura 4.1 , assim, ao aumentarmos a amplitude da segunda onda, aumentamos também a complexidade das estruturas com alta difusão. Portanto, quanto maior a amplitude da segunda onda, mais distorcidas ficarão as ELCs.

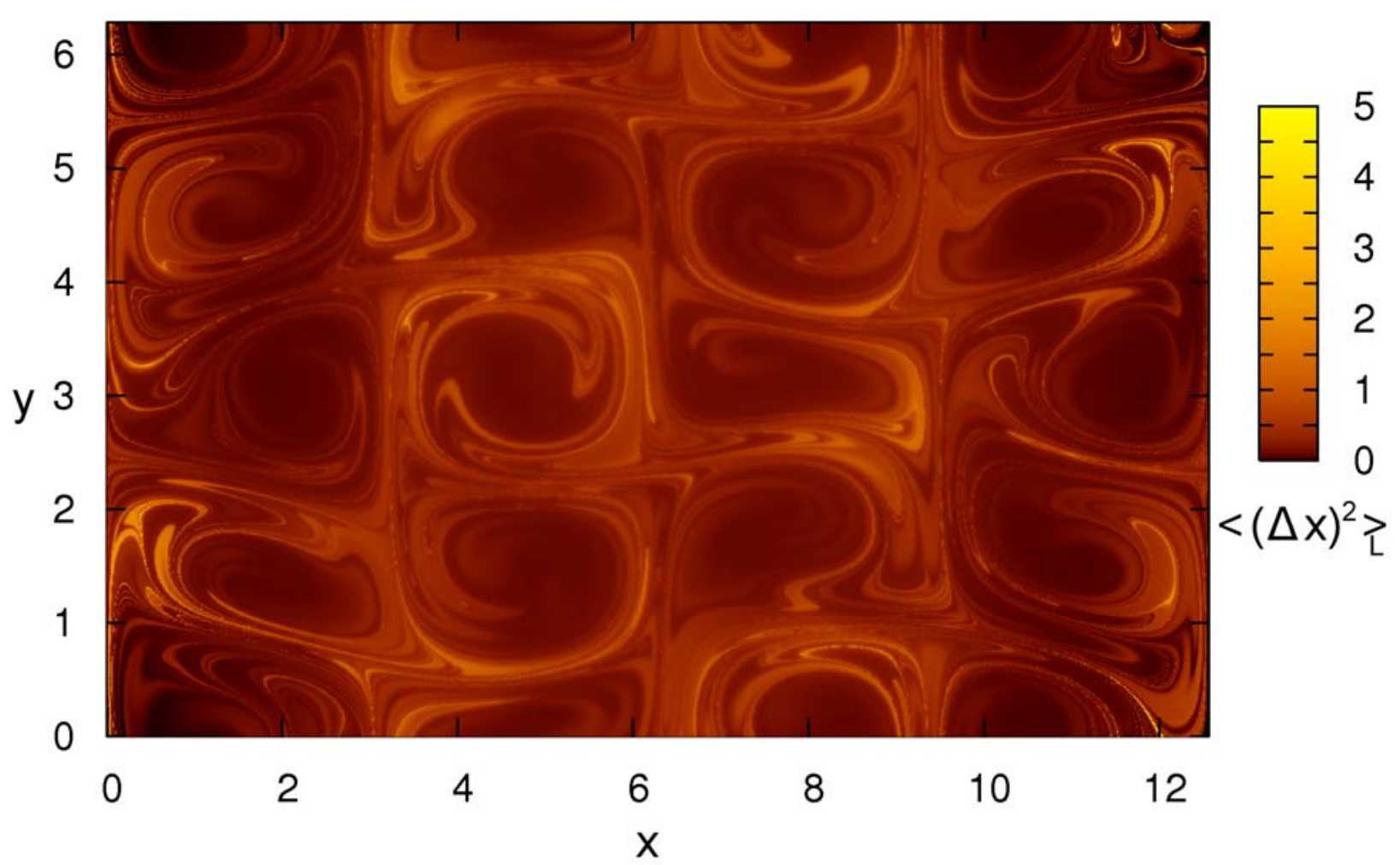

Figura 4.2: Campo de difusão para os parâmetros $k_{x l}=1, k_{y 1}=2, A_{1}=1, k_{x 2}=\sqrt{3}, k_{y 2}=1, u=1, A_{2}=0,30$ e $t_{0}=0$ com $L=2$. 
Agora, com a amplitude da segunda onda $A_{2}=0,90$, utilizando os mesmos parâmetros da figura anterior, é possível notar que, na figura 4.3, praticamente não existem mais áreas escuras no campo de difusão e que as ELCs ocupam praticamente todo o espaço de fase e, por consequência, destroem as ilhas espalhando o caos por todo o espaço de fases.

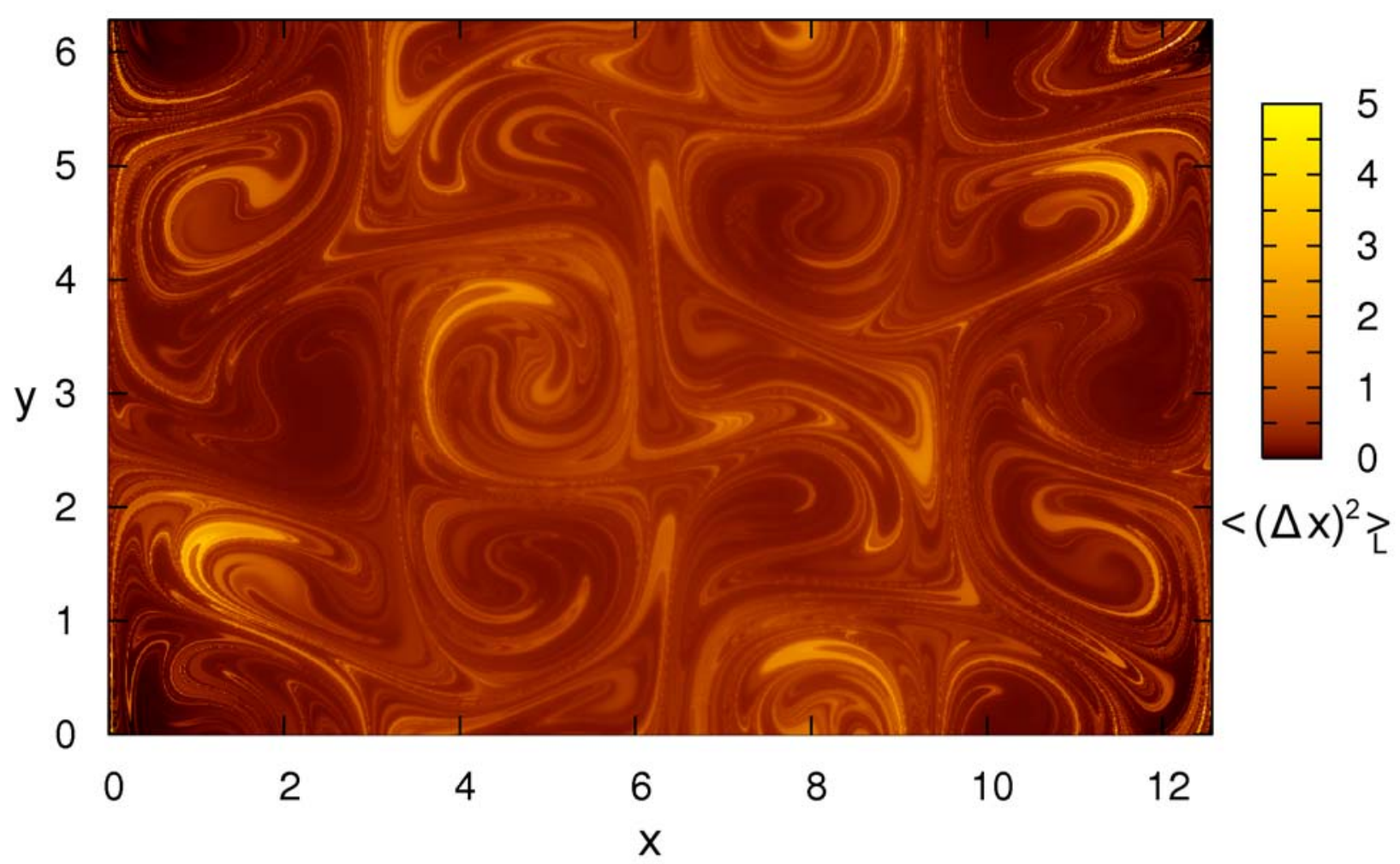

Figura 4.3: Campo de difusão para os parâmetros $k_{x l}=1, k_{y l}=2, A_{I}=1, k_{x 2}=\sqrt{3}, k_{y 2}=1, u=1, A_{2}=0,50$ e com $L=2$.

Nas figuras anteriores podemos verificar que as ELCs são curvas que funcionam instantaneamente como linhas divisórias (como as separatrizes) de movimento. Entretanto, essas curvas não são as variedades instáveis e estáveis dos pontos hiperbólicos e nem são curvas invariantes para um tempo qualquer, pois conforme o tempo evolui essas curvas se modificam, mas, mesmo assim, conservam sua função de separatriz.

As ELCs não podem ser chamadas de variedades porque a definição de variedade se torna inadequada para sistemas não autônomos, pois, esses sistemas, de maneira geral, não possuem pontos 
fixos, já que seus pontos de equilíbrio (onde o campo de velocidade é nulo) dependem do tempo.

Utilizando os parâmetros $k_{x l}=1, k_{y l}=2, A_{1}=1, k_{x 2}=\sqrt{3}, k_{y 2}=1, u=0,5, \quad A_{2}=0,50$ e com $L=5$, vamos variar o tempo inicial $\left(t_{0}\right)$ que é utilizado para começar o cálculo do deslocamento quadrático. Para estudar a evolução temporal das ELCs, utilizaremos $1 \times 10^{6}$ condições inicias uniformemente espalhadas entre 0 e $4 \pi$ na direção x e entre 0 e $2 \pi$ na direção y. Todas trajetórias das condições iniciais serão integradas de $t_{0}$ até $L \tau+t_{0}$ e as difusões médias serão calculadas de acordo com a equação 4.1 .

Da figura 4.4 a figura 4.16 é mostrada uma seqüência de campos de difusão para diferentes $t_{0}$. Nelas utilizamos os parâmetros $k_{x l}=1, k_{y l}=2, A_{1}=1,00, k_{x 2}=\sqrt{3}, k_{y 2}=1, u=0,5$ e $A_{2}=0,50$ com $L=5$.

No primeiro campo de difusão da seqüencia, com $t_{0}$ igual 0 (figura 4.4a), observamos que, aparentemente, existem ilhas no espaço de fases. Entretanto, nos instantes seguintes, uma ELC se aproxima da ilha e a distorce, ocupando, então, seu lugar.
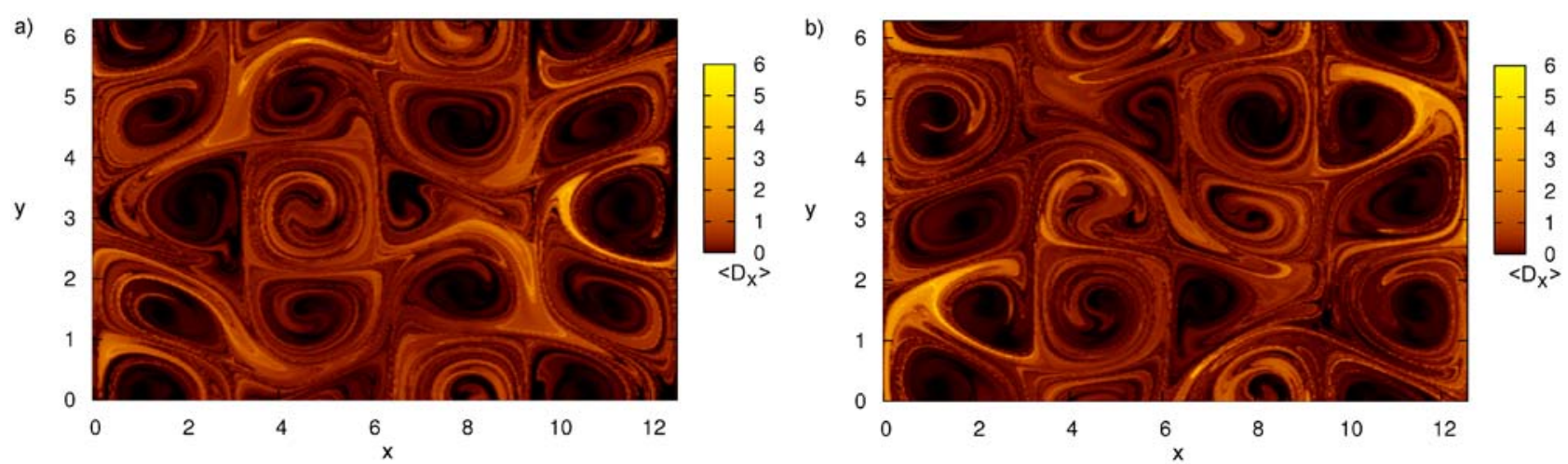

Figura 4.4: Seqüencia de campos de difusão utilizando os parâmetros $k_{x l}=1, k_{y l}=2, A_{l}=1,00, k_{x 2}=\sqrt{3}, k_{y 2}=1, u=0,5$ e

$$
A_{2}=0,50 \operatorname{com} L=5 \text { para } t_{0} \text { igual a (a) } 0,0 \tau \text { e b) } 0,2 \tau \text {. }
$$

Nessas figura notamos que as ELCs, responsáveis pela dinâmica desse espaço de fase, são dependentes do tempo inicial escolhido. Cada tempo inicial define uma seção de Poincaré, portanto, quando variamos $t_{0}$, variamos, na verdade, a seção de Poincaré escolhida. 

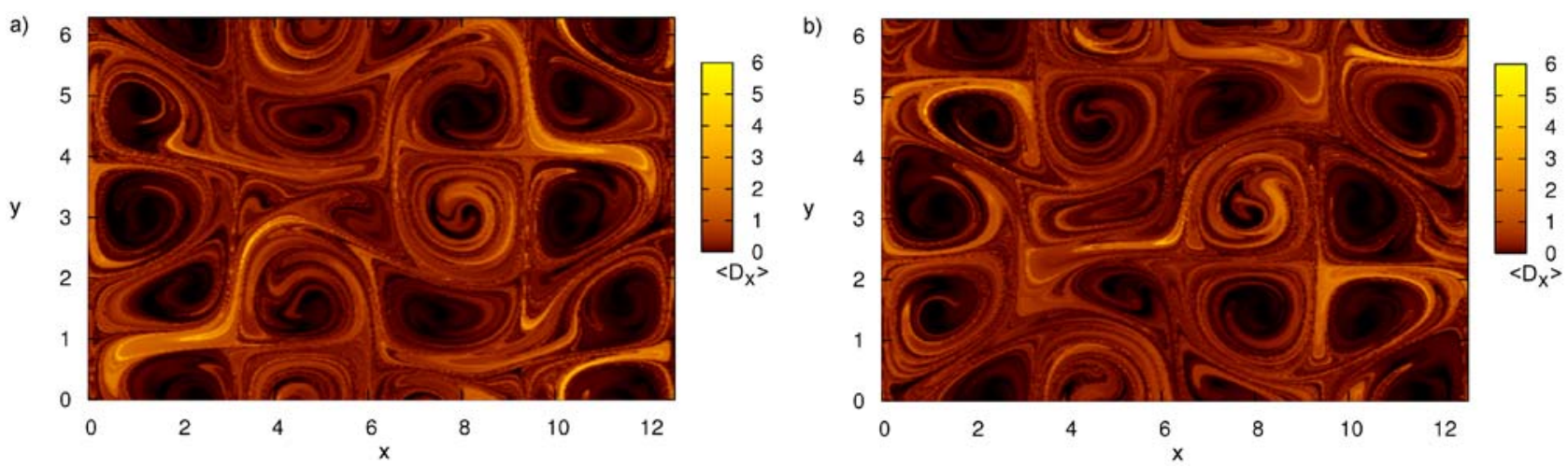

Figura 4.5: Seqüencia de campos de difusão utilizando os parâmetros $k_{x l}=1, k_{y l}=2, A_{1}=1,00, k_{x 2}=\sqrt{3}, k_{y 2}=1, u=0,5$ e $A_{2}=0,50 \operatorname{com} L=5$ para $t_{0}$ igual a (a) $0,4 \tau$ e b) $0,6 \tau$

Na figura 4.5 estão mais dois exemplos do comportamento das ELCs e na figura 4.6 vemos que, assim como a hamiltoniana do sistema, as ELS também são periódicas de período $\tau$ e na figura 4.6b, com $t_{0}=1 \tau$, obtemos exatamente o mesmo campo de difusão da figura 4.4a, com $t_{0}=0$.
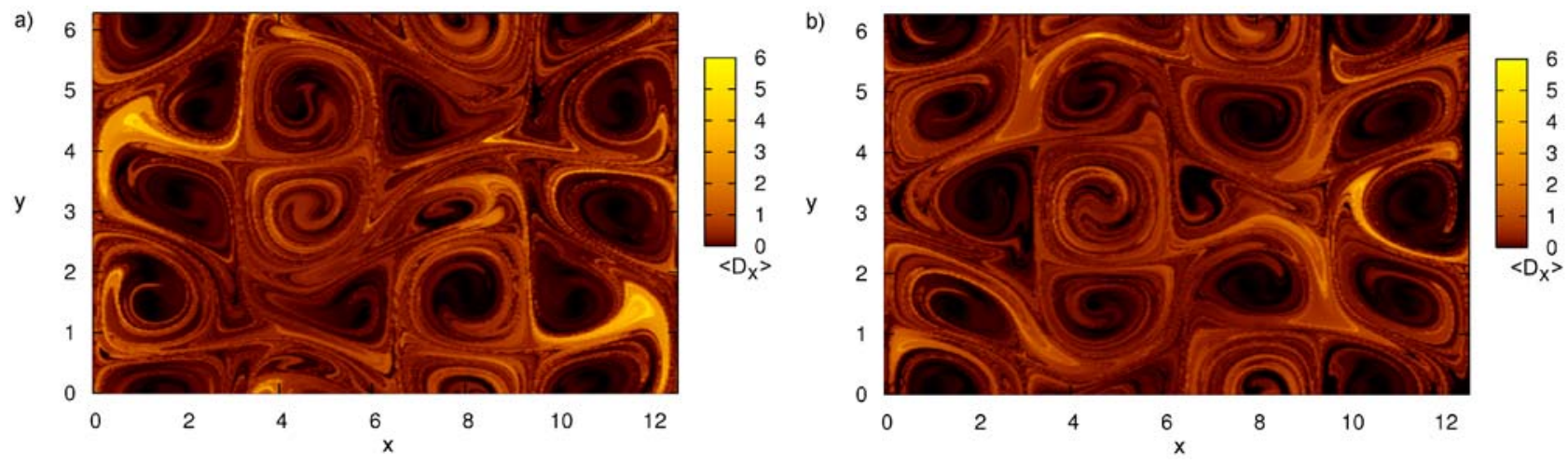

Figura 4.6: Seqüencia de campos de difusão utilizando os parâmetros $k_{x l}=1, k_{y l}=2, A_{1}=1,00, k_{x 2}=\sqrt{3}, k_{y 2}=1, u=0,5 \mathrm{e}$

$$
A_{2}=0,50 \operatorname{com} L=5 \text { para } t_{0} \text { igual a (a) } 0,8 \tau \text { e b) } 1,0 \tau \text {. }
$$

Os exemplos mostrados na seqüência de campos de difusão sugerem que não existe nenhuma área significativa em que, para qualquer tempo, o deslocamento quadrático seja nulo. No entanto, analisando uma série maior de campos obtidos para esse parâmetro, é possível ver que, de fato, nenhuma área de baixa difusão persiste num mesmo lugar por muito tempo. Deste modo, não existem ilhas, pois, mesmo que instantaneamente consigamos ver uma região que aparenta ser uma ilha, no instante seguinte essa região é ocupada por uma ELC. 


\subsection{Esticamentos e Dobras no Plano de Fase}

Uma característica comum em sistemas caóticos que é gerada por variedades, no caso autônomo, e por ELCs, no caso não autônomo, são os efeitos de esticamentos e dobras [34] sofridos por um conjunto de condições iniciais no mapa de Poincaré do plano de fase. Para estudar esse efeito, serão obtidos os mapas de Poincaré de um conjunto de condições iniciais em forma de círculo.

Esse pequeno volume de condições iniciais é uma esfera de raio 0,02 que foi colocada no plano de fase inicialmente na posição $(0,5 ; 1)$. Essa esfera foi integrada durante 8 períodos de perturbação, utilizando os parâmetros $k_{x l}=1, k_{y l}=2, A_{1}=1, k_{x 2}=\sqrt{3}, k_{y 2}=1, u=0,5$ e $A_{2}=0,10$. A figura 4.7 mostra o plano de fase para $L=1$ e $L=2$ e a figura 4.8 mostra o plano de fase para $L=4$ e $L=8$.
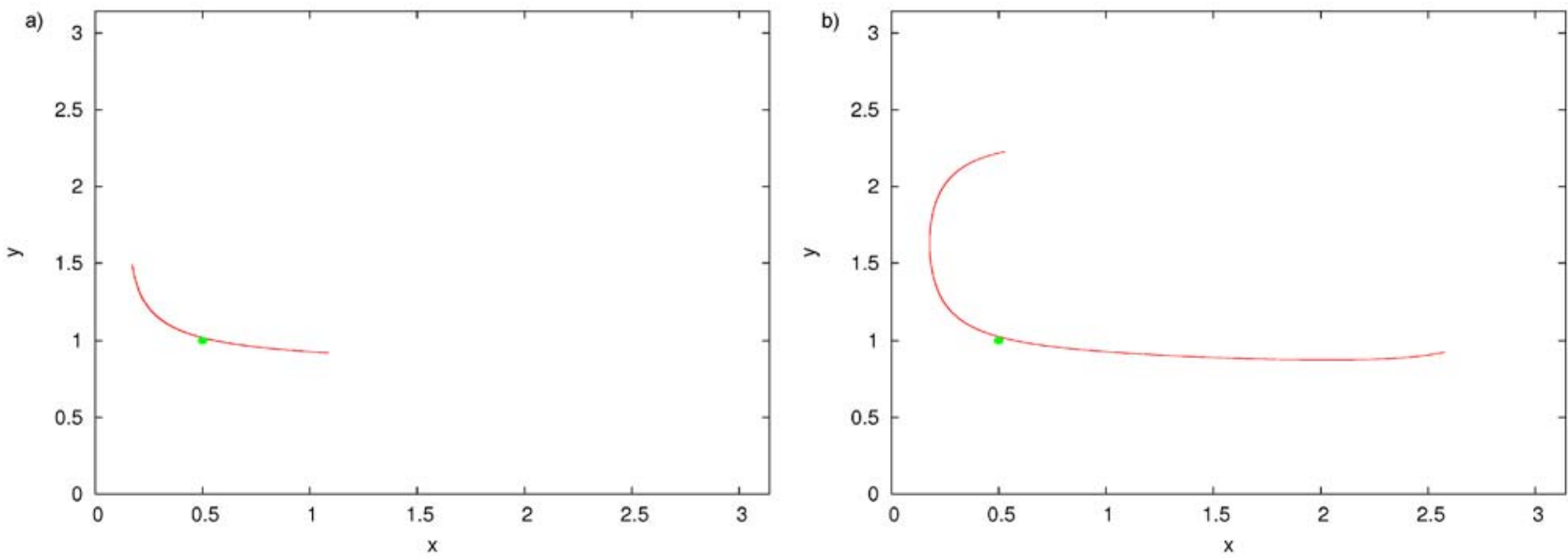

Figura 4.7: Evolução, em vermelho, de um volume de condições iniciais, em verde, de raio 0,02 utilizando os parâmetros $k_{x 1}=1, k_{y 1}=2, A_{1}=1,00, k_{x 2}=\sqrt{3}, k_{y 2}=1, u=0,5$ e $A_{2}=0,10$ com (a) $L=1$ e (b) $L=2$.

Na figura 4.7 é possível observar que existe uma direção na qual o volume de condições iniciais é esticado e outra na qual esse volume é encolhido. 

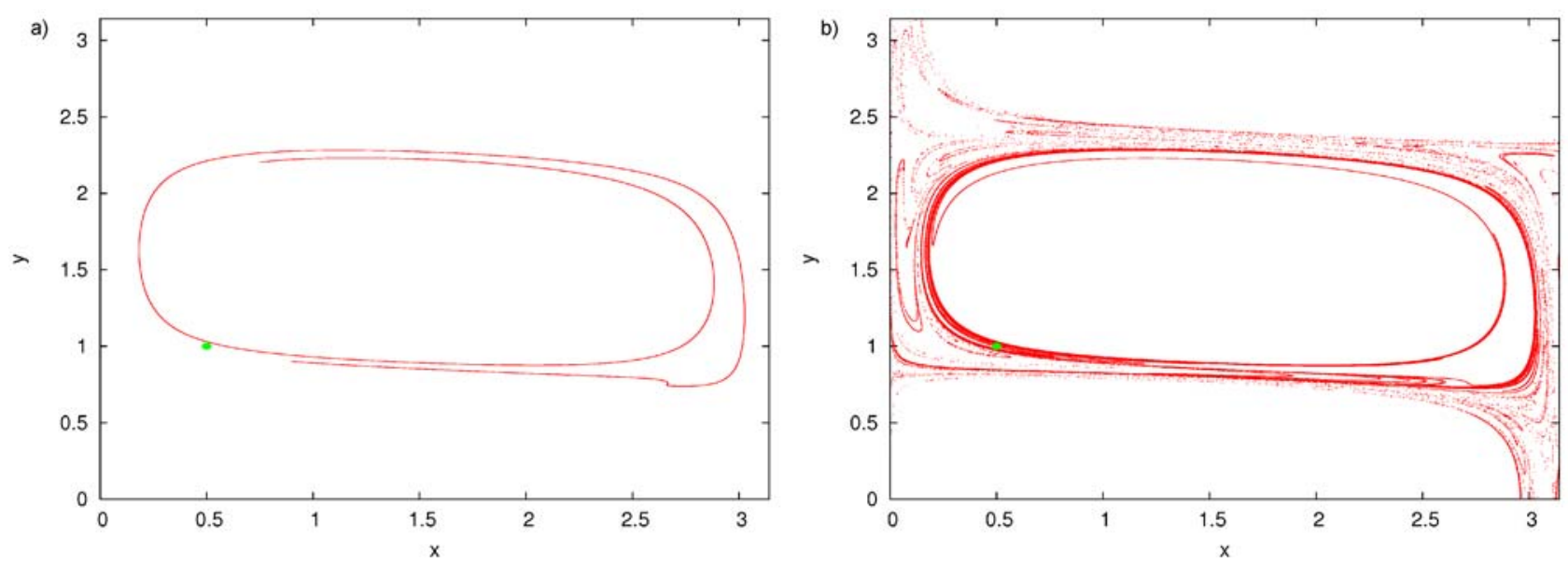

Figura 4.8: Evolução, em vermelho, de um volume de condições iniciais, em verde, de raio 0,02 utilizando os parâmetros $k_{x l}=1, k_{y l}=2, A_{1}=1,00, k_{x 2}=\sqrt{3}, k_{y 2}=1, u=0,5$ e $A_{2}=0,10$ com (a) $L=4$ e (b) $L=8$.

$\mathrm{Na}$ figura 4.8, vemos que quanto mais integramos esse sistema, mais esticamos esse volume de condições iniciais, até o ponto em que, na parte (b) dessa figura, o volume é esticado até uma região caótica. Nessa região caótica os efeitos de esticamentos são ainda mais intensos e a separação entre duas condições próximas aumenta consideravelmente.

Assim, vimos que esses efeitos de esticamento e dobra que são induzidos pelas ELCs são mais intensos nas proximidades das paredes da célula, pois é nessa região que as ELCs se concentram quando a amplitude da segunda onda é baixa.

Para demonstrar esse efeito em todo plano de fase, serão integrados quatro conjuntos densos de condições iniciais durante $L$ períodos de perturbação $\left(\tau=2 \pi /\left(k_{y 2} u\right)\right)$. Os parâmetros utilizados serão $k_{x l}=1, k_{y l}=2, A_{1}=1, k_{x 2}=\sqrt{3}, k_{y 2}=1, u=0,5$ e $A_{2}=0,50$. Cada conjunto será escolhido como uma faixa de pontos com largura $\Delta x=\pi$ e $\Delta y=2 \pi$. Essas faixas serão colocadas de modo a preencher o espaço de fases entre $x=0$ e $x=4 \pi$, conforme mostra a figura 4.9. 

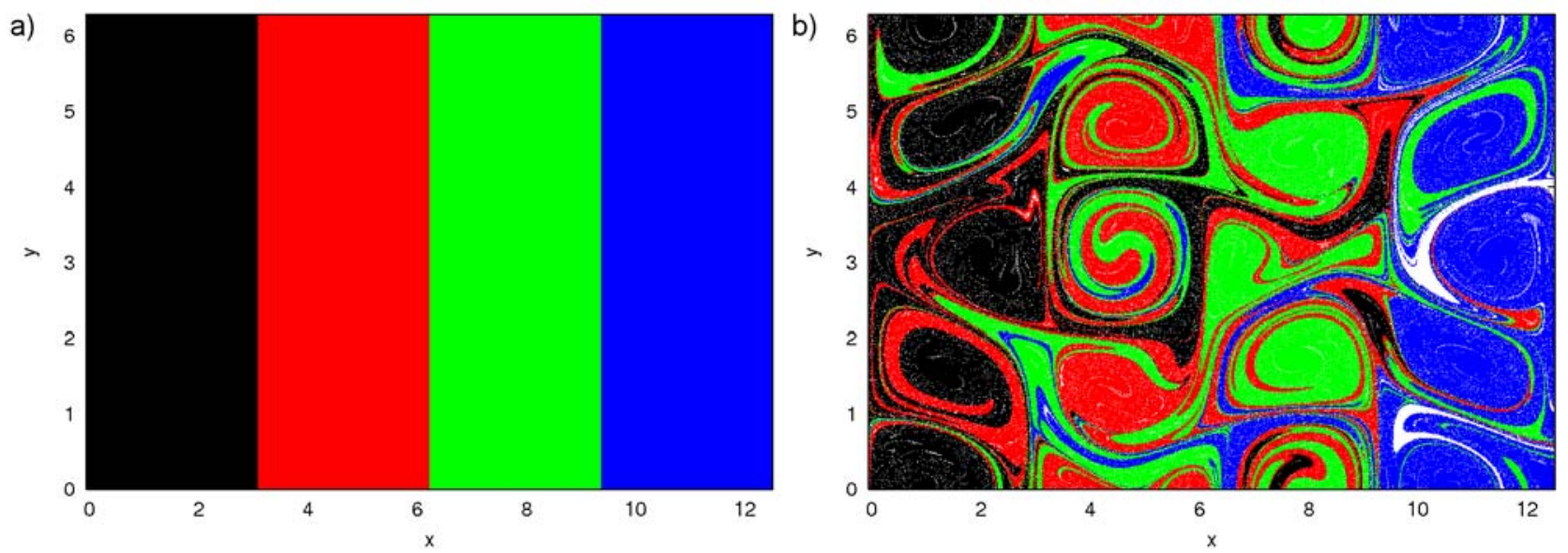

Figura 4.9: (a)Condições iniciais escolhidas para o estudo dos esticamentos e dobras induzidos pelas ELCs. (b) Efeito desse mecanismo no transporte de partículas entre células com $A_{2}=0,5$ para $L=1$.

Inicialmente, temos quatro regiões distintas, indicadas por cores diferentes e separadas por uma linha vertical bem definida que define uma fronteira. A medida que o sistema evolui, surge uma migração de partículas induzida pelas ELCs instáveis de uma região para outra que deforma essa fronteira. [31]
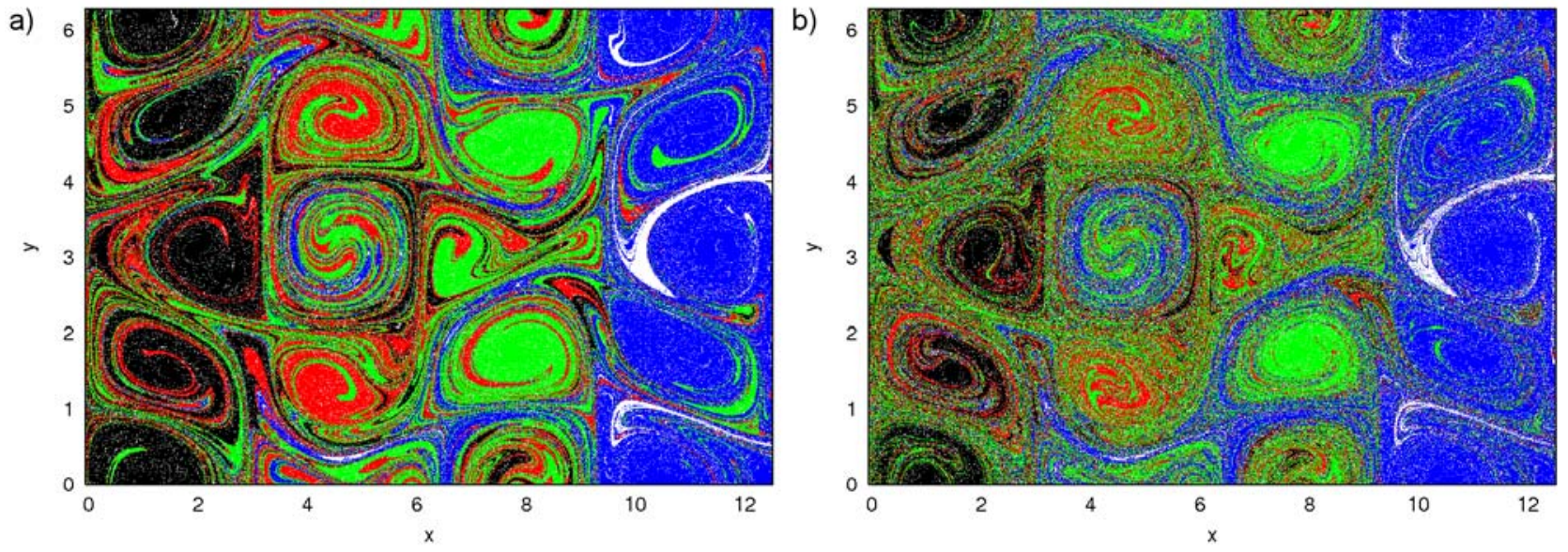

Figura 4.10: Efeito de esticamento e dobra induzido pelas ELCs no transporte de partículas entre células com $A_{2}=0,5$

para (a) $L=2$ e (b) $L=4$. 
Acompanhando a evolução temporal desses conjuntos de dados para os tempos iguais a dois e quatro períodos de perturbação $(L=2$ e 4$)$, podemos ver, na figura 4.10 que quanto maior o tempo de integração, mais entrelaçadas ficam as fronteiras dos conjuntos de pontos. Na figura 4.11 está mostrada uma ampliação para $L=4$.

Utilizando a amplitude da segunda onda $A_{2}=0,5$, podemos verificar como o caos aparece e como as ilhas do plano de fase são destruídas pelas ELCs instáveis. Pois, com a amplitude $A_{2}$ alta, o movimento das ELCs toma conta de praticamente todo o plano de fase, impossibilitando a existência de ilhas grandes, entrelaçando de maneira complexa as fronteiras das ilhas remanescentes e induzindo transporte de partículas na direção paralela as ELCs estáveis.

$\mathrm{Na}$ ampliação da figura 4.11, podemos verificar a complexidade da mistura que ocorre entre os quatro conjuntos de condições iniciais escolhidos. Essa mistura no espaço de fase é aparentemente fractal, porém nenhuma medida dessa fractalidade ainda foi feita.

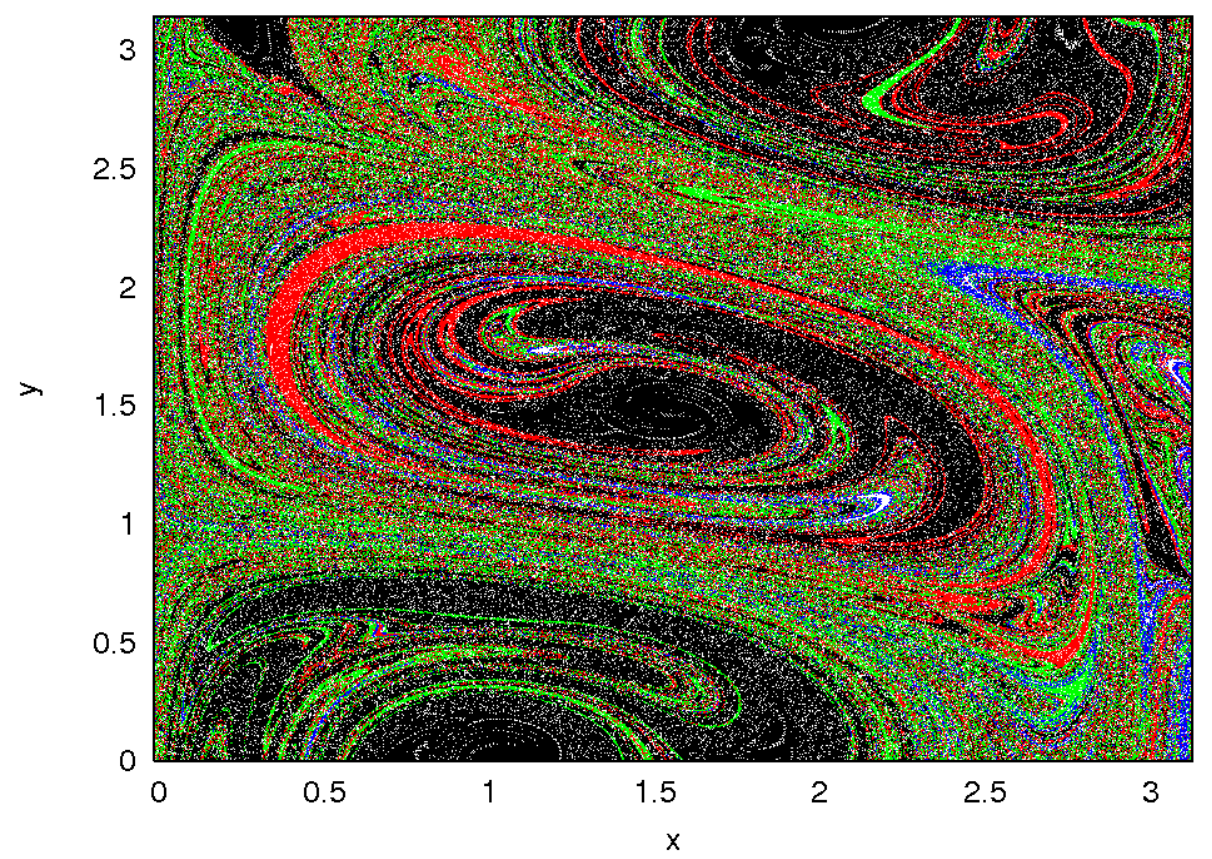

Figura 4.11: Ampliação do efeito de esticamento e dobra induzido pelas ELCs no transporte de partículas entre células $\operatorname{com} A_{2}=0,5$ para $L=4$. 
Apesar de se tratar de uma estrutura extremamente complexa, ainda é possível encontrar pequenas áreas formando ilhas que não podiam ser vistas anteriormente, na figura 3.13 do capítulo 3. Isso ocorre porque, o método utilizado no capítulo 3 era capaz de reconhecer apenas ilhas periódicas ou quase-periódicas, enquanto o método da figura 4.11 consegue reconhecer ilhas que não tem período definido.

\subsection{Método para Calcular as ELCs}

Na seção 4.1 vimos que as ELCs estáveis são responsáveis pelo aparecimento de picos de deslocamento quadrático nos campos de difusão, e na seção 4.2 vimos que as ELCs instáveis definem as fronteiras de regiões dinamicamente diferentes no plano de fase [35]. Utilizando o que foi verificado na seção 4.2, vamos obter as ELCs integrando numericamente um conjunto de pontos que é inicialmente uma fronteira que separa regiões de movimentos distintos. A integração ocorrerá a partir de um tempo inicial $t_{0}$ até um tempo futuro ("para frente"), a fim de obtermos as ELCs instáveis; e até um tempo passado (“para trás”), a fim de obtermos as ELCs estáveis. O conjunto que inicialmente, para um tempo fixo, servia como separatriz será nossa separatriz em $t_{0}$. [31]

Para entender o que são separatrizes em um tempo fixo, voltemos a figura 3.3 do capítulo 3 , como exemplo. Nessa figura, as trajetória calculadas para o parâmetro $u=0$ são equivalentes as

possíveis trajetórias calculadas para um parâmetro $u \neq 0$ em $t=0$. Dentre essas trajetórias, existem algumas que funcionam instantaneamente como separatrizes.

Para um $t=t_{0}$ fixo, a hamiltoniana é uma constante e, portanto, podemos calcular uma curva fictícia $H(x, y)=c t e=H\left(x^{*}, y^{*}\right)$, onde $x^{*}$ e $y^{*}$ são pontos de equilíbrio instável (onde o campo de velocidades é nulo) no tempo $t_{0}$. A possível trajetória que é descrita por essa curva fictícia é instantaneamente uma separatriz no tempo $t_{0}$, portanto, será nossa separatriz em $t_{0}$. 
A evolução temporal dos pontos da separatriz em $t_{0}$ até um tempo final $T+t_{0}$ será nossa ELC estável em $t_{0}$ relacionada à primeira ilha. Caso queiramos calcular a ELC em outro tempo $t=t_{1}$ devemos calcular novamente a separatriz em $t_{l}$ e a partir da evolução temporal dos pontos dessa curva obtemos nossa ELC calculada por um tempo $T$ a partir do tempo $t_{l}$. O processo para obtenção da ELC estável é análogo ao da instável, apenas trocando o tempo final por $-T+t_{0}$.
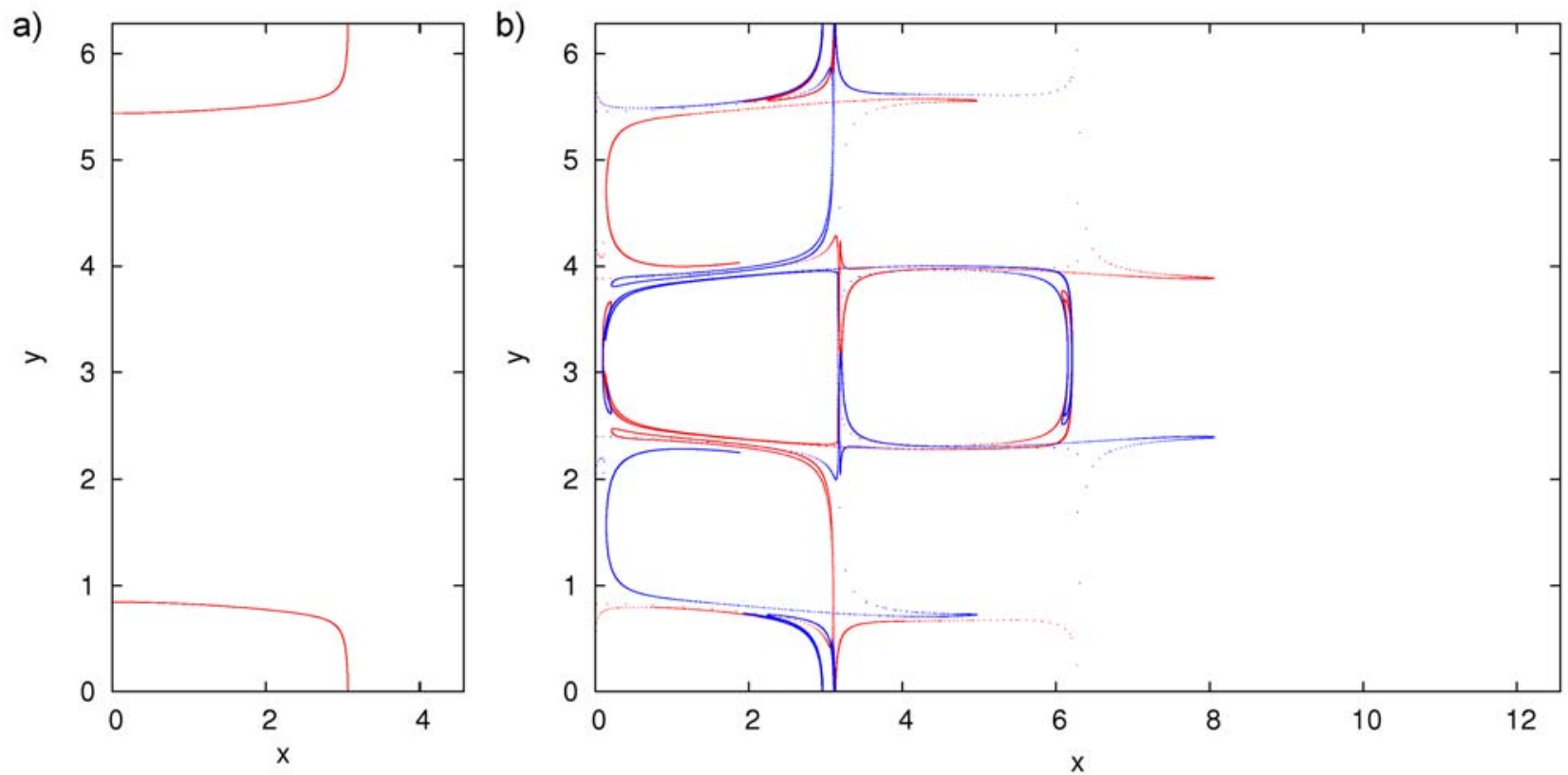

Figura 4.12: (a) Curva que no instante $t_{0}=0$ serve de separatriz. (b)ELC estável $(-T)$ em azul e instável $(+T)$ em vermelho calculadas para o campo de difusão da figura 4.1. Com $A_{2}=0,1$ para $L=1$.

A figura 4.12 mostra as ELCs, em $t_{0}=0$, relacionadas ao campo de difusão da figura 4.1 para diferentes tempos de integração $T=L \tau$. Nessa figura estão a ELC estável, calculada para o tempo final igual a $-T$, e a ELC instável, calculada para o tempo final igual a $+T$. A ELC estável está vinculada às trajetórias que se aproximam das ilhas com o passar do tempo, e a ELC instável, às trajetórias que saem de perto das ilhas com o passar do tempo. 


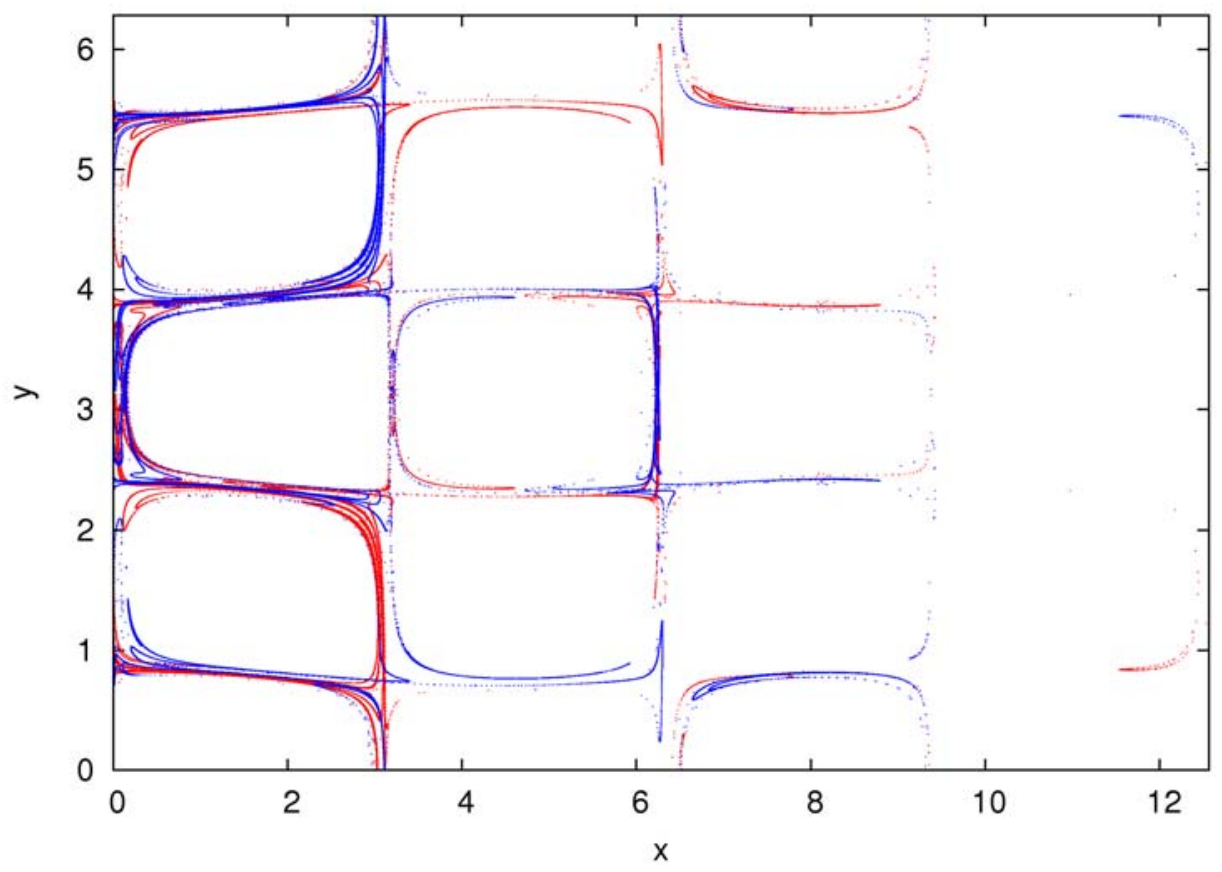

Figura 4.13: (a) Curva que no instante $t_{0}=0$ serve de separatriz. (b)ELC estável $(-T)$ em azul e instável $(+T)$ em vermelho calculadas para o campo de difusão da figura 4.1. $\operatorname{Com} A_{2}=0,1$ para $L=2$.

Na figura 4.13 vemos que o tempo de integração está relacionado com o nível de detalhes que queremos enxergar as ELCs: quanto maior o tempo de integração, maiores são os detalhes.

Calculando agora as ELC para um caso em que já não existem ilhas no plano de fase, obtemos a figura 4.14. Essa figura está relacionada com o campo de difusão da figura 4.3 e é calculada utilizando $A_{2}=0,5$.

Comparando a figura 4.14 com a figura 4.4a, vemos que a ELC estável (azul) é responsável pelo aparecimento dos picos no campo de difusão da figura 4.4a. Comparando, agora, a figura 4.14 com a figura 4.9, vemos que a ELC instável (vermelha) age como a fronteira das ilhas na figura 4.9. Portanto, com esses dois exemplos, conseguimos verificar a correlação entre as ilhas do plano de fase com a ELC instável e os picos no campo de difusão com a ELC estável. 
a)

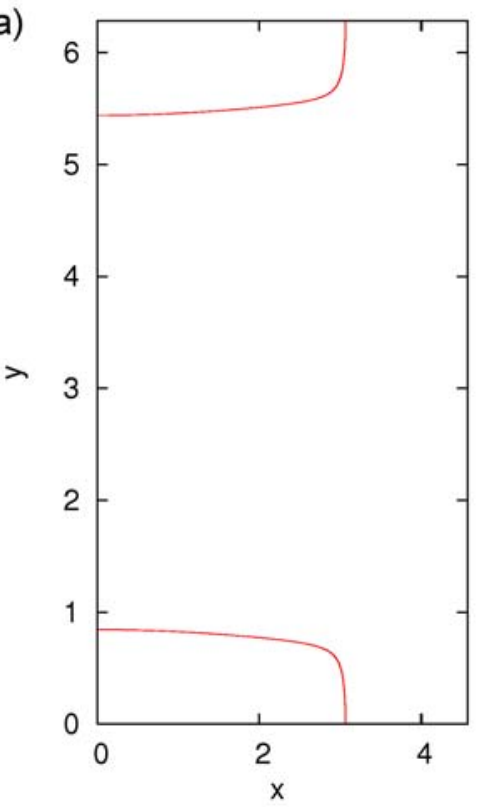

b)

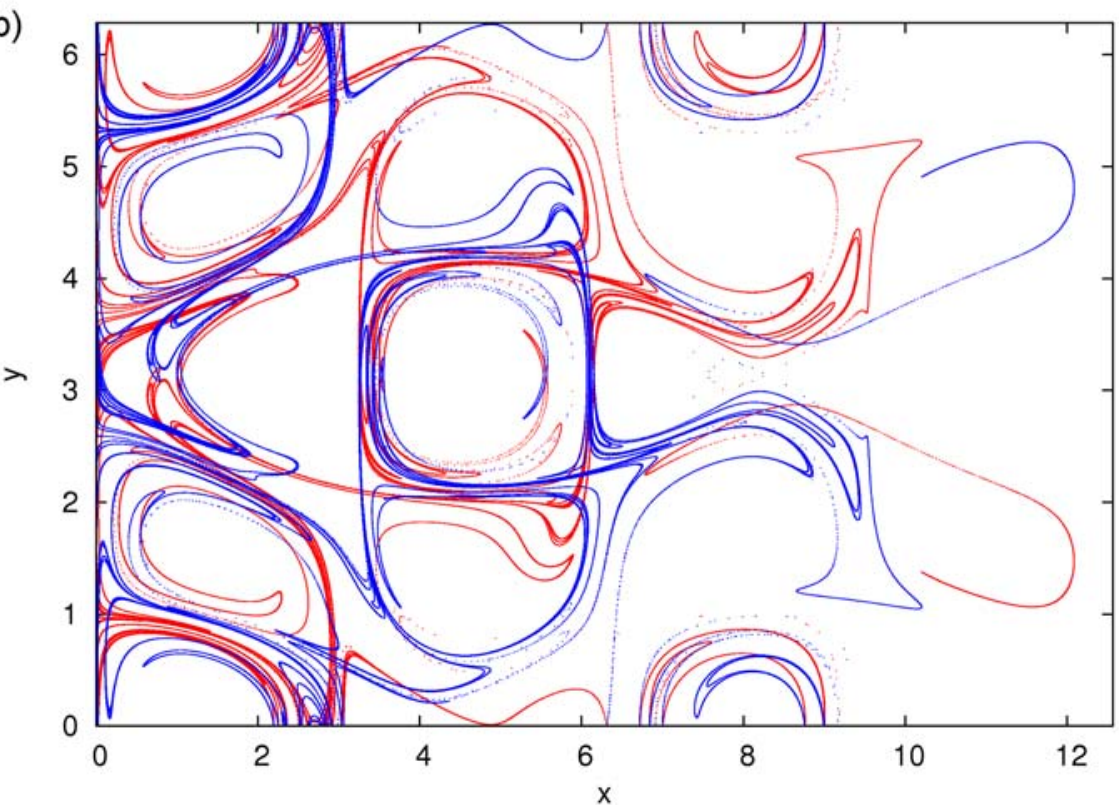

Figura 4.14: (a) Curva que no instante $t_{0}=0$ serve de separatriz. (b) ELC estável $(-T)$ em azul e instável $(+T)$ em vermelho calculadas para $t_{0}=0 . \operatorname{Com} A_{2}=0,5$ para $L=1$.

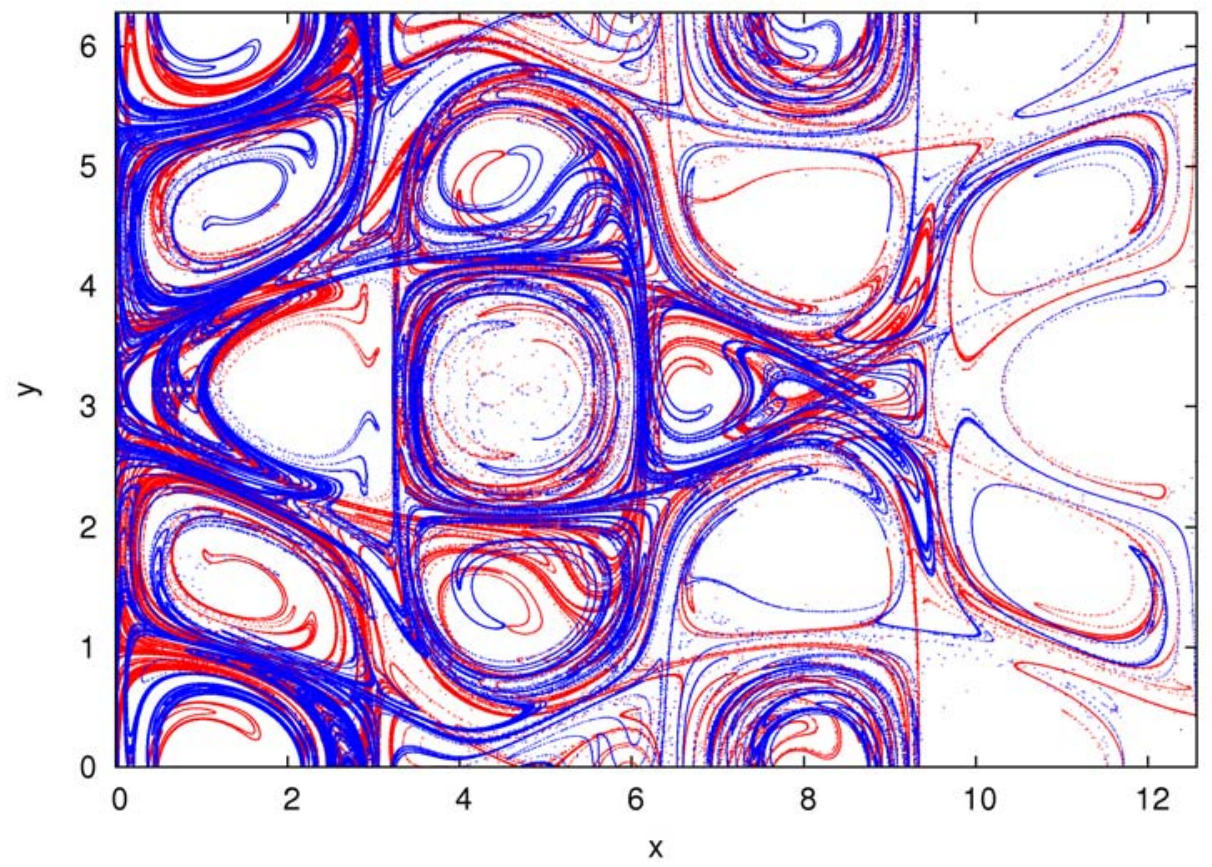

Figura 4.15: ELC estável $(-T)$ em azul e instável $(+T)$ em vermelho calculadas para $t_{0}=0$. Com $A_{2}=0,5$ para $L=2$. 
Aumentando o tempo de integração para $L=2$, é possível ver na figura 4.15 que o nível de complexidade da ELC aumenta, assim, quanto mais aumentarmos esse tempo de integração, mais detalhes serão obtidos.

Assim como os campos de difusão, as figuras 4.14 e 4.15, que mostram as ELCs, devem ser analisadas com cuidado, pois instantaneamente permitem a existência de ilhas no plano de fase, entretanto, devemos lembrar que essas estruturas não são estáticas e, conforme visto na seqüência de campos de difusão mostrado nas figuras 4.4, 4.5 e 4.6, tem movimento periódico de período igual ao da perturbação. Assim, as ELCs se movem com o passar do tempo e ocupam o lugar que no instante anterior aparentava ser uma ilha. Desta forma, caso queiramos extrair informações sobre a dinâmica do sistema analisando as ELC, devemos levar em consideração tanto sua estrutura espacial, quanto sua evolução temporal.

\subsection{Conclusões}

O sistema de equações estudado nessa dissertação possui campos de difusão com grande complexidade relacionados à existência de ELCs. Essas ELCs regem a dinâmica de todo o espaço de fases e deixam no campo de difusão uma assinatura característica: nas proximidades da ELC estável, os valores de deslocamento quadrático são elevados. Por outro lado, as ELCs instáveis funcionam como barreira de transporte e estão associadas à existência de ilhas.

Além disso, as ELCs são responsáveis pelo efeito de esticamento e dobramento de um conjunto de condições iniciais no espaço de fases e esse efeito é mais intenso nas paredes das células. Em decorrência disso, regiões inicialmente separadas por uma fronteira lisa, tendem a apresentar fronteiras deformadas e extremamente complexas após algum tempo de integração.

Utilizando o fato de que as ELCs tem a característica de "deformar fronteiras", calculamos numericamente, de maneira alternativa aos picos nos campos de expoente de Lyapunov a tempo 
finito, as ELCs. Podemos, então, a partir do estudo do comportamento temporal das ELCs, prever o aparecimento de ilhas ou de barreiras de transporte no espaço de fase.

Analisando as figuras 4.12 e 4.14, podemos observar que a medida que aumentamos a amplitude das segunda onda, aumentamos a área ocupada pelas ELCs. Esse resultado está de acordo com os campos de difusão mostrados nas figuras 4.1, 4.2 e 4.3. Nessas figuras constatamos que, a medida que aumentamos a amplitude da segunda onda, aumentamos também a área que possui trajetórias com deslocamento quadrático elevado. Portanto, é possível relacionar os máximos nos campos de difusão com as ELCs estáveis.

Outro resultado importante foi obter a relação entre as ELC instáveis e as fronteiras das ilhas. Na figura 4.9 é possível relacionar a fronteira entre células com a ELC instável da figura 4.14. 


\section{Capítulo 5}

\section{Conclusão}

Nesse trabalho, estudamos alguns aspectos do transporte radial de partículas em Tokamaks induzido por ondas de deriva. De maneira geral, vimos que o modelo usado possui equações de movimento que são: integráveis para uma ou duas ondas com mesma velocidade de fase e; caóticas para duas ondas com velocidade de fase diferentes. O movimento caótico dessas trajetórias é determinado por um conjunto de estruturas chamado de Estruturas Lagrangianas Coerentes (ELCs), que são a generalização do conceito de variedades para sistemas dependentes do tempo [35]. Quanto maior o espaço ao qual essas estruturas se distribuem no plano de fase, maior será o transporte de partículas.

No capítulo 2, vimos que quando utilizamos apenas uma onda de deriva o sistema é integrável e todas as trajetórias são curvas invariantes que aparecem no plano de fase como ilhas, ou linhas abertas. As trajetórias fechadas são curvas que ficam confinadas em ilhas, já as linhas abertas são trajetórias que se estendem por todo plano de fase. Tanto as linhas abertas, como as ilhas servem como barreiras de transporte, pois são todas curvas invariantes. Entretanto, as linhas abertas são mais persistentes do que as linhas fechadas quando uma perturbação nas equações de movimento é introduzida. Esse efeito é descrito pelo parâmetro que define a quantidade de linhas abertas no plano de fase, chamado de parâmetro de confinamento $U$. [26, 27]

A maior parte dessa dissertação trata do modelo com $U=0$, ou seja, sem linhas abertas que funcionam como barreiras de transporte. Nesse caso, para uma onda, todas as trajetórias do plano de 
fase estão em ilhas, com exceção das órbitas heteroclínicas que ligam pontos fixos distintos. Devido a essas órbitas o sistema é estruturalmente instável, assim, uma pequena perturbação nas equações de movimento pode modificar completamente a estrutura do plano de fases. [7]

Comparando o que foi visto no capítulo 2 com o capítulo 3, vimos que quando a razão entre os números de onda na direção x é um número racional existe no plano de fase uma barreira vertical ao transporte na direção $x$ [22]. Portanto, é possível confinar trajetórias caóticas nesse sistema escolhendo números de onda cuja razão seja um número racional. No entanto, como estamos interessados em estudar o transporte de partículas, utilizamos essa razão como um número irracional.

No capítulo 3, vimos que, para determinados parâmetros existem ilhas no plano de fase. Cada ilha contém trajetórias com freqüência natural de oscilação que depende da distância da trajetória até o centro da ilha. Devido a quase-periodicidade da hamiltoniana essa dependência é aproximadamente igual para todas as ilhas. De maneira geral, vimos que um conjunto de curvas é destruído quando a diferença na velocidade de fase das ondas tem freqüência aproximadamente igual a freqüência natural de oscilação desse conjunto de trajetórias. Foi mostrado que o transporte de partículas é máximo quando as trajetórias destruídas estão localizadas próximas às paredes de cada célula, ou seja, na região periférica da ilha.

Uma das contribuições mais importantes ao problema estudado dessa dissertação pode ser vista no capítulo 4. A partir da metodologia desenvolvida nesse capítulo, verificamos que a quebra das separatrizes [30], quando uma segunda onda é inserida no sistema, cria uma região de dinâmica extremamente complexa e é decorrente do surgimento das Estruturas Lagrangianas Coerentes (ELCs), assim como foi obtido na referência [33]. Verificamos também que, dependendo do movimento dessas ELCs ao longo do tempo no plano de fase, podem existir ilhas, pois as ELCs criam uma barreira de transporte na sua direção transversal, impedindo o transporte de partículas. [8]

No capítulo 3, devido ao tempo de integração grande, as ELCs induziram tantos esticamentos e dobras que toda a região caótica em torno das ilhas era praticamente homogênea. Já no capítulo 4 , 
para um tempo de integração curto, não puderam ser observados tantos esticamentos e dobras, sendo assim possível identificar as ELCs através do movimento das trajetórias próximas a elas.

No capítulo 4 foram construídos gráficos do deslocamento quadrático em $x$ de uma trajetória em função da sua condição inicial e definidos como campos de difusão. Esses campos possuem picos de deslocamento quadrático nas proximidades de uma ELC, entretanto, não foram utilizados para o calculo da mesma. Ao invés disso, utilizamos para calcular as ELCs o efeito delas sobre as fronteiras das ilhas. Esses dois métodos de análise se mostraram coerentes, pois foi possível relacionar os picos dos campos de difusão com a evolução temporal das fronteiras. Embora esses dois métodos precisem ser melhor trabalhados, eles se mostraram eficazes.

A variação ao longo do tempo dos picos de deslocamento quadrático nos campos de difusão foi capaz de fornecer valiosas informações sobre o comportamento das ELCs, pois a partir dessas informações conseguimos prever a existência de ilhas ou de barreiras para o transporte. Esse tipo de análise é possível devido a periodicidade da perturbação, se durante um período existir uma região no espaço de fase a qual a ELC não tem acesso, essa região será uma ilha. Assim, com essa dissertação conseguimos mostrar que existe uma relação entre o transporte radial de partículas em Tokamaks e as ELCs.

Comparando os resultados dos capítulos 3 e 4, verificamos que o transporte de partículas é máximo quando as ELCs se esticam e se espalham por grande parte do plano de fase. Por outro lado, quando essas ELCs se esticam e se concentram em uma pequena região o transporte de partículas é pequeno. Por isso, existem parâmetros para os quais a área do plano de fase ocupada por trajetórias caóticas é grande, e o valor de transporte pequeno (ver figura 3.6), e parâmetros para os quais a área caótica é pequena e o transporte é grande (ver figura 3.4).

Assim, caso queiramos controlar o transporte de partículas desse sistema, devemos que obter parâmetros para os quais as ELCs sejam confinadas em pequenas regiões do plano de fase. Portanto, mesmo com conclusões extraídas de um modelo simplificado de apenas duas ondas de deriva, esses 
resultados podem servir de guia para estudos mais detalhados sobre as ELCs em Tokamaks. 


\section{Referências Bibliográficas}

[1] J.Wesson. Tokamaks. Oxford University Press, 3rd Edition (2004).

[2] F. F. Chen. Introduction to Plasma Physics. Plenum Press (1974).

[3] C. Hidalgo, M. A. Pedrosa, B. Gonçalves. Fluctuations, sheared radial eletric fields and transport interplay in fusion plasmas. New Journal of Physics 4, 51 (2002).

[4] W. Horton. Onset of stochasticity and the diffusion approximation in drift waves. Plasma Physics and Controlled Fusion 27, 937 (1985).

[5] A. Lichtenberg, M. A. Lieberman. Regular and Chaotic Motion. Springer (1995).

[6] I. Doxas, W. Horton, H. L. Berk. Stochastic Diffusion in Two-Dimensional Periodic Flow. Physics of Fluids 2, 1906 (1990).

[7] R. G. Kleva, J. F. Drake. Stochastic E X B particle transport. Physics of Fluids 27, 1686 (1984).

[8] F. J. Beron-Vera, M. J. Olascoaga, M. G. Brown, H. Koçak, I. I. Rypina. Invariant-tori-like Lagrangian coherent structuries in geophysical flows. Chaos 20, 017514 (2010).

[9] W. P. de Sá. Medida da Turbulência na Perifería do TBR-1. Dissertação de Mestrado, Instituto de Física da USP. (1987).

[10] D. F. Cruz Junior. Análise do Espectro de Turbulência no TBR-1. Dissertação de Mestrado, Instituto de Física da USP (1987).

[11] R. M. Castro. Controle de Turbulência no Tokamak TBR-1. Tese de Doutorado, Instituto de Física da USP (1996).

[12] R. P. da Silva. Transporte de Partículas e Energia no Plasma do Tokamak TBR-1: Diagnóstico e estudo experimental. Tese de Doutorado, Instituto de Física da USP (1989). 
[13] A. A Ferreira, M. V. A. P. Heller, I. L. Caldas. Experimental Analysis of Mode Coupling and Plasma Turbulence induced by Magnetic Fields. Physics of Plasmas 7, 3567 (2000).

[14] R. S. Dallaqua, A. Hershcovitch, R. P. da Silva, I. C. Nascimento, R. M. O. Galvão. Particle Diffusion in TBR. Il Nuovo Cimento 83, 1 (1984).

[15] F. A. Marcus. Instabilidades Dinâmicas das Flutuações Eletrostáticas em Tokamaks. Dissertação de mestrado, Instituto de Física da USP (2002).

[16] F. A. Marcus. Transporte de Partículas Induzido por Ondas de Deriva. Tese de Doutorado, Instituto de Física da USP (2007).

[17] F. A. Marcus, I. L. Caldas, Z. O. Guimarães-Filho, P. J. Morrison, W. Horton, Yu. K. Kuznetsov and I. C. Nascimento. Reduction of chaotic particle transport driven by drift waves in sheared flows. Physics of plasmas 15,112304 (2008).

[18] E. C. Silva, I. L. Caldas, R. L. Viana. Field Line Diffusion in a Tokamak with Ergodic Limiter. Physics of Plasmas 8, 2855 (2001).

[19] K. Ullmann, I. L. Caldas. A Symplectic Mapping for the Ergodic Magnetic Limiter and its Dynamical Analysis. Chaos and Solitons and Fractals 11, 2129 (2000).

[20] K. T. Alligood, T. D. Sauer, J. A. Yorke. Chaos: An introduction to dynamical systems. Springer (1997).

[21] William H. Press, et al. Numerical Recipes in C, Second Edition, Cambridge University Press (1992).

[22] C.G.L. Martins, F.A. Marcus, I.L. Caldas, R. Egydio de Carvalho. Robust Tori in a DoubleWaved Hamiltonian Model. Physica A, 389, 5511(2010).

[23] F. Lekien, S. D. Ross. The computation of finit-time Lyapunov exponents on unstructured meshes and for non-Euclidean manifolds. Chaos 20, 017505 (2010).

[24] J.D. Szezech Jr., S.R. Lopes, R.L. Viana. Onset of Spatiotemporal Chaos in a Nonlinear System. Phys. Rev. E 7567202 (2007). 
[25] I. Percival. Introduction to Dynamics. Cambridge University Press (1983).

[26] I. Doxas. Two Case Studies of Stochastic Trasnport: Anomalous Transport in Two Drift Waves, and Collisionless Reconnection. Tese de doutorado apresentada ao Institute for Fusion Studies, The University of Texas at Austin (1988).

[27] I. Osipenkov. Diffusion in Chaotic Systems. MSc Dissertation, Report IFSR \#885. Institute for Fusion Studies, The University of Texas at Austin (2000).

[28] R. M. Castro, Turbuência Eletrostática e Magnética em Tokamaks, Tese de doutorado, Instituto de Física da USP (1996).

[29] D. Szezech I. L. Caldas, S. R. Lopes, R. L. Viana, and P. J. Morrison. Transport Properties in Nontwist Area-Preserving Maps. Chaos 19, 043108 (2009).

[30] A. A. Chernikov, R. S. Sagdeev, D. A. Usikov, G. M. Zaslavsky. Weak Chaos and Structuries. Soviet Scientific Reviews C Mathematical Physics, Volume 8, Part 2 (1989).

[31] G. Haller and G. Yuan 2000. Lagrangian Coherent Structures and Mixing in Two-Dimensional Turbulence. Physica D, 147, 352 (2000).

[32] G. Haller. Lagrangian Coherent Structures from Approximate Velocity Data. Physics of Fluids A, 141851 (2002).

[33] G.C. Yuan, L.J. Pratt, and C.K.R.T Jones. Barrier Destruction and Lagrangian Predictability at Depth in a Meandering Jet. Dynamics Of Atmospheres And Oceans, 35, 41 (2002).

[34] J. M. Ottino. The Kinematics of Mixing: Stretching, Chaos and Transport. Cambridge University Press (1990).

[35] S. Shadden, F. Lekien and J. Marsden. Definition and Properties of Lagrangian Coherent Structures from Finite-Time Lyapunov Exponents in Two-Dimensional Aperiodic Flows. Physica D, 212, 271 (2005). 
